UNIVERSIDADE DE SÃO PAULO

INSTITUTO DE QUÍMICA DE SÃO CARLOS

Felipe de Santis Gonçalves

Revisitando a redução de nitrosilo complexos de tetraminas de rutênio(II) 


\author{
UNIVERSIDADE DE SÃO PAULO \\ INSTITUTO DE QUÍMICA DE SÃO CARLOS
}

\title{
Revisitando a redução de nitrosilo complexos de tetraminas de rutênio(II)
}

Dissertação apresentada ao Instituto de Química de São Carlos, da Universidade de São Paulo, como parte dos requisitos para a obtenção do título de mestre em ciências.

Área de Concentração: Química Analítica e Inorgânica

Orientador: Prof. Dr. Daniel Rodrigues Cardoso

Felipe de Santis Gonçalves

São Carlos

Agosto de 2019 


\section{AGRADECIMENTOS}

À minha família, Dercy, Silvio e Isabel, pelo apoio e incentivo;

Ao Antonio Carlos Roveda Júnior, pela ajuda sempre bem-vinda na minha vida dentro e fora do laboratório;

Ao Lucyano J. A. Macedo, pela amizade e pelo auxílio com os experimentos de eletroquímica;

Ao Daniel Rodrigues Cardoso, pela orientação, paciência e oportunidades trazidas nesses anos de convivência;

Aos meus amigos Carlos, Henrique, Fernando, Thiago e Pedro, pela boa convivência tanto dentro quanto fora do laboratório;

À Jennifer, pela amizade e também pela disposição dentro do laboratório;

Ao Grupo, composto pelo pessoal dos laboratórios 02, 50 e 117, pelo ambiente sempre amigável;

Ao pessoal da turma de Química de Coordenação (I)/2018, por me aturar nas minhas primeiras experiências em ensinar;

Ao CNPq, pela bolsa de mestrado concedida. 


\section{RESUMO}

Complexos de tetraminas de rutênio(II) de fórmula geral trans- $\left[\mathrm{Ru}(\mathrm{NO})\left(\mathrm{NH}_{3}\right)_{4}(\mathrm{~L})\right]^{3+}$ (onde $\mathrm{L}$ = espécies de $\mathrm{P}(\mathrm{III})$ e $\mathrm{N}$-heterocíclicos) foram extensivamente estudados como doadores controlados de óxido nítrico. A escolha dos íons complexos trans- $\left[\mathrm{Ru}(\mathrm{NO})\left(\mathrm{NH}_{3}\right)_{4}(\mathrm{~L})\right]^{3+}$ (onde $\mathrm{L}=$ espécies de $\mathrm{P}(\mathrm{III})$ e N-heterocíclicos) como agentes doadores de óxido nítrico (NO) em meio biológico é decorrente da baixa toxicidade in vivo, por serem solúveis em meio aquoso, além de apresentarem elevada estabilidade frente a oxidação pelo $\mathrm{O}_{2}$ presente no ar. É reconhecido na literatura que a labilização do óxido nítrico nestes complexos ocorre após a redução por 1-elétron do íon complexo trans-[Ru(NO)(NH$\left.)_{4}(\mathrm{~L})\right]^{3+}$ levando a formação quantitativa do aqua-complexo trans- $\left[\mathrm{Ru}\left(\mathrm{H}_{2} \mathrm{O}\right)\left(\mathrm{NH}_{3}\right)_{4}(\mathrm{~L})\right]^{2+}$ e do $\mathrm{NO}$ em solução aquosa. No entanto, quando a redução dos complexos trans-[Ru(NO)(NH$\left.)_{4}(\mathrm{~L})\right]^{3+}$ foi investigada por espectroscopia no infravermelho in situ, um diferente comportamento químico é evidenciado, o que nos levou a revisitar o mecanismo de redução eletroquímica de nitrosilo complexos em tetraminas de rutênio(II). $\mathrm{O}$ presente trabalho investiga a química redox por espectroeletroquímica de FTIR in situ dos nitrosilo complexos trans- $\left[\mathrm{Ru}(\mathrm{NO})\left(\mathrm{NH}_{3}\right)_{4}(\mathrm{~L})\right]^{3+}$, onde $\mathrm{L}=$ isonicotinamida, piridina, ou $\mathrm{NH}_{3}$, em solução aquosa. É observado, pela primeira vez, a labilização competitiva do ligante N-heterocíclico da esfera de coordenação após redução de 1-elétron do nitrosilo complexo, levando a formação da espécie NO e dos aquacomplexos trans- $\left[\mathrm{Ru}(\mathrm{NO})\left(\mathrm{NH}_{3}\right)_{4}(\mathrm{OH})\right]^{2+}$ e trans- $\left[\mathrm{Ru}\left(\mathrm{H}_{2} \mathrm{O}\right)\left(\mathrm{NH}_{3}\right)_{4}(\mathrm{~L})\right]^{2+} \mathrm{em} \mathrm{pH} 7,4$. O aquacomplexo trans-[Ru(NO)(NH$\left.)_{4}(\mathrm{OH})\right]^{2+}$ é subsequentemente reduzido no meio $(-0,40 \mathrm{~V}$ vs. $\left.\mathrm{Ag} / \mathrm{AgCl}_{\text {sat }}\right)$ resultando na labilização de $\mathrm{NO}$ e formação do aqua-complexo trans$\left[\mathrm{Ru}\left(\mathrm{H}_{2} \mathrm{O}\right)_{2}\left(\mathrm{NH}_{3}\right)_{4}\right]^{2+}$ como produto final em meio aquoso com $\mathrm{pH}=7$,4. Não é observada a labilização do ligante trans posicionado ao $\mathrm{NO}^{+}$em tetraminas de rutênio(II) após redução por 1-elétron quando $\mathrm{L}=\mathrm{NH}_{3}$. 


\begin{abstract}
Ruthenium(II) tetraamine complexes with general formula trans$\left[\mathrm{Ru}(\mathrm{NO})\left(\mathrm{NH}_{3}\right)_{4}(\mathrm{~L})\right]^{3+}$ (where $\mathrm{L}=\mathrm{P}(\mathrm{III})$ and N-heterocycles) were extensively studied as controlled NO donors. The choice for these ion complexes, trans- $\left[\mathrm{Ru}(\mathrm{NO})\left(\mathrm{NH}_{3}\right)_{4}(\mathrm{~L})\right]^{3+}$, (where $\mathrm{L}=\mathrm{P}(\mathrm{III})$ and $\mathrm{N}$-heterocycles) as nitric oxide (NO) donors in biological media is due to their low toxicity in vivo, high solubility in aqueous solution, and their high stability against air oxidation. It is recognized in the literature that labilization of nitric oxide in these complexes occurs after a one-electron reduction of the complex ion trans$\left[\mathrm{Ru}(\mathrm{NO})\left(\mathrm{NH}_{3}\right)_{4}(\mathrm{~L})\right]^{3+}$, leading to a quantitative formation of the aquo-complex trans$\left[\mathrm{Ru}\left(\mathrm{H}_{2} \mathrm{O}\right)\left(\mathrm{NH}_{3}\right)_{4}(\mathrm{~L})\right]^{2+}$ and $\mathrm{NO}$ in aqueous solution. Although, when the reduction of trans$\left[\mathrm{Ru}(\mathrm{NO})\left(\mathrm{NH}_{3}\right)_{4}(\mathrm{~L})\right]^{3+}$ complexes was investigated by in situ infrared spectroscopy, a different chemical behavior is observed, which led us to revisit the mechanism of electrochemical reduction of ruthenium(II) tetraamine nitrosyl complexes. The present work investigates the redox chemistry by FTIR spectroelectrochemistry in situ of nitrosyl complexes trans$\left[\mathrm{Ru}(\mathrm{NO})\left(\mathrm{NH}_{3}\right)_{4}(\mathrm{~L})\right]^{3+}$, where $\mathrm{L}=$ isonicotinamide, pyridine or $\mathrm{NH}_{3}$, in aqueous solution. For the first time, it is observed a competitive labilization of the N-heterocyclic ligand from the coordination sphere upon one-electron reduction of the nitrosyl complex, leading to the formation of $\mathrm{NO}$ and the aquo-complex trans- $\left[\mathrm{Ru}(\mathrm{NO})\left(\mathrm{NH}_{3}\right)_{4}(\mathrm{OH})\right]^{2+}$ and trans$\left[\mathrm{Ru}\left(\mathrm{H}_{2} \mathrm{O}\right)\left(\mathrm{NH}_{3}\right)_{4}(\mathrm{~L})\right]^{2+}$ in $\mathrm{pH}=7.4$. The aquo complex trans- $\left[\mathrm{Ru}(\mathrm{NO})\left(\mathrm{NH}_{3}\right)_{4}(\mathrm{OH})\right]^{2+}$ is subsequently reduced in solution $(-0.40 \mathrm{~V}$ vs. $\mathrm{Ag} / \mathrm{AgCl}$ sat $)$ resulting in $\mathrm{NO}$ labilization and formation of the aquo complex trans- $\left[\mathrm{Ru}\left(\mathrm{H}_{2} \mathrm{O}\right)_{2}\left(\mathrm{NH}_{3}\right)_{4}\right]^{2+}$ as an end-product in aqueous solution with $\mathrm{pH}=7.4$. It is not observed the labilization of the ligand trans positioned to $\mathrm{NO}^{+}$in the ruthenium(II) tetraamine complex upon one-electron reduction when $\mathrm{L}=\mathrm{NH}_{3}$.
\end{abstract}




\section{LISTA DE FIGURAS}

Figura 1. Fórmula estrutural do complexo nitroprussiato.......................................................

Figura 2. Exemplo de tetraminas de rutênio contendo o ligante $\mathrm{NO}^{+}$coordenado trans a $\mathrm{N}$ heterocíclicos. No caso, isonicotinamida (à esquerda) e piridina (à direita)............................ 2

Figura 3. À esquerda, diagrama de energia simplificado para os orbitais moleculares de fronteira do íon nitrosônio. À direita, representação dos orbitais recorrentes das interações sigma e $\pi$ da molécula de $\mathrm{NO}^{\bullet}$ 3

Figura 4. Representação simplificada da interação sigma entre os centros $\mathrm{NO} \rightarrow \mathrm{Ru}$ e retrodoação $\mathrm{Ru} \rightarrow \mathrm{NO}$. Setas indicam sentido do deslocamento de densidade eletrônica...........4 Figura 5. Representação simplificada da interação $\pi$ entre os centros $\mathrm{Ru}^{\mathrm{II}}-\mathrm{NO}^{+}$e $\mathrm{Ru}^{\mathrm{II}}-\mathrm{NO} \mathrm{\bullet}^{\bullet}$. Setas indicam sentido do deslocamento de densidade eletrônica.............................................. 4

Figura 6. Rota sintética para obtenção dos nitrosilo complexos trans- $\left[\mathrm{Ru}(\mathrm{NO})\left(\mathrm{NH}_{3}\right)_{4}(\mathrm{~L})\right]^{3+}$ ( $\mathrm{L}=$ isn ou py) .6

Figura 7. Representação da célula utilizada nos experimentos de espectroeletroquímica........ 8

Figura 8. Microscopia multiplex no infravermelho do filme de amido contendo o complexo RuNOisn incorporado. (a) Imagem ótica da região limite do filme. (b) Imagem química referente à integração da região entre $1915-1945 \mathrm{~cm}^{-1}$. (c) Espectro no infravermelho das três regiões distintas do filme demarcadas na figura 8a. (d) Ampliação da região demonstrando o sinal atribuído ao ligante $\mathrm{NO}^{+}$coordenado. 10

Figura 9. Espectro da diferença na região do infravermelho do filme de amido com o íon complexo RuNOisn incorporado. Solução utilizada: HTFA pH 2,0. A variação no espectro foi acompanhada pelo tempo com passos de 30 segundos. Potencial aplicado: $-2,5 \mathrm{~V} ; \mathrm{T}=20 \pm$ $4{ }^{\circ} \mathrm{C}$

Figura 10. Espectro da diferença na região do infravermelho do filme de amido com o íon complexo RuNOisn incorporado. Solução utilizada: tampão fosfato $\mathrm{pH} 7,4$. A variação no espectro foi acompanhada pelo tempo, com passos de 30 segundos. Potencial aplicado: $-2,5 \mathrm{~V}$; $\mathrm{T}=20 \pm 4{ }^{\circ} \mathrm{C}$ 13

Figura 11. Espectroeletroquímica do íon complexo (A) RuNOisn e (B) RuNOpy no pH 7,2; $\mathrm{C}_{\mathrm{Ru}}=5 \times 10^{-3} \mathrm{~mol} \mathrm{~L}^{-1} ; \mathrm{T}=20 \pm 4{ }^{\circ} \mathrm{C}$. Potenciais exibidos utilizam como referência eletrodo de $\mathrm{Ag} / \mathrm{AgCl}_{\text {sat. }}$ Gráfico inserido representa potencial aplicado no qual não há variação no espectro. Passos de $50 \mathrm{mV}$. Linha de base deslocada para melhor clareza. 
Figura 12. Espectroeletroquímica do RuNOpy em solução de tampão fosfato $\mathrm{pH} 7,4 ; 0,1 \mathrm{~mol}$ $\mathrm{L}^{-1} ; \mu=0,262 \mathrm{~mol} \mathrm{~L}{ }^{-1}$ preparado em $\mathrm{D}_{2} \mathrm{O} . \mathrm{C}_{\mathrm{Ru}}=5 \times 10^{-3} \mathrm{~mol} \mathrm{~L}^{-1} ; \mathrm{T}=20 \pm 4{ }^{\circ} \mathrm{C}$. A variação no espectro foi acompanhada pelo tempo, com passos de 30 segundos. Potencial exibido utiliza como referência eletrodo de $\mathrm{Ag} / \mathrm{AgCl}_{\text {sat }}$. Gráfico inserido representa potencial aplicado no qual não há variação no espectro

Figura 13. Espectro no infravermelho da região de 1650 a $1400 \mathrm{~cm}^{-1}$ do complexo trans$\left[\mathrm{Ru}(\mathrm{NO})\left(\mathrm{NH}_{4}\right)(\mathrm{py})\right]\left(\mathrm{PF}_{6}\right)_{3}$ registrado em pastilha de $\mathrm{KBr}$, representado por piridina coordenada, e de solução de piridina $0,3 \mathrm{~mol} \mathrm{~L}^{-1} \mathrm{em}_{2} \mathrm{O}$, representado por piridina livre.....17

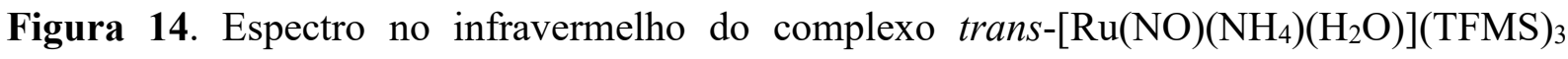
solubilizado em diferentes soluções aquosas com variada concentração hidrogeniônica $\left(\mathrm{C}_{\mathrm{H}^{+}}\right)$.

Figura 15. Fórmula estrutural dos complexos trans- $\left[\mathrm{Ru}(\mathrm{NO})\left(\mathrm{NH}_{4}\right)\left(\mathrm{H}_{2} \mathrm{O}\right)\right]^{3+}$ e trans$\left[\mathrm{Ru}(\mathrm{NO})\left(\mathrm{NH}_{4}\right)(\mathrm{OH})\right]^{2+}$

Figura 16. Espectroeletroquímica do $\operatorname{RuNO}(\mathbf{O H})$ em solução de tampão fosfato $\mathrm{pH} 7,4 ; 0,1$ mol L-1; $\mu=0,262 \mathrm{~mol} \mathrm{~L}^{-1} ; \mathrm{C}_{\mathrm{Ru}}=5 \times 10^{-3} \mathrm{~mol} \mathrm{~L}^{-1} ; \mathrm{T}=20 \pm 4{ }^{\circ} \mathrm{C}$. A variação no espectro foi acompanhada pelo tempo, com passos de 17,5 segundos. Potencial exibido utiliza como referência eletrodo de $\mathrm{Ag} / \mathrm{AgCl}_{\text {sat. }}$ Gráfico inserido representa potencial aplicado no qual não há variação no espectro.

Figura 17. Espectroeletroquímica do RuNOpy em solução de tampão fosfato $\mathrm{pH} 7,4 ; 0,1 \mathrm{~mol}$ $\mathrm{L}^{-1} ; \mu=0,262 \mathrm{~mol} \mathrm{~L}{ }^{-1} ; \mathrm{C}_{\mathrm{Ru}}=5 \times 10^{-3} \mathrm{~mol} \mathrm{~L}^{-1} ; \mathrm{T}=20 \pm 4{ }^{\circ} \mathrm{C}$. A variação no espectro foi acompanhada pelo tempo, com passos de 10 segundos. Potencial exibido utiliza como

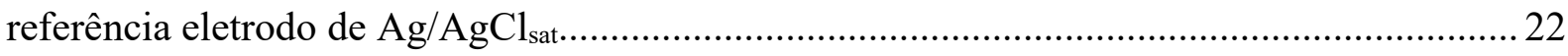

Figura 18. Variação da absorbância do sinal em $1607 \mathrm{~cm}^{-1}$ com o tempo.............................. 23

Figura 19. Diagrama de energia simplificado dos orbitais moleculares de fronteira do complexo RuNOpy, assumindo orbital $d_{x y}$ como não ligante..............................................24

Figura 20. Representação simplificada dos orbitais $\pi$ ligante e $\pi$ antiligante da piridina........25

Figura 21. Diagrama de energia simplificado dos orbitais moleculares de fronteira do complexo RuNOpy, assumindo interação $d_{x y}-\pi$ py..... .26

Figura 22. Espectroeletroquímica do $\mathbf{R u N O}\left(\mathbf{N H}_{3}\right)$ em solução de tampão fosfato $\mathrm{pH}$ 7,4; 0,1 mol L-1 $; \mu=0,262 \mathrm{~mol} \mathrm{~L}^{-1} ; \mathrm{C}_{\mathrm{Ru}}=5 \times 10^{-3} \mathrm{~mol} \mathrm{~L}^{-1} ; \mathrm{T}=20 \pm 4{ }^{\circ} \mathrm{C}$. A variação no espectro foi acompanhada pelo tempo, com passos de 14 segundos. Potencial exibido utiliza como referência eletrodo de $\mathrm{Ag} / \mathrm{AgCl}_{\text {sat }}$. Gráfico inserido representa potencial aplicado no qual não há variação no espectro. 
Figura 23. Espectro no infravermelho do $\mathbf{R u N O}\left(\mathbf{N H}_{3}\right)$ em solução de tampão fosfato $\mathrm{pH}$ 7,4; $0,1 \mathrm{~mol} \mathrm{~L}{ }^{-1} ; \mu=0,262 \mathrm{~mol} \mathrm{~L}^{-1} ; \mathrm{C}_{\mathrm{Ru}}=5 \times 10^{-3} \mathrm{~mol} \mathrm{~L}^{-1}$. Potencial exibido utiliza como referência

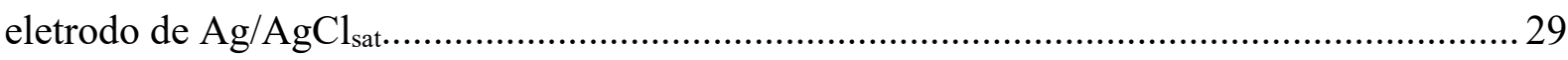

Figura 24. Diagrama de energia simplificado dos orbitais de fronteira do complexo

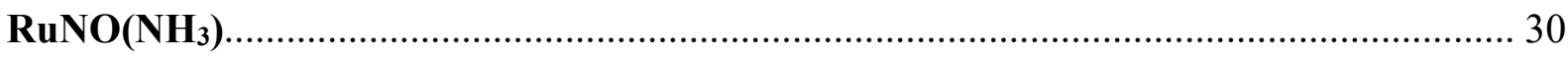




\section{LISTA DE ABREVIATURAS}

\begin{tabular}{|c|c|c|}
\hline RuNOisn & - & trans $-\left[\mathrm{Ru}(\mathrm{NO})\left(\mathrm{NH}_{3}\right)_{4}(\mathrm{isn})\right]^{3+}$ \\
\hline RuNOpy & - & trans $-\left[\mathrm{Ru}(\mathrm{NO})\left(\mathrm{NH}_{3}\right)_{4}(\mathrm{py})\right]^{3+}$ \\
\hline $\mathrm{RuNO}\left(\mathrm{H}_{2} \mathrm{O}\right)$ & - & trans $-\left[\mathrm{Ru}(\mathrm{NO})\left(\mathrm{NH}_{3}\right)_{4}\left(\mathrm{H}_{2} \mathrm{O}\right)\right]^{3+}$ \\
\hline $\mathrm{RuNO}(\mathrm{OH})$ & - & trans $-\left[\mathrm{Ru}(\mathrm{NO})\left(\mathrm{NH}_{3}\right)_{4}(\mathrm{OH})\right]^{2+}$ \\
\hline $\mathrm{RuNO}\left(\mathrm{NH}_{3}\right)$ & - & {$\left[\mathrm{Ru}(\mathrm{NO})\left(\mathrm{NH}_{3}\right)_{5}\right]^{3+}$} \\
\hline py & - & piridina \\
\hline py $\bullet^{\bullet}$ & - & piridina ânion radical \\
\hline isn & - & isonicotinamida \\
\hline NO & - & óxido nítrico \\
\hline MCT & - & Detector de mercúrio, cádmio e telúrio \\
\hline $\mathrm{RMN}$ & - & Ressonância Magnética Nuclear \\
\hline RPE & - & Ressonância Paramagnética de Elétrons \\
\hline HOMO & - & Orbital molecular ocupado de maior energia (Highest Occupied \\
\hline
\end{tabular}

Molecular Orbital)

LUMO - $\quad$ Orbital molecular desocupado de menor energia (Lowest Unoccupied Molecular Orbital)
HTFA
- $\quad$ Ácido trifluoroacético
HTFMS
- $\quad$ Ácido trifluorometanosulfônico
FTIR
- $\quad$ Espectroscopia no infravermelho com transformada de Fourier 


\section{SUMÁRIO}

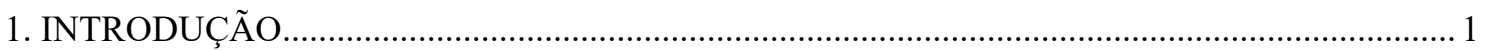

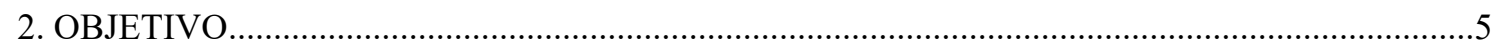

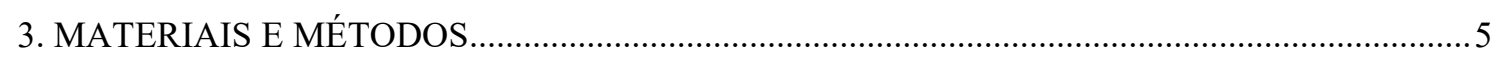

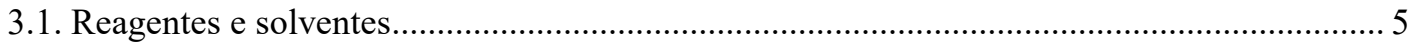

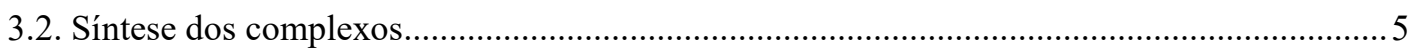

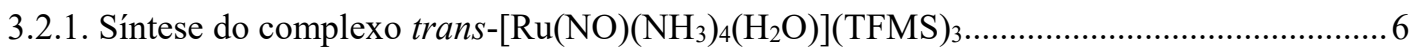

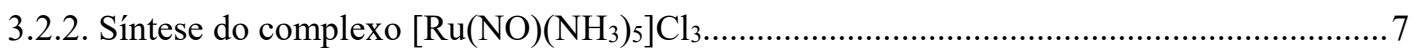

3.3. Preparo do filme de amido com o complexo RuNOisn incorporado........................................

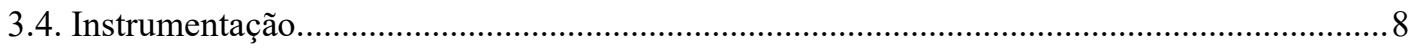

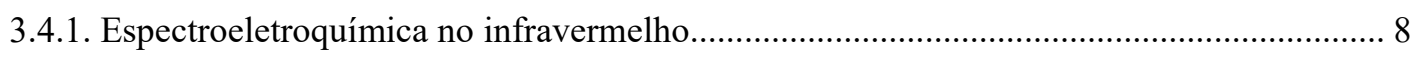

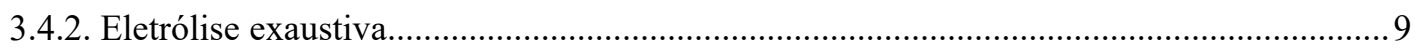

3.4.3. Microscopia multiplex no infravermelho.................................................................... 9

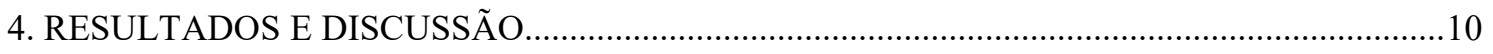

4.1. Liberação controlada da espécie $\mathrm{NO}^{\bullet}$ a partir do filme de amido biodegradável................. 10

4.2 Espectroeletroquímica de nitrosilo complexos em solução aquosa.......................................... 13

4.3. Proposta de liberação de piridina ânion radical pela redução do nitrosilo complexo............24

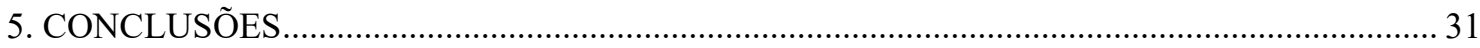

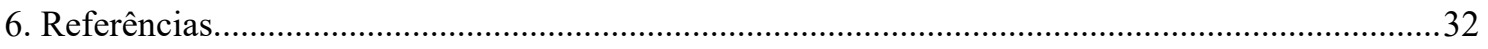

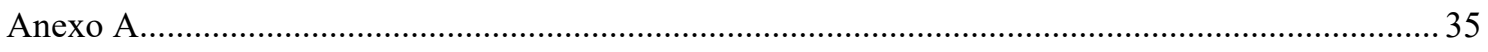

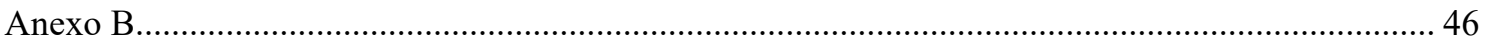

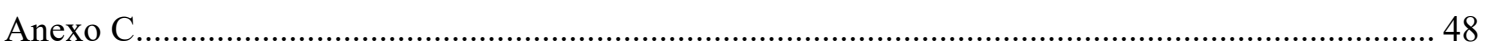

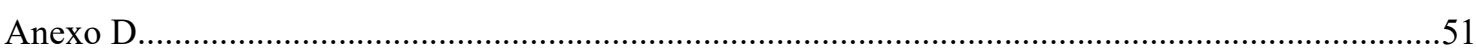

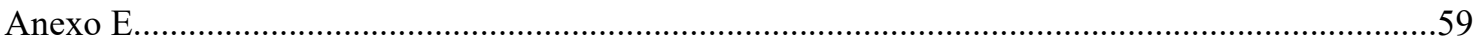




\section{INTRODUÇÃO}

Estudos com relação ao oxido nítrico $\left(\mathrm{NO}^{\bullet}\right)$ mostram que essa molécula executa controle de funções biológicas no organismo ${ }^{1}$. Desde que foi comprovado seu papel em funções como atividade imunológica, controle da pressão sanguínea, neurotransmissão e carcinogênese ${ }^{2-4}$, muito se foi destinado a estudos que envolvessem a liberação controlada dessa espécie. A presença de óxido nítrico no organismo pode ser tanto benéfica quanto prejudicial, dependendo da sua concentração e biodisponibilidade ${ }^{5}$. Sendo assim, tanto doadores quanto retiradores de NO foram desenvolvidos. Com relação à liberação controlada de óxido nítrico, uma das maneiras amplamente estudadas foi sua liberação pela redução de compostos de coordenação que continham o ligante nitrosônio $\left(\mathrm{NO}^{+}\right)$coordenado a centro metálicos ${ }^{6-10}$. Dentre esses compostos de coordenação, um dos primeiros a ser utilizado em tratamento terapêutico foi o íon complexo nitroprussiato, de fórmula $\left[\mathrm{Fe}(\mathrm{NO})(\mathrm{CN})_{5}\right]^{2-}$, com a aplicação de vasodilatação ${ }^{11}$

Figura 1. Fórmula estrutural do complexo nitroprussiato.

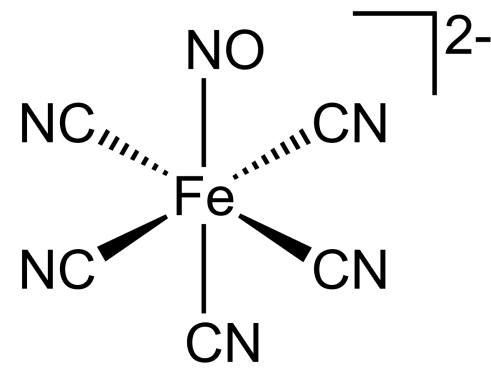

Dentre outros nitrosilo complexos, tetraminas de rutênio de fórmula geral trans$\left[\mathrm{Ru}(\mathrm{NO})\left(\mathrm{NH}_{3}\right)_{4}(\mathrm{~L})\right]^{3+}$ (como exemplo, $\mathrm{L}=$ espécies de $\mathrm{P}(\mathrm{III})$ e $\mathrm{N}$-heterocíclicos) foram extensivamente estudadas com relação a liberação controlada de óxido nítrico, sendo que a escolha por esse sistema ocorre devido a propriedades como baixa toxicidade in vivo, por serem solúveis em meio aquoso, além de apresentarem elevada estabilidade frente a oxidação pelo $\mathrm{O}_{2}$ presente no $a^{5}$. Além de propriedades de interesse biológico, essas tetraminas auxiliam no entendimento da química do NO pelo fato de apresentarem aminas no plano equatorial que se comportam como ligantes inocentes ${ }^{12}$. Sendo assim, o ligante trans posicionado é o maior responsável pela reatividade do ligante $\mathrm{NO}^{+5}$ e o controle de sua reatividade é importante quando se trata da modulação de complexos para um alvo de interesse ${ }^{13}$. 
Figura 2. Exemplo de tetraminas de rutênio contendo o ligante $\mathrm{NO}^{+}$coordenado trans a $\mathrm{N}$ heterocíclicos. No caso, isonicotinamida (à esquerda) e piridina (à direita).

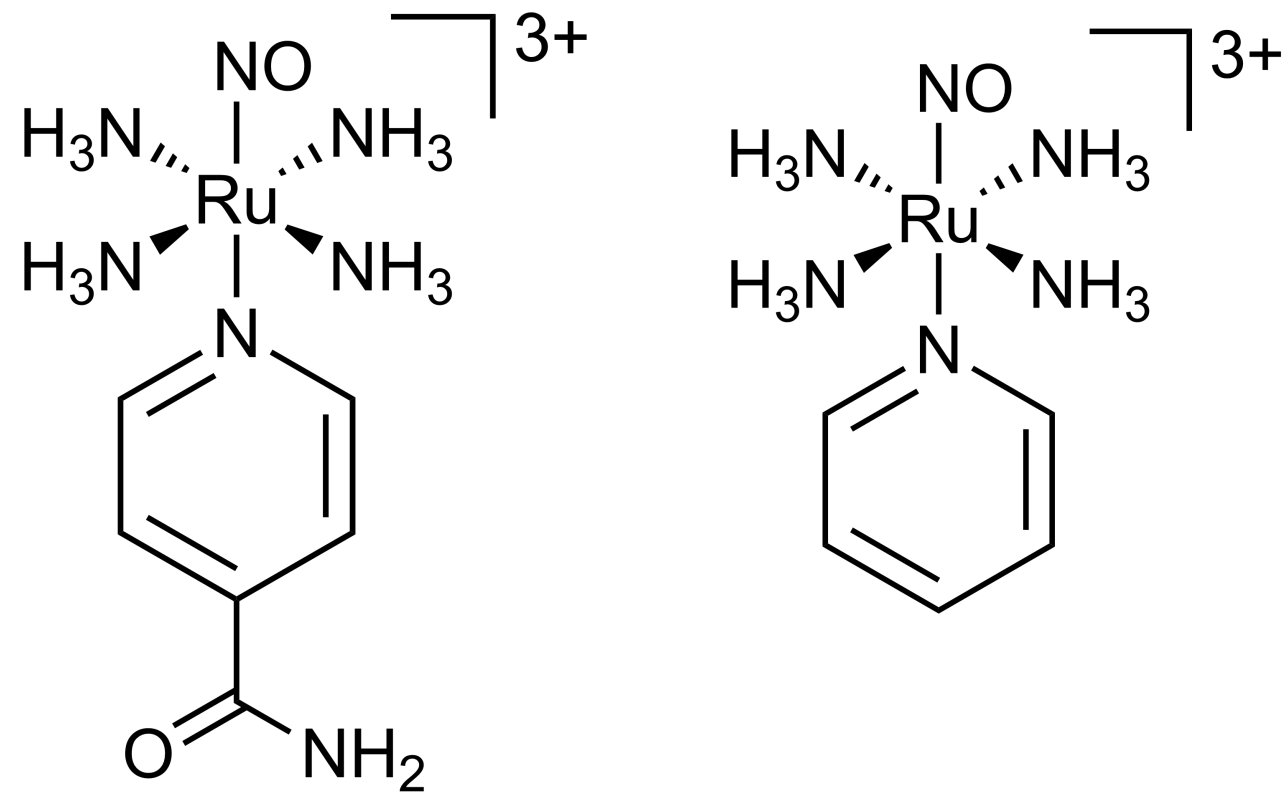

Fonte: Autoria própria

Esses nitrosilo complexos levam a liberação de $\mathrm{NO}^{\bullet}$ quando reduzidos, de acordo com as reações 1 e $2^{13}$ :

$$
\begin{gathered}
\operatorname{trans}-\left[\mathrm{Ru}(\mathrm{NO})\left(\mathrm{NH}_{3}\right)_{4}(\mathrm{~L})\right]^{3+}+\mathrm{e}^{-} \rightarrow \text { trans- }\left[\mathrm{Ru}(\mathrm{NO})\left(\mathrm{NH}_{3}\right)_{4}(\mathrm{~L})\right]^{2+}(1) \\
\text { trans }-\left[\mathrm{Ru}(\mathrm{NO})\left(\mathrm{NH}_{3}\right)_{4}(\mathrm{~L})\right]^{2+}+\mathrm{H}_{2} \mathrm{O} \rightarrow \text { trans }-\left[\mathrm{Ru}\left(\mathrm{NH}_{3}\right)_{4}\left(\mathrm{H}_{2} \mathrm{O}\right)(\mathrm{L})\right]^{3+}+\mathrm{NO}^{\bullet}(2)
\end{gathered}
$$

Estudos envolvendo o complexo trans $-\left[\mathrm{Ru}(\mathrm{NO})\left(\mathrm{NH}_{3}\right)_{4} \mathrm{P}(\mathrm{OEt})_{3}\right]^{3+}$ mostraram que esse composto pode levar à liberação controlada de $\mathrm{NO}^{\bullet}$ por redução química com íons de európio(II) ${ }^{14}$ e também em meio biológico na presença de NADH mitocondrial ${ }^{15}$. No entanto, essas reações de redução podem levar à formação de produtos secundários, muito pouco explorados até então, sendo necessário, assim, um estudo mais aprofundado.

Essa classe de complexos foi muito estudada nos últimos anos, com a finalidade de entregar óxido nítrico de forma controlada ${ }^{16}$. A imobilização desses complexos em matrizes biocompatíveis tem sido de grande utilidade na questão de atingir um alvo específico ${ }^{17}$. Dentre diversos materiais entregadores de NO desenvolvidos, destacamos a utilização de filme de amido de mandioca, no qual o complexo trans- 
$\left[\mathrm{Ru}(\mathrm{NO})\left(\mathrm{NH}_{3}\right)_{4}(\mathrm{isn})\right]^{3+}$ foi incorporado ${ }^{18}$. A preferência pelo filme de amido se deve pelo fato de que esse tipo de polímero apresenta características de biodegradabilidade, além de apresentar baixa toxicidade e baixo custo ${ }^{18}$. Nesse trabalho, a liberação de óxido nítrico ocorre via fotoquímica, sendo possível acompanhar o consumo da espécie $\mathrm{NO}^{+}$ coordenada após a incidência de luz.

A ligação do nitrosônio ao centro metálico de $\mathrm{Ru}(\mathrm{II})$ se dá pela interação sigma $\mathrm{NO} \rightarrow \mathrm{Ru}$ além da retrodoação $\mathrm{Ru} \rightarrow \mathrm{NO}$, pelo fato do ligante apresentar orbitais $\pi^{*}$ vazios de energia e simetria favoráveis a interação com orbitais $d_{\pi}$ populados do $\mathrm{Ru}(\mathrm{II})$.

Figura 3. À esquerda, diagrama de energia simplificado para os orbitais moleculares de fronteira do íon nitrosônio. À direita, representação dos orbitais recorrentes das interações sigma e $\pi$ da molécula de $\mathrm{NO}^{\bullet}$.

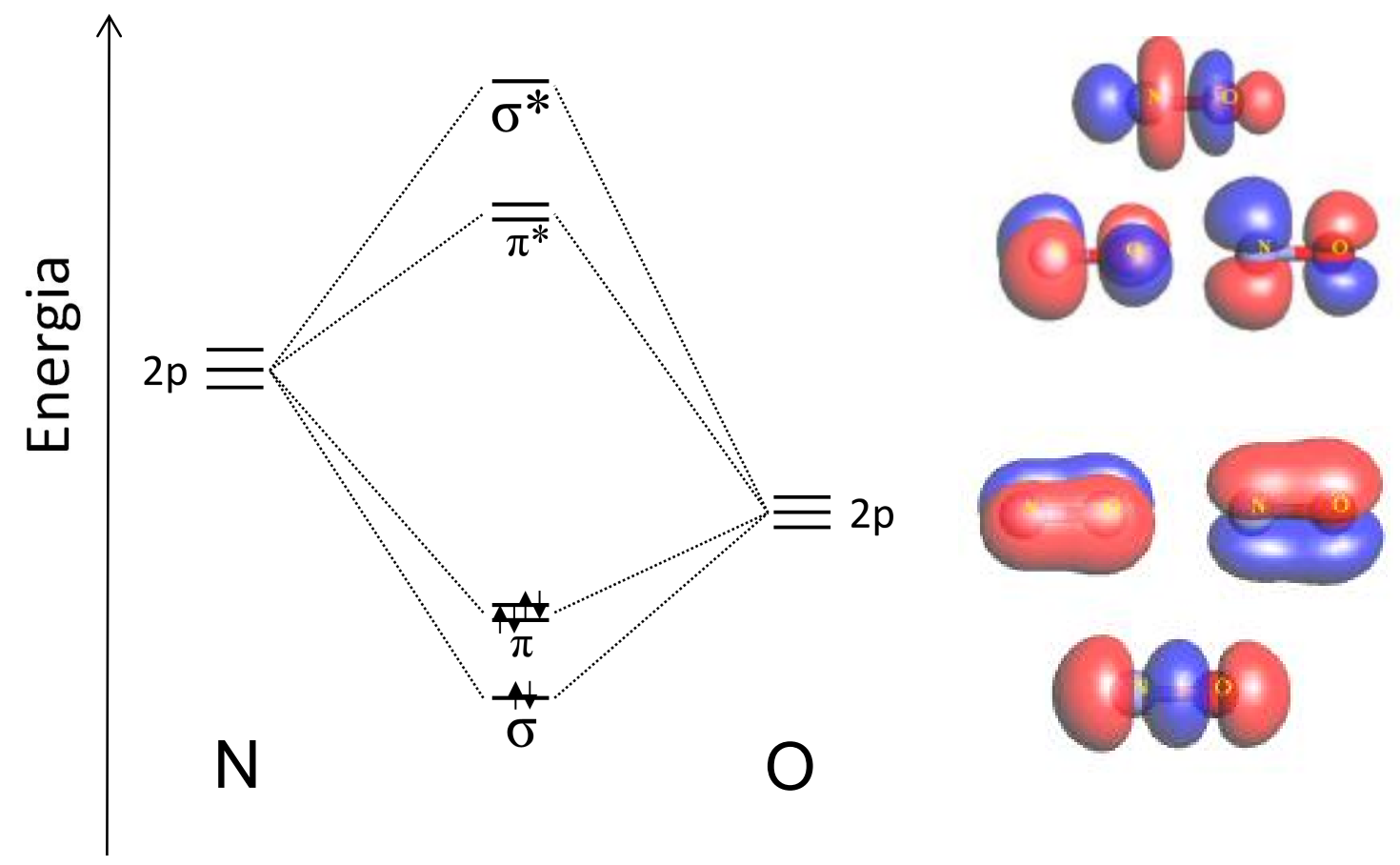

Fonte: refs. ${ }^{1,19}$ 
Figura 4. Representação simplificada da interação sigma entre os centros $\mathrm{NO} \rightarrow \mathrm{Ru}$ e retrodoação $\mathrm{Ru} \rightarrow \mathrm{NO}$. Setas indicam sentido do deslocamento de densidade eletrônica.

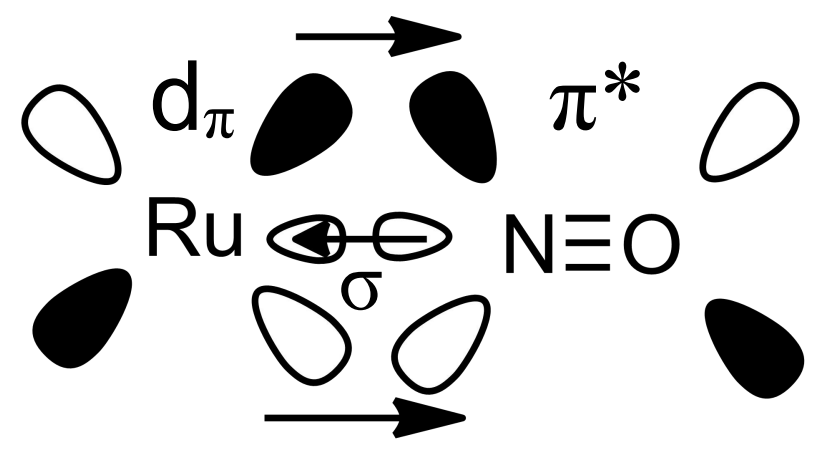

Fonte: Autoria própria. ref. ${ }^{20}$

Em decorrência da elevada interação dos orbitais $d_{\pi^{-}} \pi^{*} \mathrm{NO}$, a porção [RuNO] do complexo apresenta elevada linearidade, com ângulo de ligação RuNO próximo a $180^{\circ}$. No entanto, com a ocupação de um elétron no orbital $\pi^{*}$ do ligante NO, a interação dos orbitais $\mathrm{d}_{\pi}-\pi^{*} \mathrm{NO}$ diminui, e a porção [RuNO] perde a linearidade, tendo ângulos de ligação próximos a $140^{\circ} 12$.

Figura 5. Representação simplificada da interação $\pi$ entre os centros $\mathrm{Ru}^{\mathrm{II}}-\mathrm{NO}^{+}$e $\mathrm{Ru}^{\mathrm{II}}-\mathrm{NO}{ }^{\bullet}$. Setas indicam sentido do deslocamento de densidade eletrônica.

$$
\left[\mathrm{Ru}-\mathrm{NO}^{+}\right]
$$

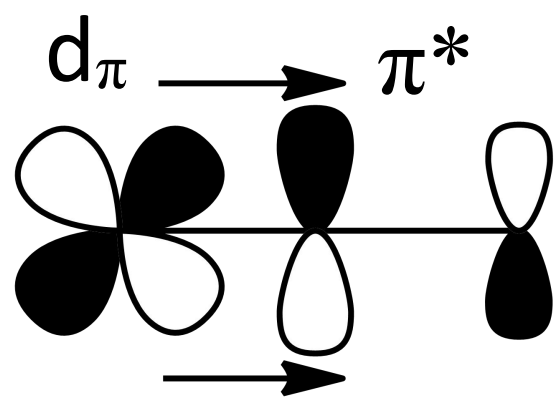

$\left[\mathrm{Ru}-\mathrm{NO}^{\bullet}\right]$

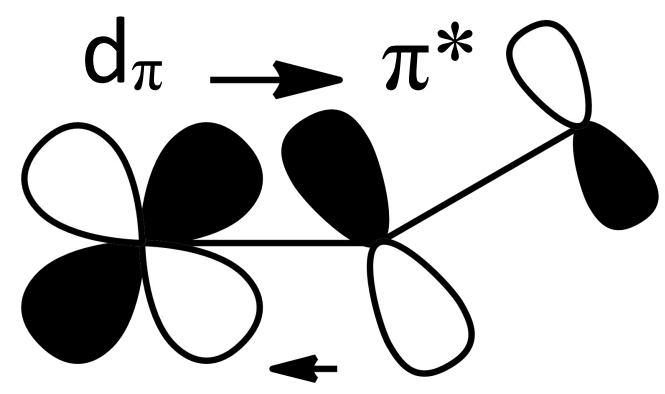

Fonte: Autoria própria. ref. ${ }^{12}$

A perda da linearidade da ligação RuNO leva a diminuição da afinidade do ligante NO pelo centro metálico de $\mathrm{Ru}(\mathrm{II})$, levando a quebra da ligação Ru-NO. Com isso, há a labilização do ligante reduzido da esfera e coordenação. Como contraste, quando na forma de $\mathrm{NO}^{+}$, a afinidade pelo centro metálico de $\mathrm{Ru}(\mathrm{II})$ é tão elevada que o NO 
apresenta a capacidade de labilizar o ligante trans posicionado a ele quando em solução aquosa com $\mathrm{pH}$ próximo do neutro ${ }^{21}$.

Diante da capacidade de nitrosilo complexos liberarem óxido, e sua facilidade de incorporação a materiais biodegradáveis, este trabalho teve como ideia inicial explorar a possibilidade de liberação de óxido nítrico de forma controlada, com a aplicação de potencial, a partir de filme biodegradável de amido de mandioca contendo o complexo RuNOisn. No entanto, resultados inesperados nos levaram revisitar o mecanismo de redução eletroquímica de nitrosilo complexos em solução aquosa.

\section{OBJETIVO}

Estudar de forma mais aprofundada a reação de redução de nitrosilo complexos do tipo trans- $\left[\mathrm{Ru}(\mathrm{NO})\left(\mathrm{NH}_{3}\right)_{4}(\mathrm{~L})\right]^{3+}$ (em que $\mathrm{L}=$ isn, py, $\mathrm{NH}_{3}$ ou $\left.\mathrm{OH}^{-}\right)$via espectroeletroquímica de FTIR in situ.

\section{MATERIAIS E MÉTODOS}

\subsection{Reagentes e solventes}

Todos os reagentes utilizados foram adquiridos das empresas Merck, SigmaAldrich e Panreac. Os solventes etanol e acetona (grau HPLC) foram adquiridos das empresas Panreac e Honeywell, respectivamente, e foram utilizados sem purificação prévia. O tricloreto de rutênio(III) hidratado $\left(\mathrm{RuCl}_{3} \times \mathrm{nH}_{2} \mathrm{O}\right.$, Sigma Aldrich, 40 - 49\%) foi o precursor sintético dos complexos utilizados. Quanto aos gases, argônio 5.0; dióxido de enxofre 3.0 e óxido nítrico foram adquiridos da empresa White Martins. Anteriormente a cada experimento, soluções foram desaeradas com argônio 5.0.

\subsection{Síntese dos complexos}

A rota sintética para a obtenção dos complexos trans- $\left[\mathrm{Ru}(\mathrm{NO})\left(\mathrm{NH}_{3}\right)_{4}(\mathrm{~L})\right]^{3+}(\mathrm{L}=$ isn ou py) foi realizada de acordo com procedimentos reportados na literatura ${ }^{22-24}$. As etapas estão resumidas na Figura 6. 
Figura 6. Rota sintética para obtenção dos nitrosilo complexos trans-[Ru(NO)(NH$\left.)_{4}(\mathrm{~L})\right]^{3+}$ ( $\mathrm{L}=$ isn ou py).

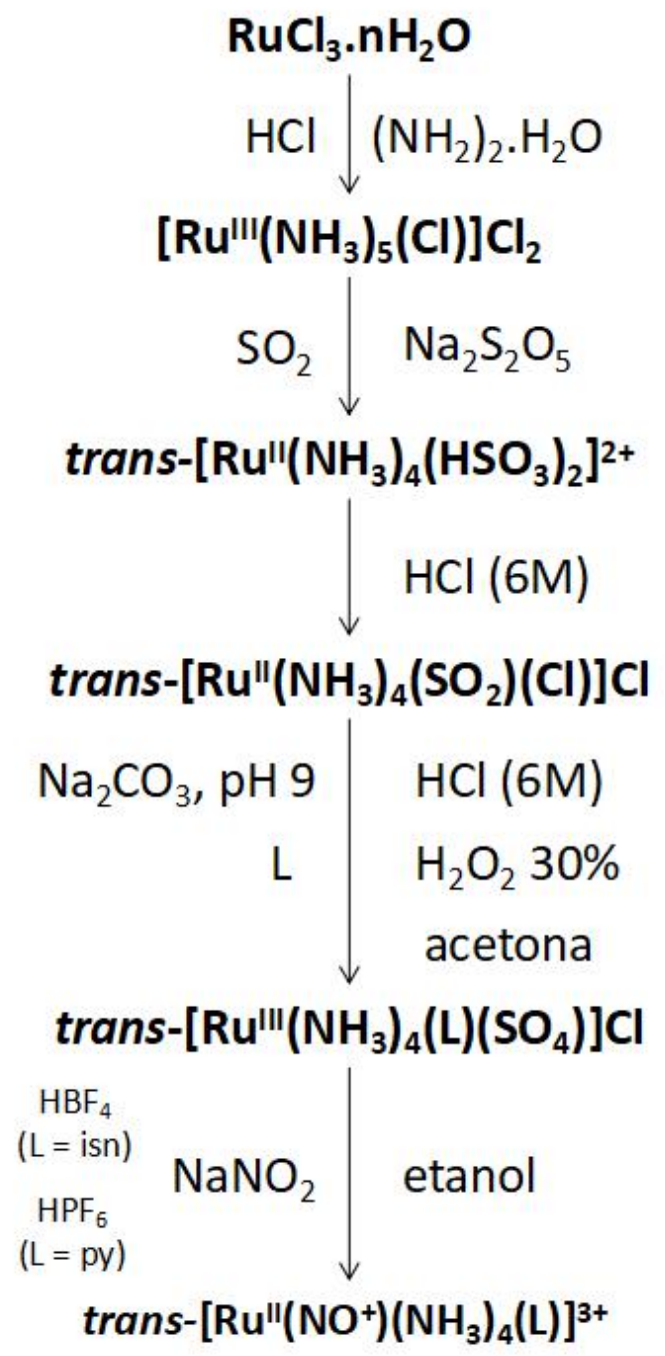

A caracterização dos nitrosilo complexos foi realizada pelas técnicas de espectroscopia de absorção no infravermelho e UV-Vis, Ressonância Magnética Nuclear (RMN), e estão de acordo com o reportado na literatura ${ }^{16,21}$

\subsubsection{Síntese do complexo trans- $\left[\mathrm{Ru}(\mathrm{NO})\left(\mathrm{NH}_{3}\right)_{4}\left(\mathrm{H}_{2} \mathrm{O}\right)\right](\mathrm{TFMS})_{3}$}

O complexo trans- $\left[\mathrm{Ru}(\mathrm{NO})\left(\mathrm{NH}_{3}\right)_{4}\left(\mathrm{H}_{2} \mathrm{O}\right)\right](\mathrm{TFMS})_{3}$ foi isolado a partir do trans$\left[\mathrm{Ru}(\mathrm{NO})\left(\mathrm{NH}_{3}\right)_{4}(\mathrm{isn})\right]^{3+}$. Para isso, $70 \mathrm{mg}$ de RuNOisn foram solubilizados em $4 \mathrm{~mL}$ de tampão fosfato $\mathrm{pH} 7,4 ; 0,1 \mathrm{~mol} \mathrm{~L}-1 ; \mu=0,262 \mathrm{~mol} \mathrm{~L}^{-1}$. Essa solução foi mantida a $50{ }^{\circ} \mathrm{C}$ por 24 h. Em seguida, adiciona-se $1 \mathrm{~mL}$ de solução de ácido trifluorometanosulfônico (HTFMS) 5 mol L-1. A solução foi mantida refrigerada por $12 \mathrm{~h}$. Em seguida, essa 
solução teve seu volume reduzido pelo uso de pressão reduzida, utilizando uma linha de Schlenk, até a formação de cristais de cor amarela, que por fim, foram filtrados e armazenados sob vácuo e ao abrigo da luz.

A caracterização do complexo trans- $\left[\mathrm{Ru}(\mathrm{NO})\left(\mathrm{NH}_{3}\right)_{4}\left(\mathrm{H}_{2} \mathrm{O}\right)\right](\mathrm{TFMS})_{3}$ foi realizada pelas técnicas espectroscopia de absorção no UV-Vis e análise elementar, estando de acordo com o reportado na literatura ${ }^{25}$.

\subsubsection{Síntese do complexo $\left[\mathrm{Ru}(\mathrm{NO})\left(\mathrm{NH}_{3}\right)_{5}\right] \mathrm{Cl}_{3}$}

Em um balão de fundo redondo contendo $3 \mathrm{~mL}$ de água deionizada, são solubilizados $100 \mathrm{mg}$ de $\left[\mathrm{Ru}\left(\mathrm{NH}_{3}\right)_{6}\right] \mathrm{Cl}_{3}$. Esse balão é conectado, via cânula de teflon, a um segundo balão de fundo redondo, contendo $5 \mathrm{~mL}$ de solução de $\mathrm{HCl}$ (Panreac) 0,1 mol L-1. Sob atmosfera de argônio, borbulha-se óxido nítrico à solução de $\mathrm{HCl}$. Então, a solução do balão com o complexo é transferida ao segundo balão. Deixa-se reagir por uma hora, mantendo o borbulhamento de óxido nítrico. O $\left[\mathrm{Ru}(\mathrm{NO})\left(\mathrm{NH}_{3}\right)_{5}\right] \mathrm{Cl}_{3}$ é precipitado pela adição de $20 \mathrm{~mL}$ de etanol gelado. O sólido é filtrado e armazenado sob vácuo e ao abrigo da luz.

A caracterização do complexo $\left[\mathrm{Ru}(\mathrm{NO})\left(\mathrm{NH}_{3}\right)_{5}\right] \mathrm{Cl}_{3}$ foi realizada pelas técnicas de espectroscopia de absorção no infravermelho e voltametria cíclica, estando de acordo com o reportado na literatura ${ }^{16}$.

\subsection{Preparo do filme de amido com o complexo RuNOisn incorporado}

O procedimento para o preparo dos filmes de amido foi realizado baseado com o já reportado na literatura ${ }^{18}$, e consistiu em adicionar $75 \mathrm{mg}$ de glicerol, $470 \mathrm{mg}$ de amido modificado com trimetafosfato de sódio (STMP, Synth) e 7,0 mL de água destilada à um béquer. Essa solução foi aquecida até temperatura entre $75-80^{\circ} \mathrm{C}$, em banho termostático, sob agitação constante. Com isso, obtêm-se um gel transparente, que é deixado para resfriar até temperatura ambiente. Ao fim desse processo, uma solução contendo $50 \mu \mathrm{mol}$ do complexo RuNOisn, dissolvido em 7,0 mL de água deionizada, foi adicionada ao gel de amido. Essa solução final é mantida sob agitação por 5 minutos, e então é transferida para uma placa de Petri de acrílico com área de 28,3 $\mathrm{cm}^{2}$. Para secagem do gel, essa placa foi mantida em uma estufa $\left(\mathrm{T}=40 \pm 2{ }^{\circ} \mathrm{C}\right)$ por 18 horas. Quando seco, o filme foi armazenado em dessecador com umidade controlada. 


\subsection{Instrumentação}

\subsubsection{Espectroeletroquímica no infravermelho}

A configuração instrumental consistiu no acoplamento de uma célula eletroquímica de três eletrodos controlados por um potenciostato/galvanostato Autolab PGSTAT128N a um espectrômetro de infravermelho Bruker Vertex 70v. Utilizou-se um disco de ouro devidamente polido como eletrodo de trabalho ao passo que um fio de platina e $\mathrm{Ag} / \mathrm{AgCl}_{\text {sat }}$ foram usados como eletrodo auxiliar e eletrodo de referência, respectivamente. A face do eletrodo de trabalho foi posicionada diretamente sobre uma janela de $\mathrm{CaF}_{2}$ para a incidência do feixe de infravermelho e subsequente reflexão, a fim de se analisar as mudanças químicas que acontecem diretamente sob a influência de um sobre-potencial eletroquímico. A Figura 7 representa a célula eletroquímica utilizada durante o experimento.

Figura 7. Representação da célula utilizada nos experimentos de espectroeletroquímica.

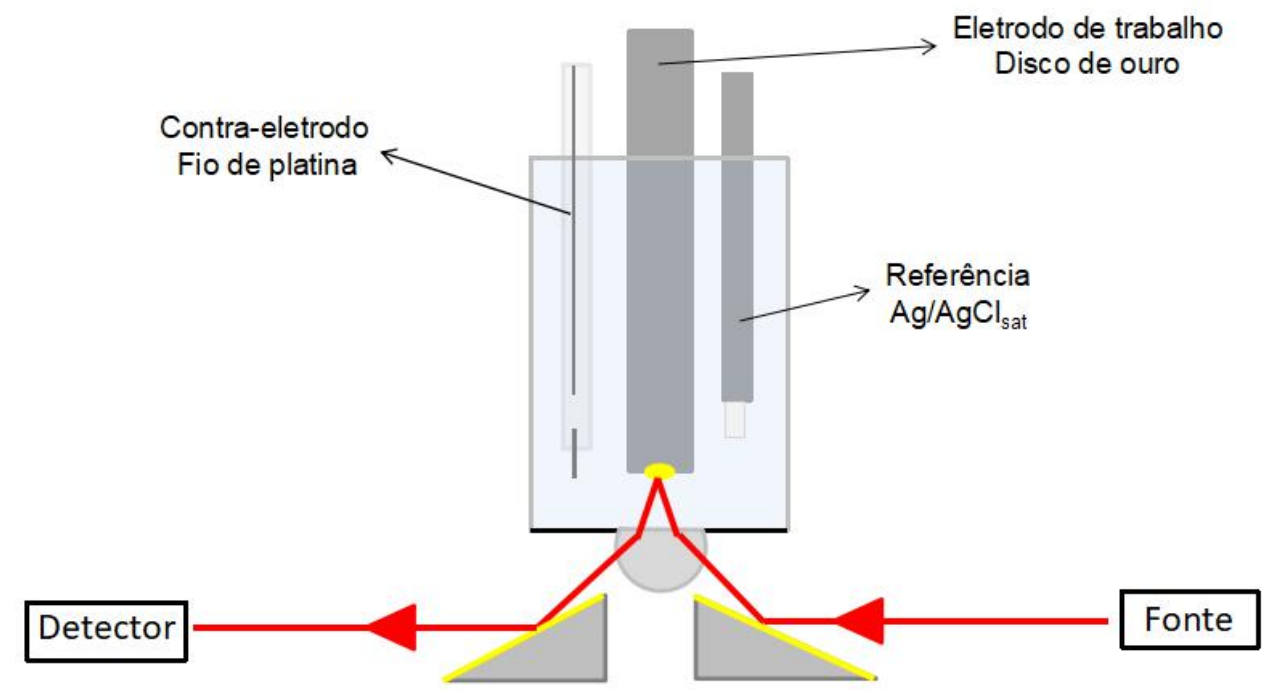

Fonte: Autoria Própria

Todos os experimentos de espectroeletroquímica foram realizados em solução de tampão fosfato. Quando preparado em solução de óxido de deutério $\left(\mathrm{D}_{2} \mathrm{O}\right.$, SigmaAldrich, 99,9\%), o valor de $\mathrm{pH}$ foi ajustado conforme descrito na literatura, sendo que $\mathrm{pH}=\mathrm{pH}_{\text {registrado }}+0,4^{26}$. Os experimentos foram feitos utilizando-se 7,0 mL de solução do complexo RuNOL $\left(\mathrm{L}=\right.$ isn, py, $\mathrm{NH}_{3}$ ou $\left.\mathrm{OH}^{-}\right)\left(\mathrm{C}_{\mathrm{Ru}}=5 \times 10^{-3} \mathrm{~mol} \mathrm{~L}^{-1}\right)$. As medidas foram realizadas pela varredura de potencial de $+0,25 \mathrm{~V}$ até $-0,50 \mathrm{~V}$ vs. $\mathrm{Ag} / \mathrm{AgCl}_{\text {sat }}$, 
com passos de $50 \mathrm{mV}$. Os experimentos foram realizados a uma tempratura de $20 \pm 4$ ${ }^{\circ} \mathrm{C}$. Os espectros apresentados correspondem ao espectro da diferença ( $\Delta$ Absorção) utilizando-se como espectro de referência aquele obtido no potencial mais positivo, $+0,25 \mathrm{~V}$ vs. $\mathrm{Ag} / \mathrm{AgCl}_{\text {sat, }}$ (potencial aplicado por um minuto) no qual nenhum processo eletroquímico ocorre com os complexos estudados. Foram acumulados ns $=32$ interferogramas por espectro, utilizando-se um detector de $\mathrm{HgCdTe}(\mathrm{MCT})$, refrigerado com nitrogênio líquido $(77 \mathrm{~K})$, com o interferômetro trabalhando a $160 \mathrm{kHz}$, a uma resolução espectral de $4 \mathrm{~cm}^{-1}$.

\subsubsection{Eletrólise exaustiva}

A configuração instrumental consistiu da utilização de uma célula eletroquímica de três eletrodos controlados por um potenciostato/galvanostato Autolab PGSTAT204. Utilizou-se uma rede de ouro como eletrodo de trabalho, ao passo que um fio de platina e $\mathrm{Ag} / \mathrm{AgCl}_{\text {sat }}$ foram usados como eletrodo auxiliar e eletrodo de referência, respectivamente. A eletrólise exaustiva foi realizada em uma célula eletroquímica contendo $5 \times 10^{-3} \mathrm{~mol} \mathrm{~L}^{-1}$ do complexo $\left[\mathrm{Ru}(\mathrm{NO})\left(\mathrm{NH}_{3}\right)_{5}\right]^{3+}$ em tampão fosfato $\mathrm{pH} 7,4 ; 0,1$ mol L ${ }^{-1}$ e $\mu=0,262 \mathrm{~mol} \mathrm{~L}^{-1}$. Após a aplicação de $-0,35 \mathrm{~V}$ vs. $\mathrm{Ag} / \mathrm{AgCl}_{\text {sat }}$ por uma hora, um espectro no infravermelho foi registrado.

\subsubsection{Microscopia multiplex no infravermelho}

Utilizou-se um microscópio Hyperion 3000 acoplado a um espectrômetro de infravermelho Vertex 70v (Bruker). Este microscópio é equipado com um detector composto por um arranjo de fotodetectores no plano focal (FPA) com $64 \times 64$ elementos, possibilitando a coleta de espectros simultaneamente de 4096 regiões da amostra. As medidas foram realizadas no modo transmissão com ambas as lentes objetiva e condensadora de $15 \times$, acumulando-se $\mathrm{ns}=32$ medidas por espectro a uma resolução de $4 \mathrm{~cm}^{-1}$. Os mapas químicos foram construídos pela distribuição matricial da área integrada sob cada sinal de absorção de interesse para se ter uma correlação com a imagem ótica da amostra. A amostra analisada foi referente ao filme de amido com o complexo RuNOisn incorporado à ele. 


\section{RESULTADOS E DISCUSSÃO}

\subsection{Liberação controlada da espécie $\mathrm{NO}^{\bullet}$ a partir do filme de amido biodegradável}

Na Figura 8 são apresentados os resultados referentes à microscopia multiplex no infravermelho do filme de amido contendo o complexo RuNOisn incorporado à ele.

Figura 8. Microscopia multiplex no infravermelho do filme de amido contendo o complexo RuNOisn incorporado. (a) Imagem ótica da região limite do filme. (b) Imagem química referente à integração da região entre 1915-1945 $\mathrm{cm}^{-1}$. (c) Espectro no infravermelho das três regiões distintas do filme demarcadas na figura 8a. (d) Ampliação da região demonstrando o sinal atribuído ao ligante $\mathrm{NO}^{+}$coordenado
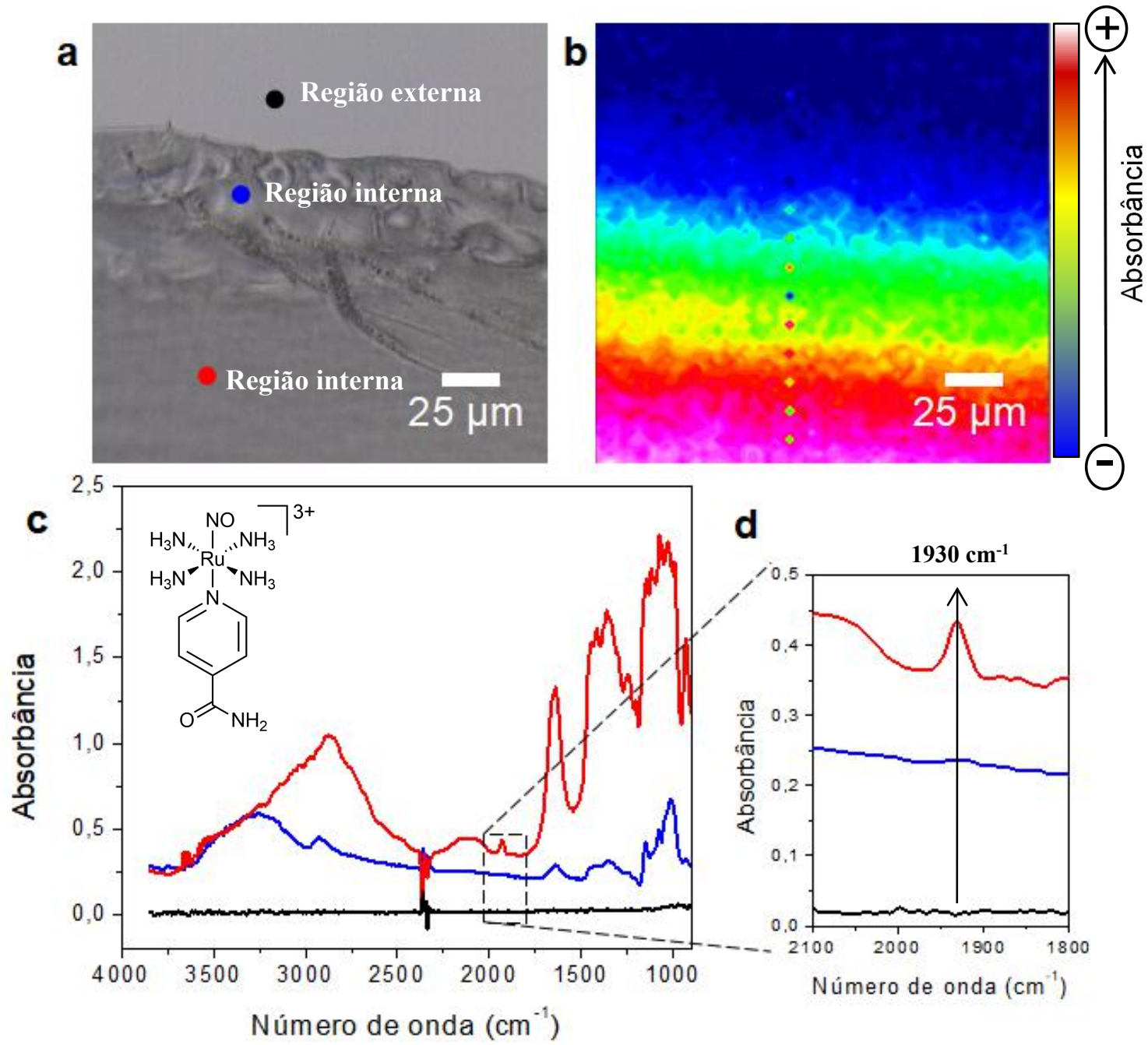

A figura 8a exibida acima foi retirada da borda do filme de amido. Os pontos escolhidos em preto, azul e vermelho são referentes às regiões fora do filme, logo na borda, e mais interna desse filme, respectivamente. O espectro de FTIR de cada uma dessas regiões é exibido na figura 8c. Observa-se que para o ponto mais interno no 
filme (vermelho), mais intenso é o sinal do valor do estiramento em $1930 \mathrm{~cm}^{-1}$, atribuído ao estiramento $v(\mathrm{NO})$ do ligante $\mathrm{NO}^{+}$coordenado ao centro metálico ${ }^{18}$.

A figura $8 b$ é referente à integral da região no espectro entre $1915-1945 \mathrm{~cm}^{-1}$, delimitada pelo sinal do estiramento $v(\mathrm{NO})$, sendo proporcional à quantidade de complexo RuNOisn. Nela, em azul, temos que a concentração da espécie RuNOisn é muito baixa ou zero, no caso da coloração azul escura. Conforme a coloração passa de verde, indo até rosa, maior é a intensidade do sinal do estiramento $v(\mathrm{NO})$, sendo atribuído assim, uma maior concentração do complexo RuNOisn. Podemos ver que a concentração do complexo RuNOisn é uniforme ao longo do filme, apresentando maior acumulo de complexo conforme vamos para o centro do filme.

Em seguida, elaborou-se um estudo para avaliar a capacidade desse filme de liberar $\mathrm{NO}^{\bullet}$ via eletroquímica. Para tanto, o filme foi imobilizado em uma matriz condutora de forma que fosse provocada a passagem de corrente elétrica por ele. No entanto, ao aplicar-se potencial no sistema seco, nenhuma corrente elétrica era detectada. Para contornar esse problema, uma solução de ácido trifluoroacético $(\mathrm{pH} 2,0)$ foi preparada, na qual o filme foi submergido e fixado ainda úmido na matriz condutora. Com isso, passagem de corrente foi detectada, e com a aplicação potencial no sistema, observou-se a variação no espectro de absorção no infravermelho, como mostra a Figura 9. 
Figura 9. Espectro da diferença na região do infravermelho do filme de amido com o íon complexo RuNOisn incorporado. Solução utilizada: HTFA pH 2,0. A variação no espectro foi acompanhada pelo tempo com passos de 30 segundos. Potencial aplicado: $-2,5 \mathrm{~V} ; \mathrm{T}=20 \pm 4{ }^{\circ} \mathrm{C}$.

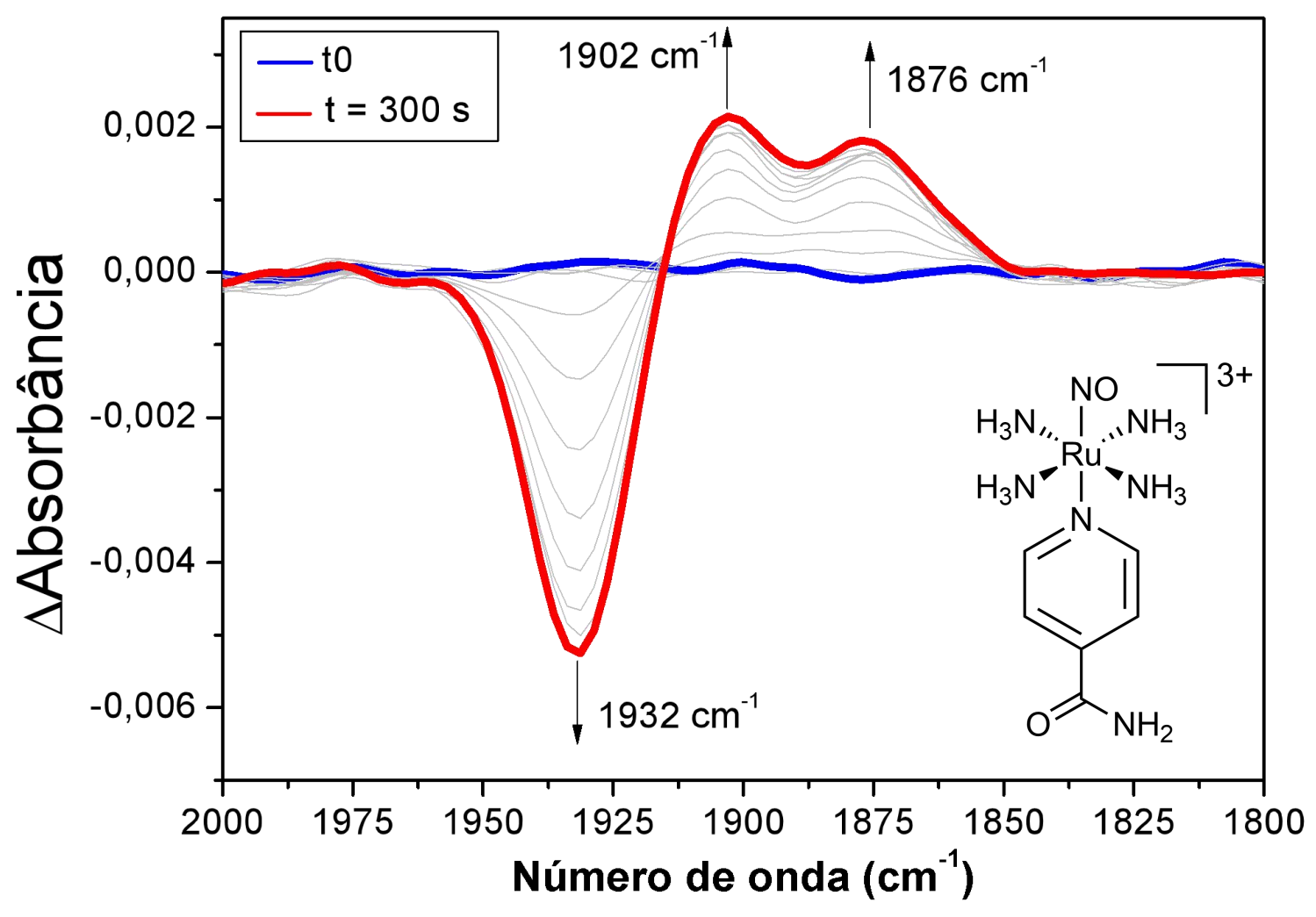

A banda centrada em $1932 \mathrm{~cm}^{-1}$ é referente ao estiramento $v(\mathrm{NO})$ da espécie $\mathrm{NO}^{+}$coordenada ao complexo RuNOisn ${ }^{16}$. Já a banda em $1876 \mathrm{~cm}^{-1}$ foi atribuída ao estiramento de $v(\mathrm{NO})$ da espécie $\mathrm{NO}^{\bullet} \operatorname{livre}^{27}$. O comportamento de consumo da primeira e formação da segunda está de acordo com o que foi reportado na literatura ${ }^{13} \mathrm{e}$ apresentado nas equações (1) e (2). No entanto, observamos o surgimento da banda centrada em $1902 \mathrm{~cm}^{-1}$, até então não reportada na literatura para esse tipo de complexo. Em adição a isso, quando esse experimento foi realizado submergindo o filme em solução com pH 7,4, o seguinte resultado é obtido. 
Figura 10. Espectro da diferença na região do infravermelho do filme de amido com o íon complexo RuNOisn incorporado. Solução utilizada: tampão fosfato pH 7,4. A variação no espectro foi acompanhada pelo tempo, com passos de 30 segundos. Potencial aplicado: $-2,5 \mathrm{~V} ; \mathrm{T}=20 \pm 4{ }^{\circ} \mathrm{C}$.

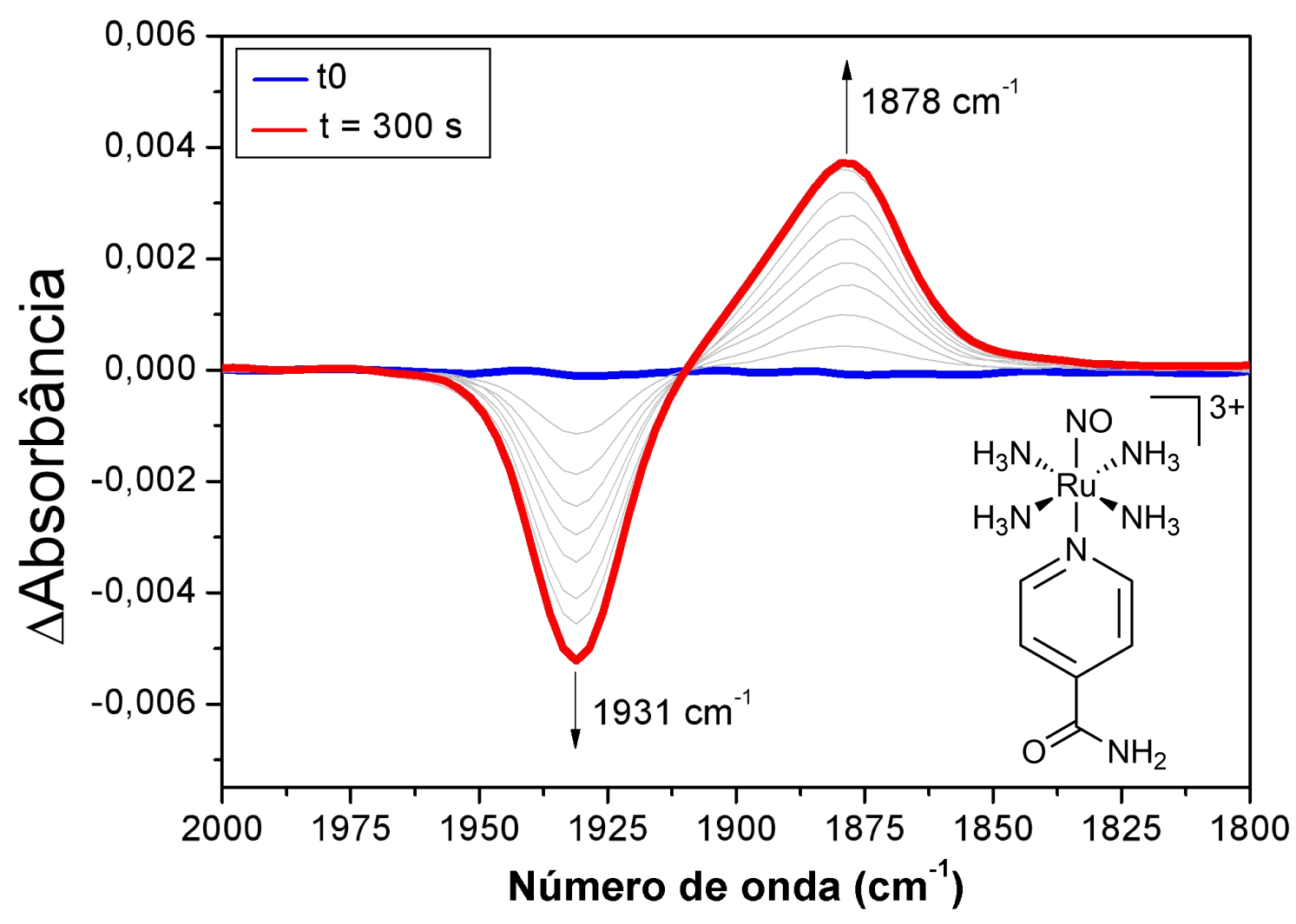

Dessa vez, não foi observado sinal em $1902 \mathrm{~cm}^{-1}$, mas apenas um estiramento $1878 \mathrm{~cm}^{-1}$. Pelo fato de termos formação de sinais dependentes do $\mathrm{pH}$, e não explicados pela literatura para esses complexos, iniciou-se o estudo em solução de espectro eletroquímica de FTIR in situ com a finalidade de explicar o surgimento dessas bandas, e avaliar esse comportamento em outros íon complexos do tipo trans$\left[\mathrm{Ru}(\mathrm{NO})\left(\mathrm{NH}_{3}\right)_{4}(\mathrm{~L})\right]^{3+}\left(\right.$ em que $\mathrm{L}=$ isn, py, $\mathrm{NH}_{3}$ ou $\left.\mathrm{OH}^{-}\right)$.

\subsection{Espectroeletroquímica de nitrosilo complexos em solução aquosa}

O resultado obtido em solução via espectroeletroquímica de FTIR in situ no pH 7,2 para o complexo trans- $\left[\mathrm{Ru}(\mathrm{NO})\left(\mathrm{NH}_{3}\right)_{4}(\mathrm{isn})\right]^{3+}$ é apresentado a seguir. O mesmo experimento foi realizado com o complexo trans-[Ru(NO)(NH$)_{4}(\text { py) }]^{3+}$, no qual observou-se a mesma tendência no comportamento da espécie diante da redução eletroquímica em pH 7,2. 
Figura 11. Espectroeletroquímica do íon complexo (A) RuNOisn e (B) RuNOpy no pH 7,2. $\mathrm{C}_{\mathrm{Ru}}=5 \times 10^{-3} \mathrm{~mol} \mathrm{~L}^{-1} ; \mathrm{T}=20 \pm 4{ }^{\circ} \mathrm{C}$. Potenciais exibidos utilizam como referência eletrodo de

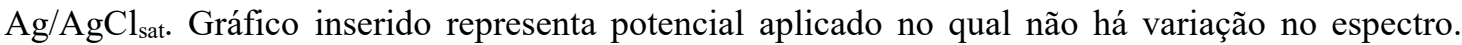
Passos de $50 \mathrm{mV}$. Linha de base deslocada para melhor clareza.
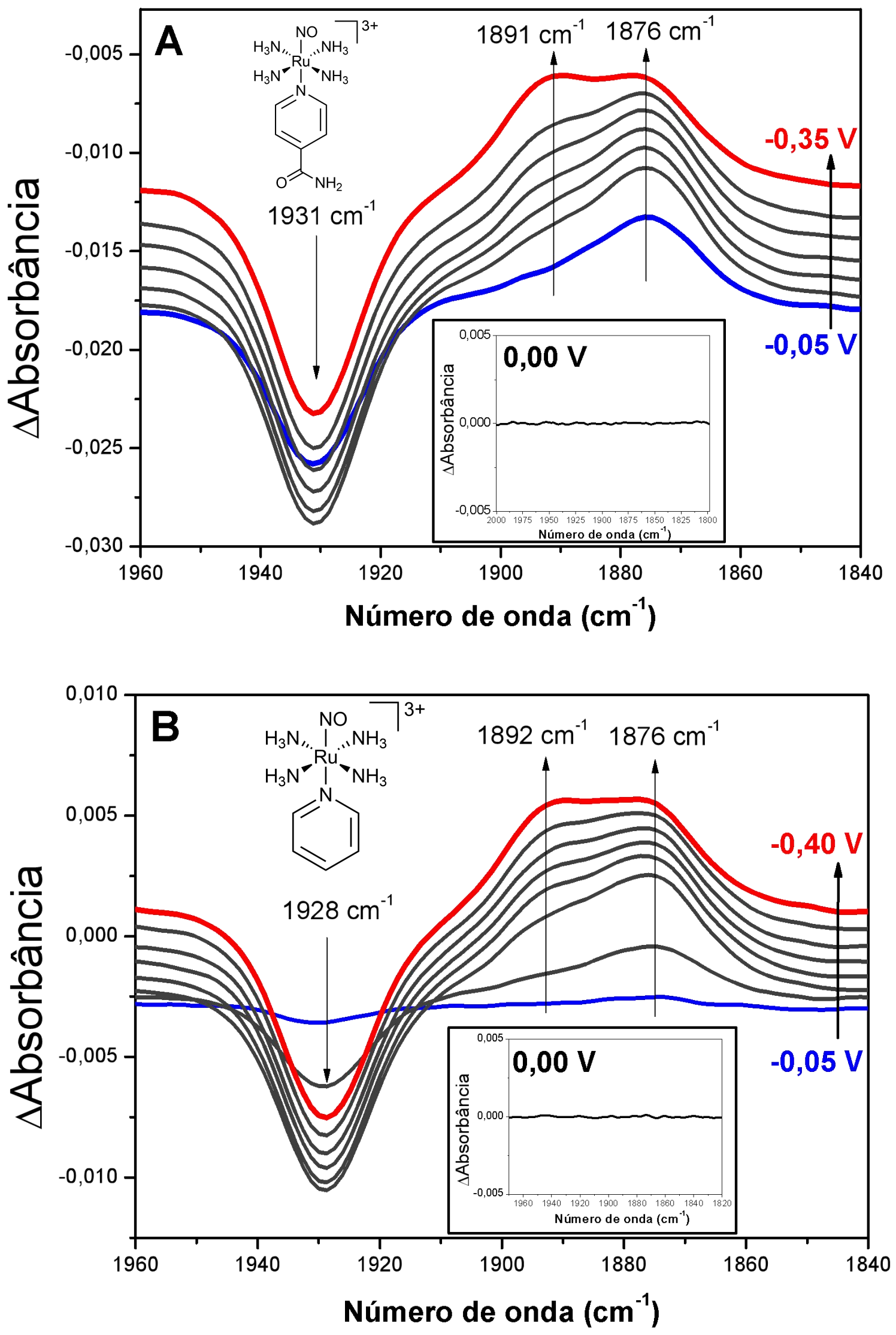
Nos gráficos apresentados nas Figuras 11a e 11b exibidos acima, observa-se:

i) Consumo de espécie com banda centrada na região de $1930 \mathrm{~cm}^{-1}$;

ii) Formação de espécie com banda centrada na região de $1876 \mathrm{~cm}^{-1}$;

iii) Formação de espécie com banda centrada na região de $1891 \mathrm{~cm}^{-1}$.

O sinal centrado na região de $1930 \mathrm{~cm}^{-1}$ é atribuído ao $v(\mathrm{NO})$ do $\mathrm{NO}^{+}$ coordenado presente nos íons complexos RuNOisn e RuNOpy ${ }^{16}$. O sinal centrado em $1876 \mathrm{~cm}^{-1}$ é atribuído ao estiramento do $\mathrm{NO}^{\bullet}$ livre $^{26}$. O comportamento desses dois sinais é descrito na literatura pela redução do fragmento $\left[\mathrm{RuNO}^{+}\right]$para $\left[\mathrm{RuNO}{ }^{\bullet}\right]^{13}$. O $\mathrm{NO}{ }^{\bullet}$ coordenado apresenta então baixa afinidade pelo centro metálico, e é labilizado da esfera de coordenação, sendo substituído por uma molécula de água ${ }^{13}$. Com isso, observa-se o consumo do sinal referente ao $v(\mathrm{NO})$ do $\mathrm{NO}^{+}$coordenado, e formação do sinal referente ao $v(\mathrm{NO})$ da espécie $\mathrm{NO} \bullet$ livre em $1876 \mathrm{~cm}^{-1}{ }^{26}$. Entretanto, em solução aquosa, é observada a formação do sinalna região de $1890 \mathrm{~cm}^{-1}$.

No intuito de entender a formação da espécie referente ao sinal em $1890 \mathrm{~cm}^{-1}$, um experimento de espectroeletroquímica de FTIR in situ, acompanhado no tempo, foi realizado. Dessa vez, a solução de tampão fosfato foi preparada em meio de $\mathrm{D}_{2} \mathrm{O}$, na qual o complexo RuNOpy foi solubilizado. A preferência por esse composto se deu por ele conter um ligante trans ao $\mathrm{NO}^{+}$estruturalmente mais simples, quando comparado ao RuNOisn. Nesse caso, foi possível acompanhar o comportamento da piridina ao reduzirmos o complexo com um elétron pela aplicação de potencial. Os demais potenciais analisados se encontram no Anexo A. 
Figura 12. Espectroeletroquímica do RuNOpy em solução de tampão fosfato $\mathrm{pH} 7,4 ; 0,1$ mol L ${ }^{-1} ; \mu=0,262 \mathrm{~mol} \mathrm{~L}^{-1}$ preparado em $\mathrm{D}_{2} \mathrm{O} . \mathrm{C}_{\mathrm{Ru}}=5 \times 10^{-3} \mathrm{~mol} \mathrm{~L}^{-1} ; \mathrm{T}=20 \pm 4{ }^{\circ} \mathrm{C}$. A variação no espectro foi acompanhada pelo tempo, com passos de 30 segundos. Potencial exibido utiliza como referência eletrodo de $\mathrm{Ag} / \mathrm{AgCl}_{\text {sat. }}$ Gráfico inserido representa potencial aplicado no qual não há variação no espectro.
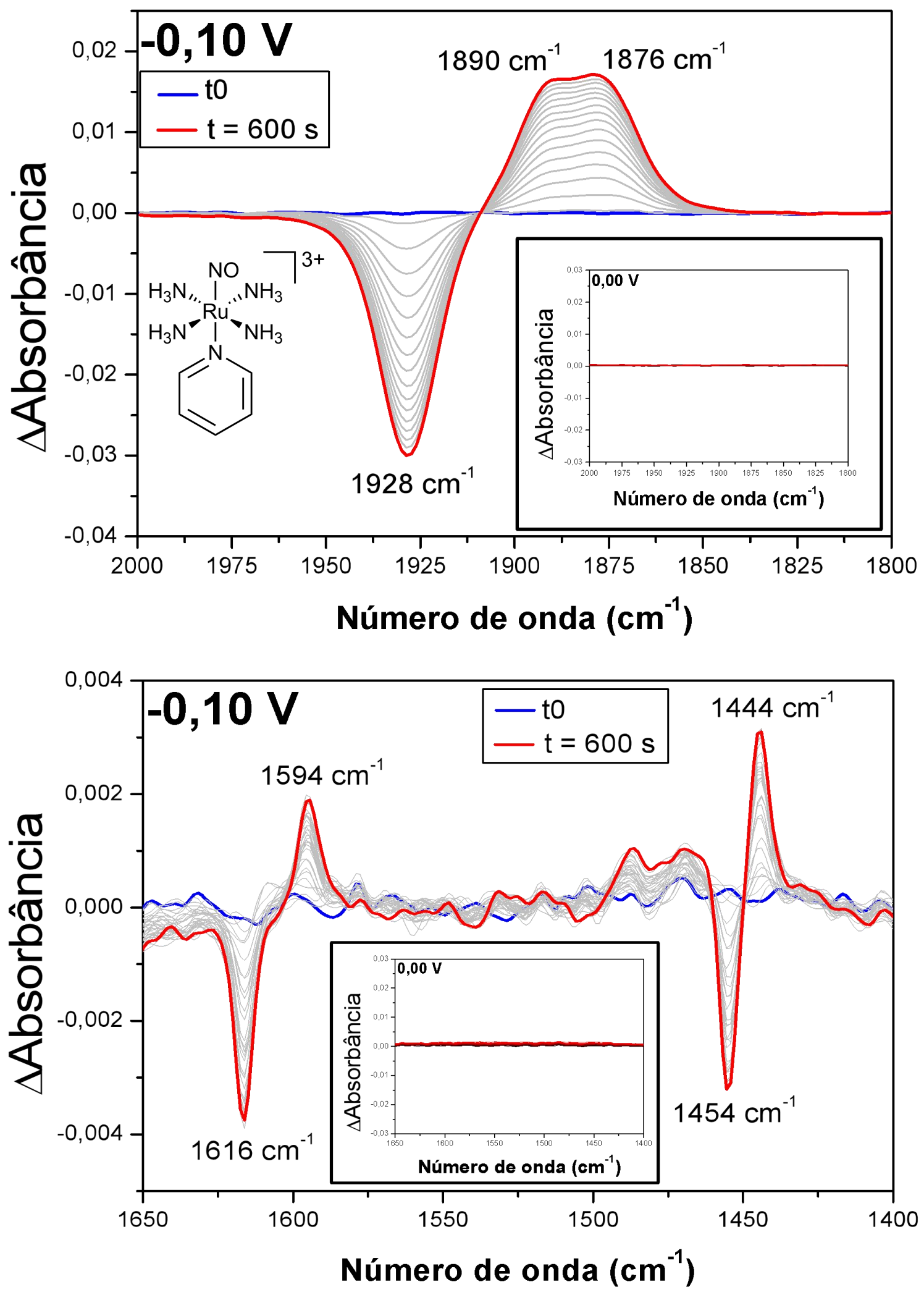
Para a redução eletroquímica do RuNOpy em pH 7,4 apresentada na Figura 12, observa-se formação das espécies com sinal centrando em $1890 \mathrm{~cm}^{-1}$ e $1876 \mathrm{~cm}^{-1}$. Além disso, que esses sinais são acompanhados do consumo de piridina coordenada pelos sinais centrados em 1614 e $1456 \mathrm{~cm}^{-1}$, e formação de piridina livre, com sinais em 1594 e $1444 \mathrm{~cm}^{-1}$, conforme pode ser verificado na Figura 13 abaixo:

Figura 13. Espectro no infravermelho da região de 1650 a $1400 \mathrm{~cm}^{-1}$ do complexo trans$\left[\mathrm{Ru}(\mathrm{NO})\left(\mathrm{NH}_{4}\right)(\mathrm{py})\right]\left(\mathrm{PF}_{6}\right)_{3}$ registrado em pastilha de $\mathrm{KBr}$, representado por piridina coordenada, e de solução de piridina $0,3 \mathrm{~mol} \mathrm{~L}^{-1}$ em $\mathrm{D}_{2} \mathrm{O}$, representado por piridina livre.

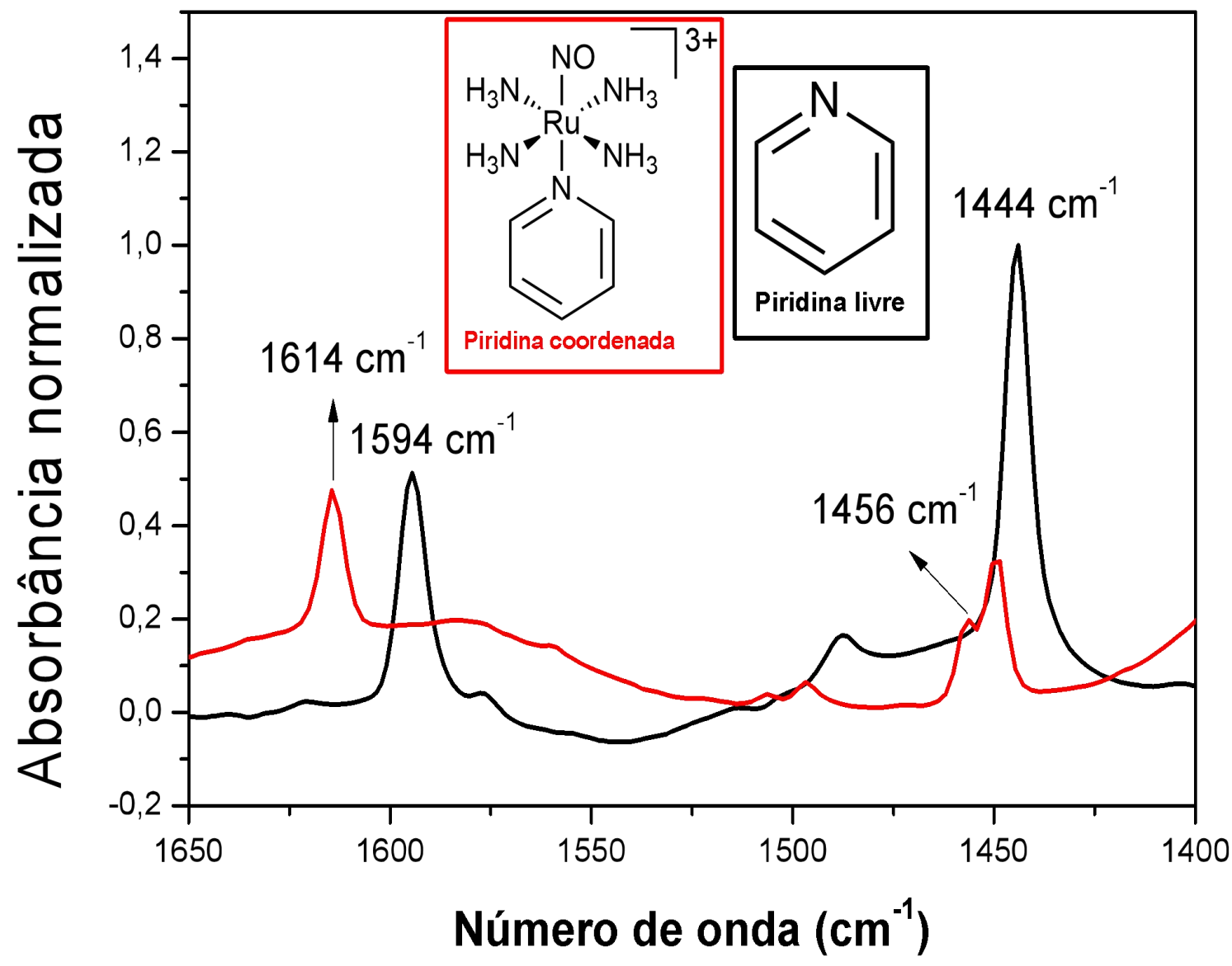

A saída do ligante piridina ainda pôde ser confirmada por ressonância magnética nuclear $(\mathrm{RMN})$ de ${ }^{1} \mathrm{H}$ pelo surgimento de sinal de piridina livre quando o complexo é reduzido (Anexo E). Além disso, todas as espécies formadas pela redução do nitrosilo complexo não apresentaram sinal de ressonância paramagnética de elétrons (RPE) a 77 K. Com isso, duas reações deveriam estar acontecendo diante da redução do nitrosilo complexo RuNOpy. Uma de formação de $\mathrm{NO}^{\bullet}$ e outra de saída de piridina, levando possivelmente a formação do complexo $\operatorname{RuNO}\left(\mathrm{H}_{2} \mathbf{O}\right)$. Para elucidar tal proposta, o complexo trans- $\left[\mathrm{Ru}(\mathrm{NO})\left(\mathrm{NH}_{3}\right)_{4}\left(\mathrm{H}_{2} \mathrm{O}\right)\right]^{3+}$ foi isolado, e o espectro no infravermelho na 
região do $\mathrm{NO}^{+}$coordenado é apresentado a seguir, em diferentes soluções aquosas com variada concentração hidrogeniônica $\left(\mathrm{C}_{\mathrm{H}^{+}}\right)$.

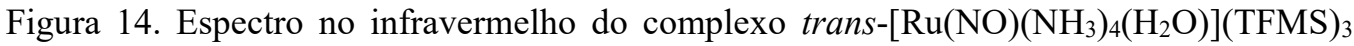
solubilizado em diferentes soluções aquosas com variada concentração hidrogeniônica $\left(\mathrm{C}_{\mathrm{H}^{+}}\right)$.

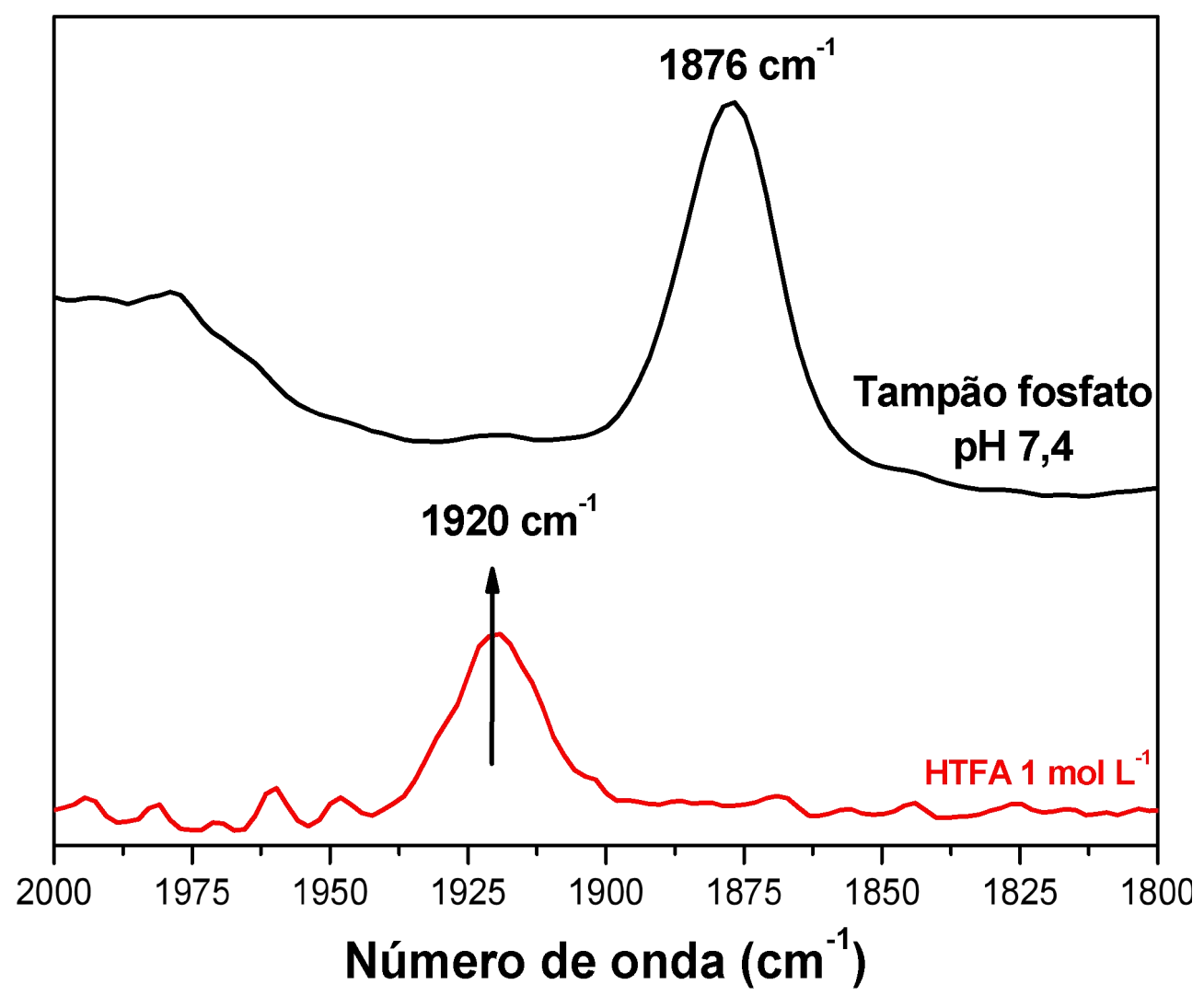

Com base no exposto, temos que o estiramento de $\mathrm{NO}^{+}$coordenado apresenta diferentes valores em diferentes pHs, devido as formas protonada e desprotonada da água trans posicionada. Na solução de tampão fosfato $\mathrm{pH} 7,4$, temos o íon hidróxido coordenado trans ao $\mathrm{NO}^{+}$, que tem estiramento em $1876 \mathrm{~cm}^{-1}$. Em solução aquosa ácida (HTFA $1 \mathrm{~mol} \mathrm{~L}^{-1}$ ), tem-se água coordenada trans ao $\mathrm{NO}^{+}$, que apresenta estiramento em $1920 \mathrm{~cm}^{-1}$. 
Figura 15. Fórmula estrutural dos complexos trans- $\left[\mathrm{Ru}(\mathrm{NO})\left(\mathrm{NH}_{4}\right)\left(\mathrm{H}_{2} \mathrm{O}\right)\right]^{3+}$ e trans$\left[\mathrm{Ru}(\mathrm{NO})\left(\mathrm{NH}_{4}\right)(\mathrm{OH})\right]^{2+}$.

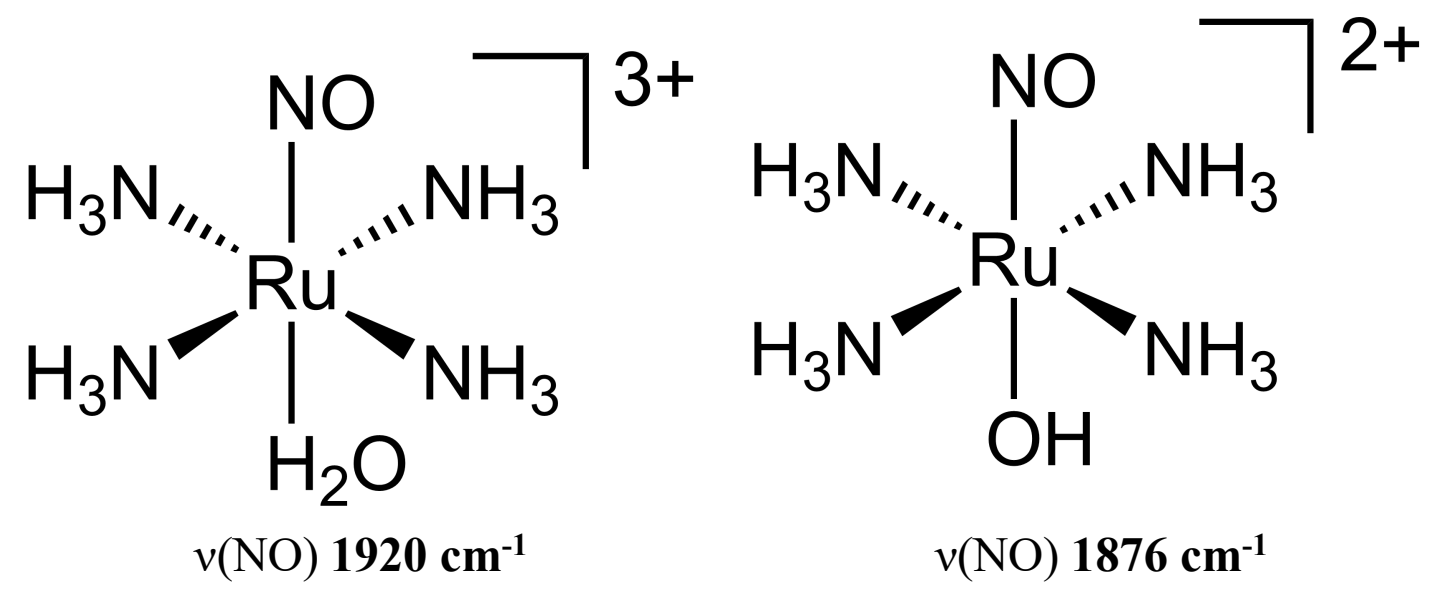

Fonte: Autoria própria.

A literatura reporta que no complexo sólido trans-[Ru(NO) $\left.\left(\mathrm{NH}_{3}\right)_{4}\left(\mathrm{H}_{2} \mathrm{O}\right)\right] \mathrm{Cl}_{3}$, o estiramento do $\mathrm{NO}^{+}$aparece em $1912 \mathrm{~cm}^{-1} 25$, valor próximo ao obtido para o complexo em solução. No entanto, para o complexo trans- $\left[\mathrm{Ru}(\mathrm{NO})\left(\mathrm{NH}_{3}\right)_{4}(\mathrm{OH})\right]^{2+}$, há grande diferença no valor de estiramento reportado para o sólido, estando centrado em 1846 $\mathrm{cm}^{-1} 28$. Ainda com relação a esse composto, há discrepância no valor de $\mathrm{p} K_{a}$ reportado para a água coordenada, sendo que são reportados valores de $\mathrm{p} K_{a} 3,5$; determinado por titulação potenciométrica ${ }^{25}$, e de $\mathrm{p} K_{a} 1,5$; determinado por $\mathrm{RMN}$ de ${ }^{14} \mathrm{~N}^{28}$. Para ambos os valores reportados, é seguro dizer que em solução de tampão fosfato $\mathrm{pH} 7,4 ; 0,1 \mathrm{~mol}$ $\mathrm{L}^{-1}$, encontra-se o complexo com íon hidróxido coordenado trans ao $\mathrm{NO}^{+}$.

Diante disso, o experimento de espectroeletroquímica de FTIR in situ, acompanhado no tempo foi realizado, dessa vez, com o trans $-\left[\mathrm{Ru}(\mathrm{NO})\left(\mathrm{NH}_{3}\right)_{4}(\mathrm{OH})\right]^{2+}$ em tampão fosfato $\mathrm{pH} 7,4$, no intuito de averiguar a formação de bandas pela redução do complexo por um elétron. Os demais potenciais analisados se encontram no Anexo B. 
Figura 16. Espectroeletroquímica do $\mathbf{R u N O}(\mathbf{O H})$ em solução de tampão fosfato $\mathrm{pH} 7,4 ; 0,1$ mol L ${ }^{-1} ; \mu=0,262 \mathrm{~mol} \mathrm{~L}^{-1} ; \mathrm{C}_{\mathrm{Ru}}=5 \times 10^{-3} \mathrm{~mol} \mathrm{~L}^{-1} ; \mathrm{T}=20 \pm 4{ }^{\circ} \mathrm{C}$. A variação no espectro foi acompanhada pelo tempo, com passos de 17,5 segundos. Potencial exibido utiliza como referência eletrodo de $\mathrm{Ag} / \mathrm{AgCl}_{\text {sat. }}$ Gráfico inserido representa potencial aplicado no qual não há variação no espectro.

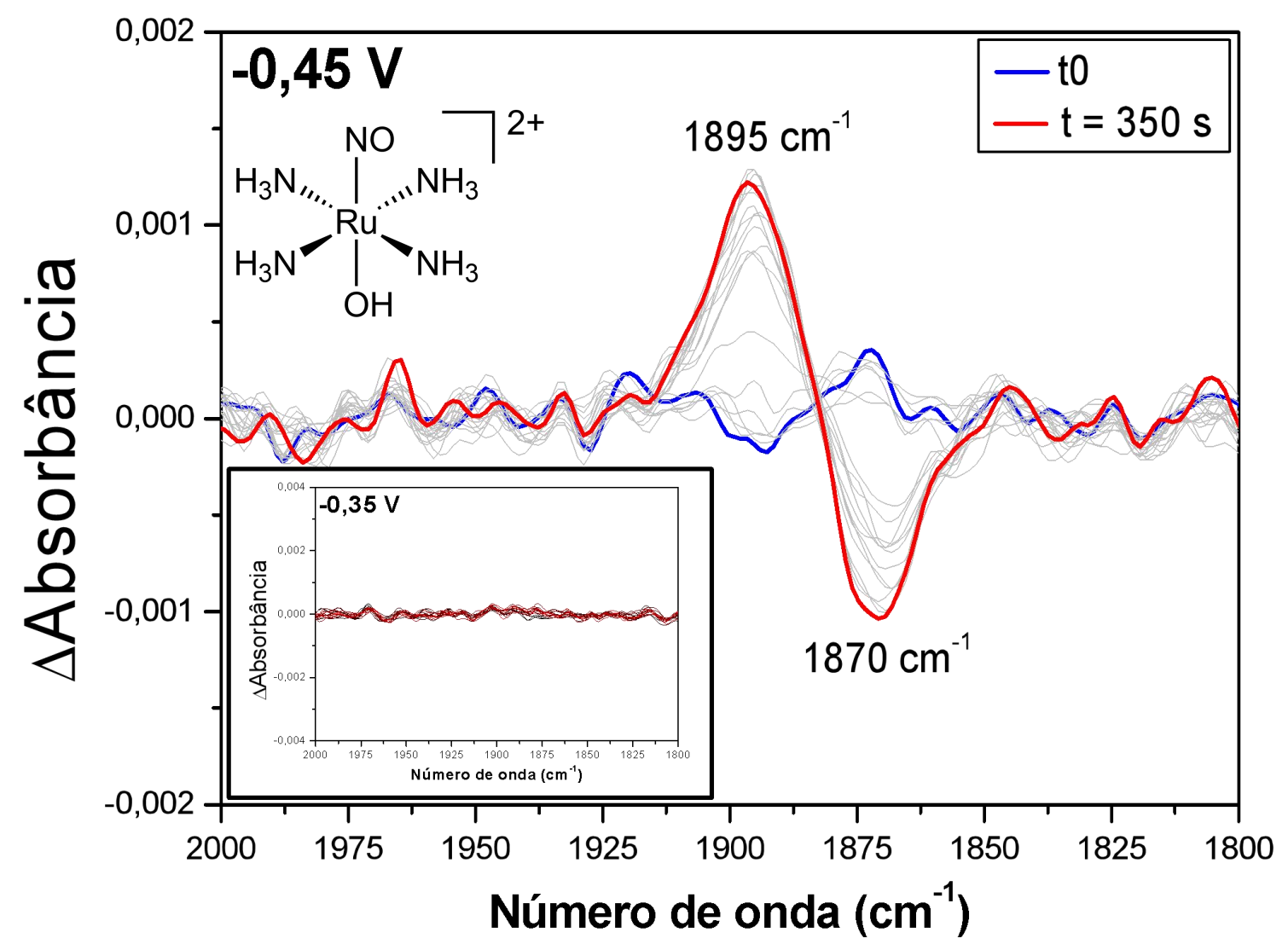

Com base no exposto na Figura 16 e informações da Figura 14, observa-se que o consumo da espécie com estiramento em $1870 \mathrm{~cm}^{-1}$ ocorre devido a redução do $\mathrm{NO}^{+}$ coordenado trans ao $\mathrm{OH}^{-}$, provocando a liberação de $\mathrm{NO} \bullet$, com sinal em $1895 \mathrm{~cm}^{-1}$, e formação do complexo trans- $\left[\mathrm{Ru}\left(\mathrm{NH}_{3}\right)_{4}\left(\mathrm{H}_{2} \mathrm{O}\right)_{2}\right]^{2+}$, como proposto na literatura ${ }^{25}$ :

$$
\begin{aligned}
& \text { trans- }\left[\mathrm{Ru}(\mathrm{NO})\left(\mathrm{NH}_{3}\right)_{4}(\mathrm{OH})\right]^{2+}+\mathrm{e}^{-}+\mathrm{H}_{2} \mathrm{O}+\mathrm{H}_{3} \mathrm{O}^{+} \rightarrow \\
& \qquad \text { trans }-\left[\mathrm{Ru}\left(\mathrm{NH}_{3}\right)_{4}\left(\mathrm{H}_{2} \mathrm{O}\right)_{2}\right]^{2+}+\mathrm{NO}^{\bullet}+\mathrm{H}_{2} \mathrm{O}
\end{aligned}
$$

Com isso, diferente do que havia sido proposto anteriormente, o sinal formado em $1876 \mathrm{~cm}^{-1}$ pela redução do RuNOpy estaria associado a formação da espécie RuNO(OH), e não a liberação do $\mathrm{NO}^{\bullet}$, que é mais provável de ter seu sinal centrado em $1890 \mathrm{~cm}^{-1}$ quando em solução aquosa, uma vez que é o sinal observado pela redução da espécie RuNO(OH). 
Sendo assim, podemos definir que a partir de $-0,10 \mathrm{~V}$ vs. $\mathrm{Ag} / \mathrm{AgCl}_{\text {(sat), }}$, em solução de tampão fosfato $0,1 \mathrm{~mol} \mathrm{~L}^{-1}, \mathrm{pH} \mathrm{7,4} \mathrm{e} \mu=0,262 \mathrm{~mol} \mathrm{~L}^{-1}$ (Figura 12) tem-se:

i) Quantidade apreciável de RuNOpy é reduzido, caracterizado pelo consumo do sinal em $1930 \mathrm{~cm}^{-1}$;

ii) Formação de RuNO(OH), caracterizado pela formação do sinal centrado em $1876 \mathrm{~cm}^{-1}$;

iii) Formação de $\mathrm{NO}^{\bullet}$, caracterizado pela formação do sinal em $1890 \mathrm{~cm}^{-1}$.

Somente esse processo ocorre até o potencial de $-0,45 \mathrm{~V}$ vs. $\mathrm{Ag} / \mathrm{AgCl} 1_{\text {sat }}$, no qual a espécie RuNO(OH) produzido passa a ser reduzido (Figura 16), levando a formação de $\mathrm{NO}^{\bullet}$ e $\mathrm{Ru}\left(\mathrm{H}_{2} \mathrm{O}\right)_{2}$, conforme ilustrado nas equações (4), (5) e (6):

trans $-\left[\mathrm{Ru}(\mathrm{NO})\left(\mathrm{NH}_{3}\right)_{4}(\mathrm{py})\right]^{3+}+\mathrm{e}^{-}+\mathrm{H}_{2} \mathrm{O} \rightarrow$

$$
\text { trans }-\left[\mathrm{Ru}\left(\mathrm{NH}_{3}\right)_{4}\left(\mathrm{H}_{2} \mathrm{O}\right)(\mathrm{py})\right]^{2+}+\mathrm{NO}^{\bullet}(4)
$$

trans $-\left[\mathrm{Ru}(\mathrm{NO})\left(\mathrm{NH}_{3}\right)_{4}(\mathrm{py})\right]^{3+}+\mathrm{e}^{-}+\mathrm{H}_{2} \mathrm{O} \rightarrow$

$$
\text { trans-[Ru(NO) } \left.\left(\mathrm{NH}_{3}\right)_{4}(\mathrm{OH})\right]^{2+}+\mathrm{py}^{\bullet-}+\mathrm{H}_{3} \mathrm{O}^{+}
$$

trans- $\left[\mathrm{Ru}(\mathrm{NO})\left(\mathrm{NH}_{3}\right)_{4}(\mathrm{OH})\right]^{2+}+\mathrm{e}^{-}+\mathrm{H}_{2} \mathrm{O}+\mathrm{H}_{3} \mathrm{O}^{+} \rightarrow$

$$
\text { trans- }\left[\mathrm{Ru}\left(\mathrm{NH}_{3}\right)_{4}\left(\mathrm{H}_{2} \mathrm{O}\right)_{2}\right]^{2+}+\mathrm{H}_{2} \mathrm{O}+\mathrm{NO}^{\bullet}(6)
$$

De acordo com a equação (5), a espécie piridina ânion radical é formada devido a labilização do ligante N-heterocíclico reduzido. Estima-se que, caso essa espécie seja formada, proporcione um sinal de curto tempo de vida durante o processo de redução do RuNOpy, na região de $1650 \mathrm{~cm}^{-1}$ a $1400 \mathrm{~cm}^{-1} 29$. De fato, em potenciais mais negativos, como em $-0,35 \mathrm{~V}$ vs. $\mathrm{Ag} / \mathrm{AgCl}_{\text {sat }}$, um sinal de curto tempo de vida é observado na redução do RuNOpy, como é ilustrado a seguir: 
Figura 17. Espectroeletroquímica do RuNOpy em solução de tampão fosfato $\mathrm{pH}$ 7,4; $0,1 \mathrm{~mol}$ $\mathrm{L}^{-1} ; \mu=0,262 \mathrm{~mol} \mathrm{~L}^{-1} ; \mathrm{C}_{\mathrm{Ru}}=5 \times 10^{-3} \mathrm{~mol} \mathrm{~L}^{-1} ; \mathrm{T}=20 \pm 4{ }^{\circ} \mathrm{C}$. A variação no espectro foi acompanhada pelo tempo, com passos de 10 segundos. Potencial exibido utiliza como referência eletrodo de $\mathrm{Ag} / \mathrm{AgCl}_{\text {sat. }}$.
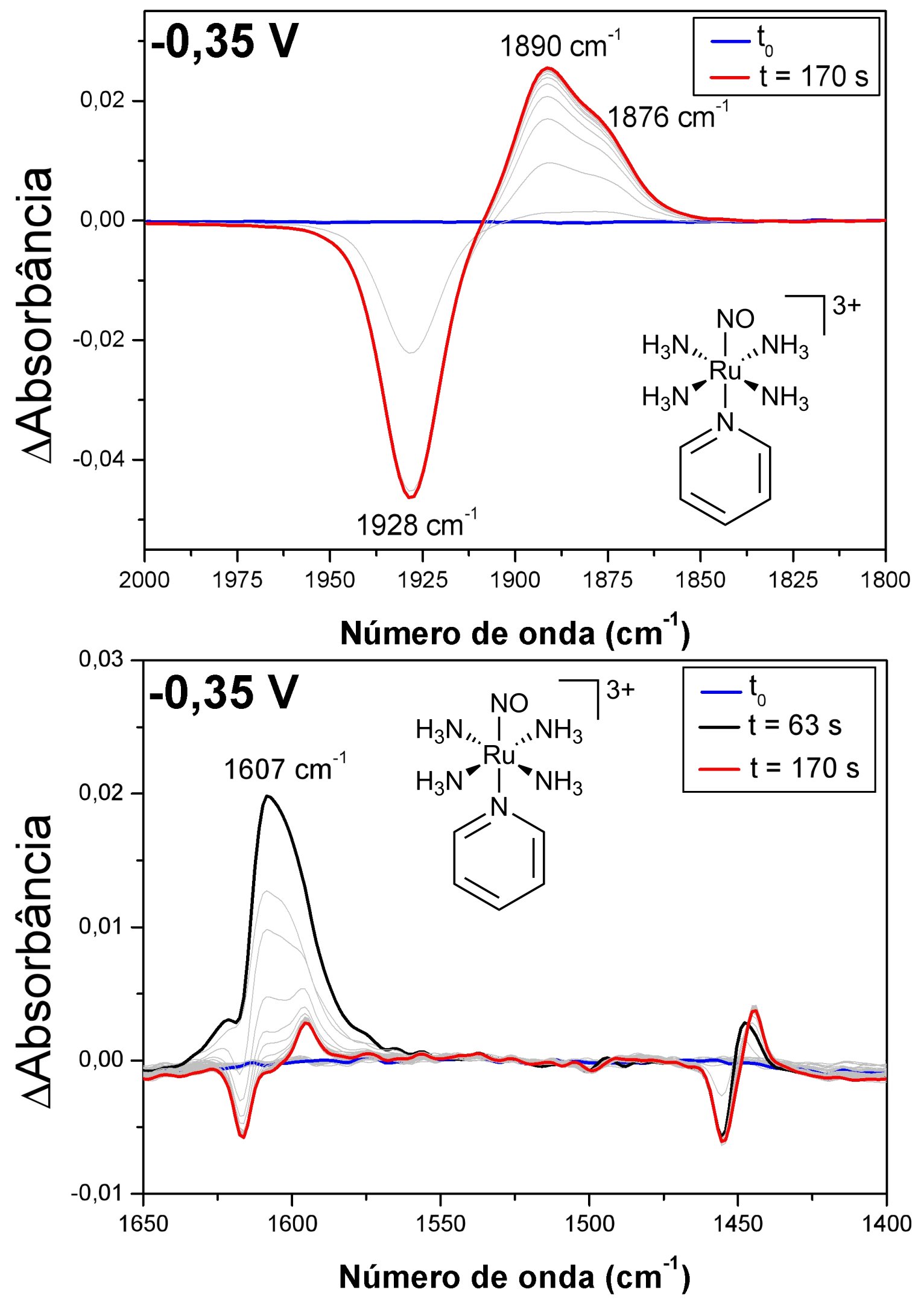
Figura 18. Variação da absorbância do sinal em $1607 \mathrm{~cm}^{-1}$ com o tempo.

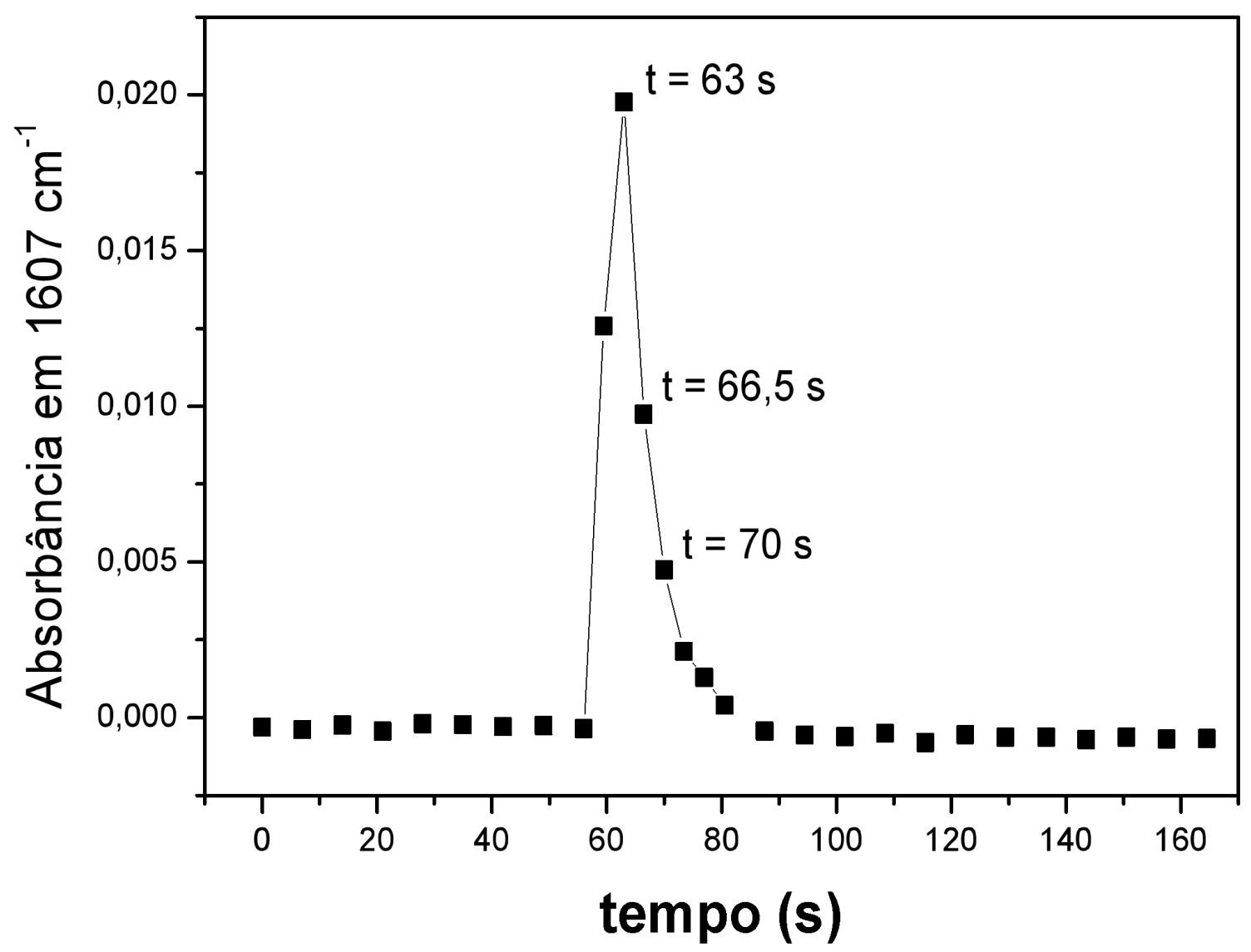

O sinal com máximo em $1607 \mathrm{~cm}^{-1}$ surge assim que o potencial é aplicado (a partir de 56 segundos, Figura 18) atinge máximo de absorbância em t $=63$ segundos, passando por dois $t_{1 / 2}$ nos próximos 7 segundos. Com um $t_{1 / 2}$ de 3,5 segundos, estima-se o sinal com máximo em $1607 \mathrm{~cm}^{-1}$ represente a formação do ânion radical de piridina. $\mathrm{O}$ $\mathrm{t}_{1 / 2}$ de 3,5 segundos representa tempo de vida menor do que o reportado para o ânion radical de piridina, gerado via eletroquímica em amônia líquida, com $\mathrm{t}_{1 / 2}$ de 45 segundos $^{30}$ detectado via RPE. Entretanto, ainda não foi possível a detecção desse radical via RPE pela redução do complexo RuNOpy em tampão fosfato $\mathrm{pH} 7,4$. 


\subsection{Proposta de liberação de piridina ânion radical pela redução do nitrosilo complexo}

Como foi discutido até então, a redução por um elétron de nitrosilo complexos contendo N-heterocíclico coordenado leva a labilização de $\mathrm{NO} \bullet$, com formação de banda centrada em $1890 \mathrm{~cm}^{-1}$. No entanto, a redução desses complexos também leva a labilização do N-heterocíclico, de forma competitiva, e com isso, há a formação do complexo RuNO(OH) no pH 7,4, caracterizado pelo sinal em $1876 \mathrm{~cm}^{-1}$.

Da química desenvolvida até então para tetraminas de rutênio(II) contendo o ligante $\mathrm{NO}^{+}$coordenado trans a N-heterocíclicos, a labilização de $\mathrm{NO}^{\bullet}$ da esfera de coordenação desses complexos, pela redução por um elétron, pode ser explicada por: $\mathrm{O}$ elétron oriundo da redução ocupa o orbital vazio de menor energia (LUMO), conforme diagrama de energia representado na Figura 19. Como esse orbital é de propriedade antiligante com relação à interação entre $\mathrm{Ru}(\mathrm{II})$ e o NO coordenado, a redução leva a diminuição da interação entre esses dois centros. Por fim, ocorre a quebra da ligação Ru-NO, e o ligante é labilizado na forma de $\mathrm{NO}^{\bullet}$.

Figura 19. Diagrama de energia simplificado dos orbitais moleculares de fronteira do complexo RuNOpy, assumindo orbital $\mathrm{d}_{\mathrm{xy}}$ como não ligante.

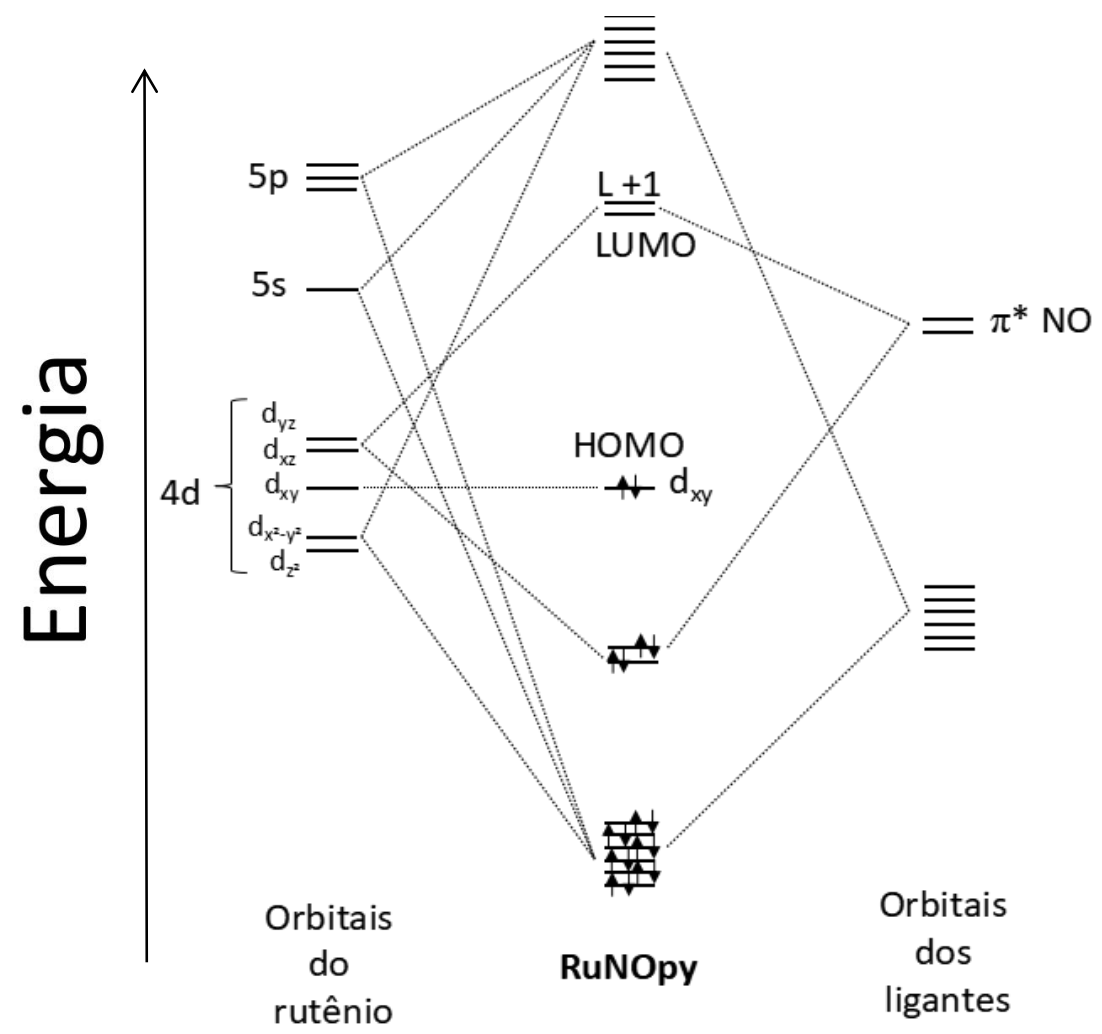

Fonte: Autoria própria. Refs. ${ }^{8,5}$ 
No diagrama representado na Figura 19, não se leva em consideração interações $\pi$ com o orbital $\mathrm{d}_{\mathrm{xy}}$ do centro metálico, e por isso esse orbital é representado como não ligante. No entanto, o digrama de energia representado da Figura 19 não exemplifica a possível labilização de piridina ânion radical para o meio, com formação do complexo RuNO(OH). Para que houvesse a labilização de py•- para o meio, seria necessária a sobreposição de orbitais de maior característica de py e Ru. A coordenação da piridina ao centro metálico se faz, inicialmente, pela sua capacidade de doar densidade eletrônica sigma ao centro metálico, caracterizado pela formação de uma ligação sigma. No entanto, esse ligante também apresenta capacidade de realizar interação $\pi$ com orbital $\mathrm{d}_{\pi}$ do centro metálico ${ }^{31}$ utilizando seu orbital $\pi^{*}$, representado na Figura 20.

Figura 20. Representação simplificada dos orbitais $\pi$ ligante e $\pi$ antiligante da piridina.

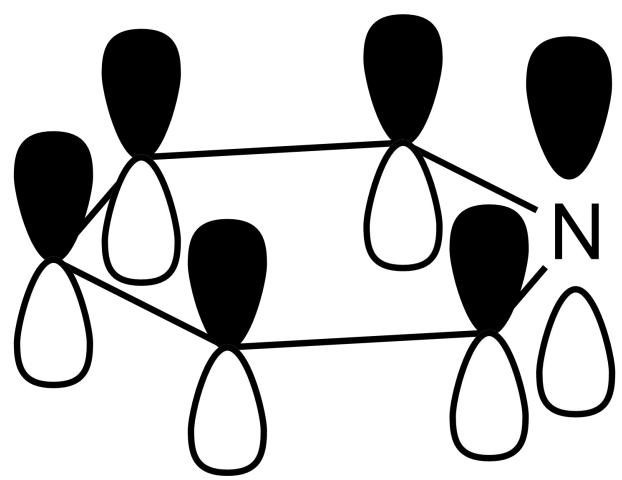

Orbital $\pi$

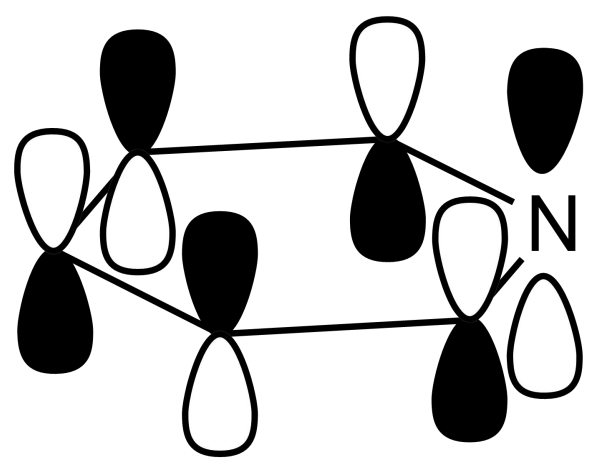

Orbital $\pi^{*}$

Fonte: Autoria própria. Ref ${ }^{31}$

Levando em consideração a forma na qual o N-heterocíclico se coordena ao centro metálico, sendo que o plano do anel aromático se encontra entre os eixos de ligação $\mathrm{Ru}-\mathrm{NH}_{3}$, propõe-se que o N-heterocíclico possa receber densidade eletrônica $\pi$ do orbital $d_{x y}$ do rutênio, em seu orbital $\pi^{*}$. Com isso, o orbital $d_{x y}$ não apresenta característica de orbital não ligante. Assim, a sobreposição $d_{x y}-\pi *$ py levaria a formação dos orbitais ligante e antiligantes dessa interação, de forma similar ao que ocorre para a sobreposição $d_{\pi}-\pi * N O$ representada na Figura 19 . Pelo fato de o complexo em estudo apresentar centro metálico $\mathrm{d}^{6}$ baixo spin, o orbital ligante da interação $\mathrm{d}_{\mathrm{xy}}-\pi$ py estaria ocupado com um par de elétrons, sendo que o orbital antiligante da interação $d_{x y}-\pi^{*}$ py estaria disponível a aceitar um elétron quando o complexo é reduzido, como representado na Figura 21. 
Figura 21. Diagrama de energia simplificado dos orbitais moleculares de fronteira do complexo RuNOpy, assumindo interação $d_{x y}-\pi^{*} p y$.

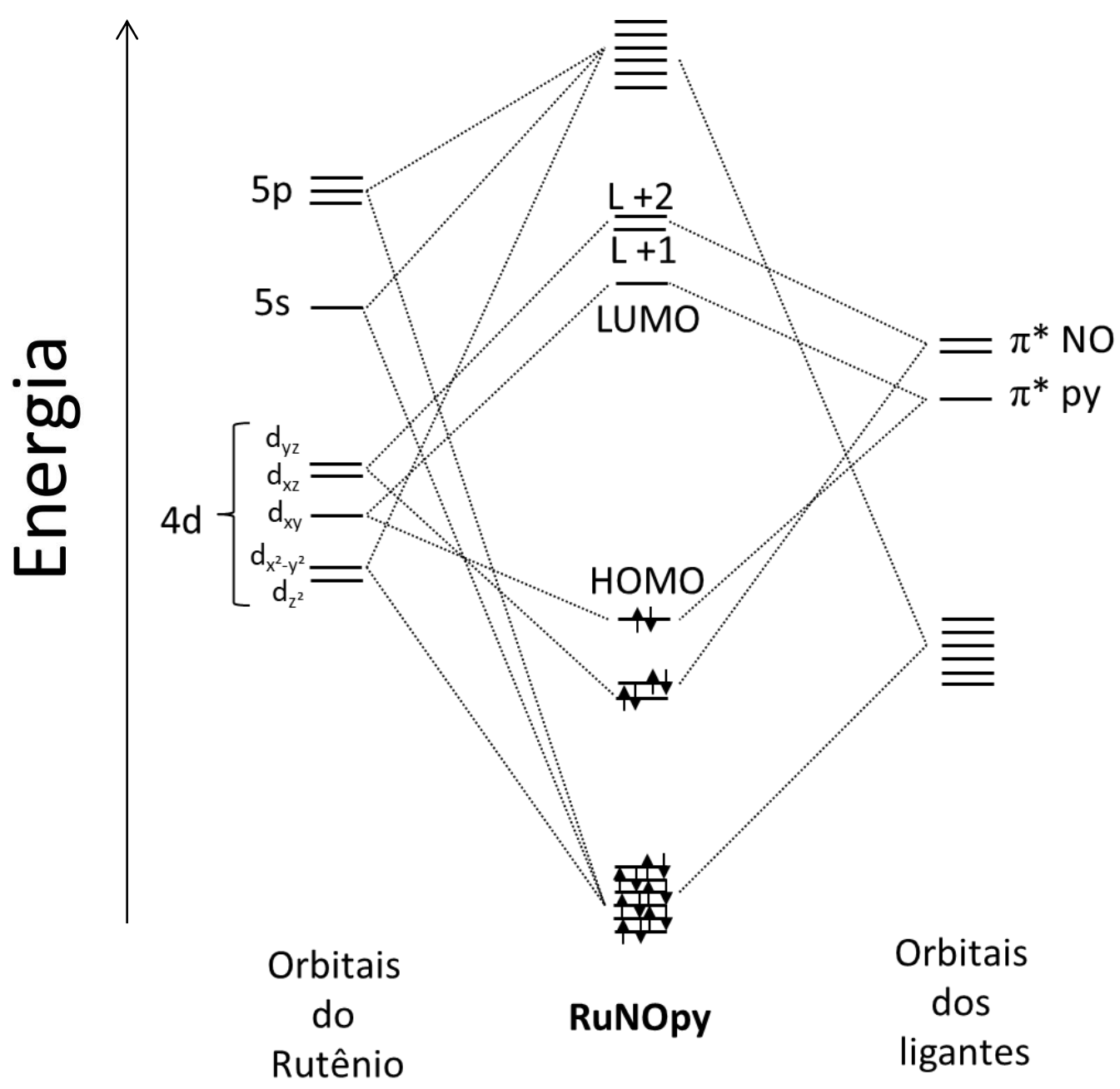

Fonte: Autoria própria.

Com isso, similar ao que ocorre com o nitrosilo coordenado, a ocupação de um elétron em um orbital de elevada contribuição $\pi^{*}$ py (LUMO, de acordo com a Figura 21) levaria a diminuição da interação Ru-py, levando a uma menor afinidade da py ao centro metálico, ocorrendo a quebra da ligação Ru-py. Assim, a espécie piridina ânion radical é labilizada da esfera de coordenação, sendo substituída por uma molécula de água. A água coordenada, por sua vez, apresenta acidez maior do que quando livre no meio, e com isso há a desprotonação desse ligante, levando a formação do complexo RuNO(OH). 
Para avaliar a hipótese de que a população por um elétron do orbital de característica antiligante da interação $\mathrm{d}_{\mathrm{xy}}-\pi^{*}$ py (LUMO, segundo Figura 21) pela redução do complexo RuNOpy pode levar a labilização da piridina, com formação do complexo RuNO(OH), um experimento de espectroeletroquímica de FTIR in situ foi realizado, dessa vez com o complexo $\mathbf{R u N O}\left(\mathbf{N H}_{3}\right)$ solubilizado em tampão fosfato $\mathrm{pH}$ 7,4. A utilização desse complexo se deu pelo fato de que o $\mathrm{NH}_{3}$ trans posicionado ao $\mathrm{NO}^{+}$é um ligante doador sigma puro, e com isso não há a interação $\pi$ entre o $\mathrm{NH}_{3}$ e o orbital $d_{x y}$ do centro metálico. Sendo assim, a redução do complexo $\operatorname{RuNO}\left(\mathbf{N H}_{3}\right)$ levaria apenas a labilização do NO coordenado, e com isso, apenas o sinal de $1890 \mathrm{~cm}^{-1}$ deveria ser observado no infravermelho, por se tratar do sinal do estiramento de NO• livre em solução, determinado pela espectroeletroquímica do complexo RuNO(OH) (Figura 16). Os resultados são apresentados a seguir. Os demais potenciais analisados se encontram no Anexo C.

Figura 22. Espectroeletroquímica do $\mathbf{R u N O}\left(\mathbf{N H}_{3}\right)$ em solução de tampão fosfato $\mathrm{pH} 7,4 ; 0,1$ mol L-1; $\mu=0,262 \mathrm{~mol} \mathrm{~L}^{-1} ; \mathrm{C}_{\mathrm{Ru}}=5 \times 10^{-3} \mathrm{~mol} \mathrm{~L}^{-1} ; \mathrm{T}=20 \pm 4{ }^{\circ} \mathrm{C}$. A variação no espectro foi acompanhada pelo tempo, com passos de 14 segundos. Potencial exibido utiliza como referência eletrodo de $\mathrm{Ag} / \mathrm{AgCl}_{\text {sat. }}$ Gráfico inserido representa potencial aplicado no qual não há variação no espectro.

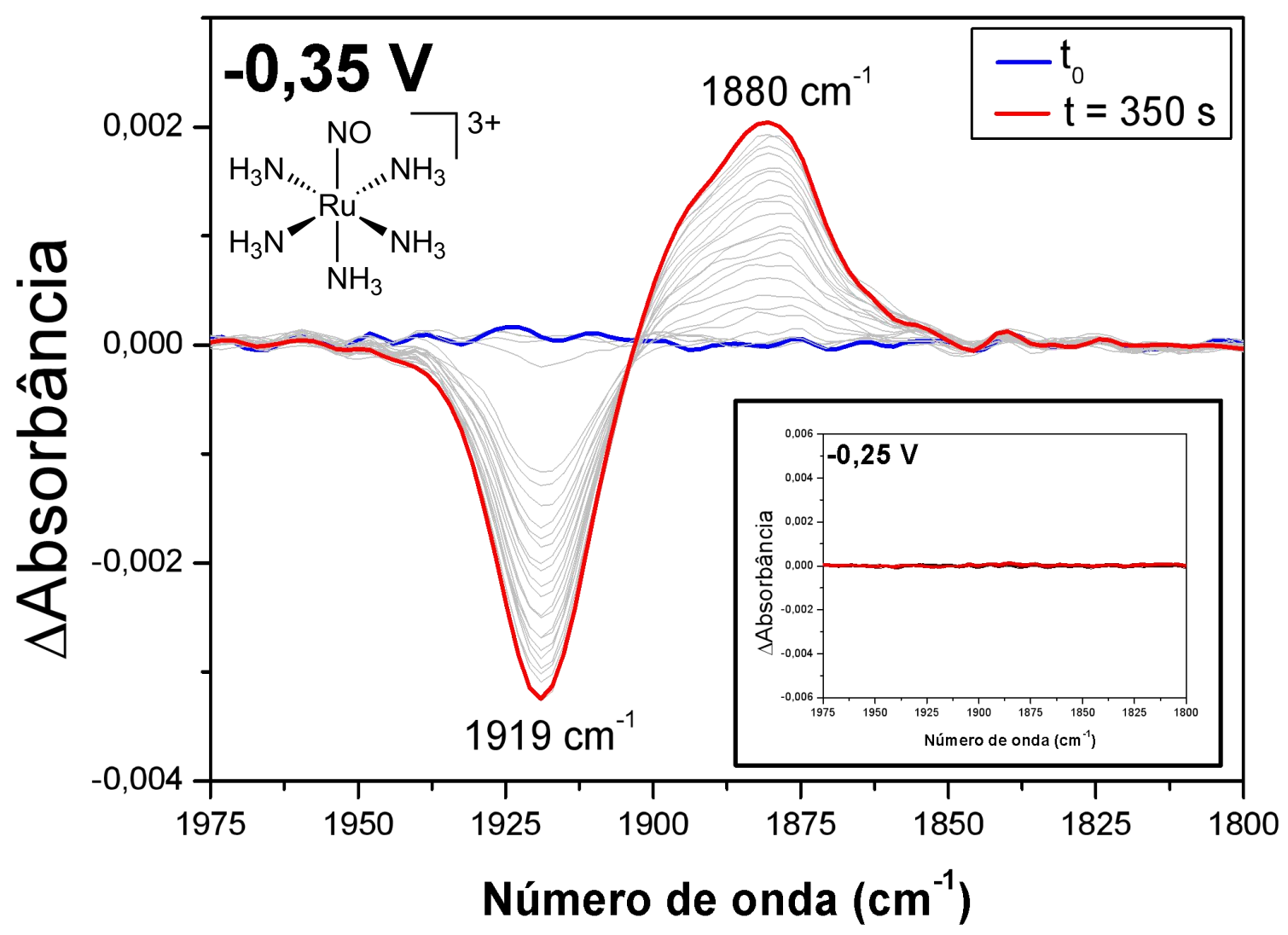


Como é observado na Figura 22, há o consumo da espécie com estiramento centrado em $1919 \mathrm{~cm}^{-1}$, sendo esse o estiramento da espécie de $\mathrm{NO}^{+}$coordenado trans a $\mathrm{NH}_{3}$ no complexo $\mathbf{R u N O}\left(\mathbf{N H}_{3}\right)$. Observa-se também a formação de sinal centrado em $1880 \mathrm{~cm}^{-1}$. A formação desse sinal gerou dúvidas quanto às espécies que estavam sendo formadas, uma vez que poderia estar relacionado à formação de sinal em $1890 \mathrm{~cm}^{-1} \mathrm{e} / \mathrm{ou}$ formação do sinal em $1876 \mathrm{~cm}^{-1}$, ambos deslocados. Sendo assim, uma eletrólise exaustiva foi realizada com o eletrodo de trabalho consistindo de uma rede de ouro diferente do disco de ouro utilizado nos experimentos de espectroeletroquímica. Durante o processo de aplicação de potencial, a solução do complexo $\mathbf{R u N O}\left(\mathbf{N H}_{3}\right)$ foi mantida sob constante fluxo de argônio, no intuito de purgar qualquer gás gerado durante o processo de redução. Sendo assim, o seguinte era esperado:

i) Caso houvesse formação de $\mathrm{NO}^{\bullet}$ pela redução do $\mathbf{R u N O}\left(\mathbf{N H}_{3}\right)$, o gás seria purgado da solução pelo fluxo de argônio, e ao fím da eletrólise, veríamos apenas consumo do sinal em $1917 \mathrm{~cm}^{-1}$, referente ao estiramento de $\mathrm{NO}^{+}$trans a $\mathrm{NH}_{3}$.

ii) Caso houvesse formação do complexo $\mathbf{R u N O}(\mathbf{O H})$ pela labilização do $\mathrm{NH}_{3}$, não seria possível purgar o complexo com um fluxo de argônio, e com isso, além do consumo do sinal em $1917 \mathrm{~cm}^{-1}$ referente ao $\mathrm{NO}^{+}$trans a $\mathrm{NH}_{3}$, haveria formação de estiramento de $\mathrm{NO}^{+}$trans a $\mathrm{OH}^{-}$, esperado em $1876 \mathrm{~cm}^{-1}$.

O resultado da eletrólise do $\mathbf{R u N O}\left(\mathbf{N H}_{3}\right)$ é apresentado a seguir na Figura 23. 
Figura 23. Espectro no infravermelho da $\mathbf{R u N O}\left(\mathbf{N H}_{3}\right)$ em solução de tampão fosfato $\mathrm{pH}$ 7,4; $0,1 \mathrm{~mol} \mathrm{~L}^{-1} ; \mu=0,262 \mathrm{~mol} \mathrm{~L}^{-1} ; \mathrm{C}_{\mathrm{Ru}}=5 \times 10^{-3} \mathrm{~mol} \mathrm{~L}^{-1}$. Potencial exibido utiliza como referência eletrodo de $\mathrm{Ag} / \mathrm{AgCl}_{\text {sat }}$

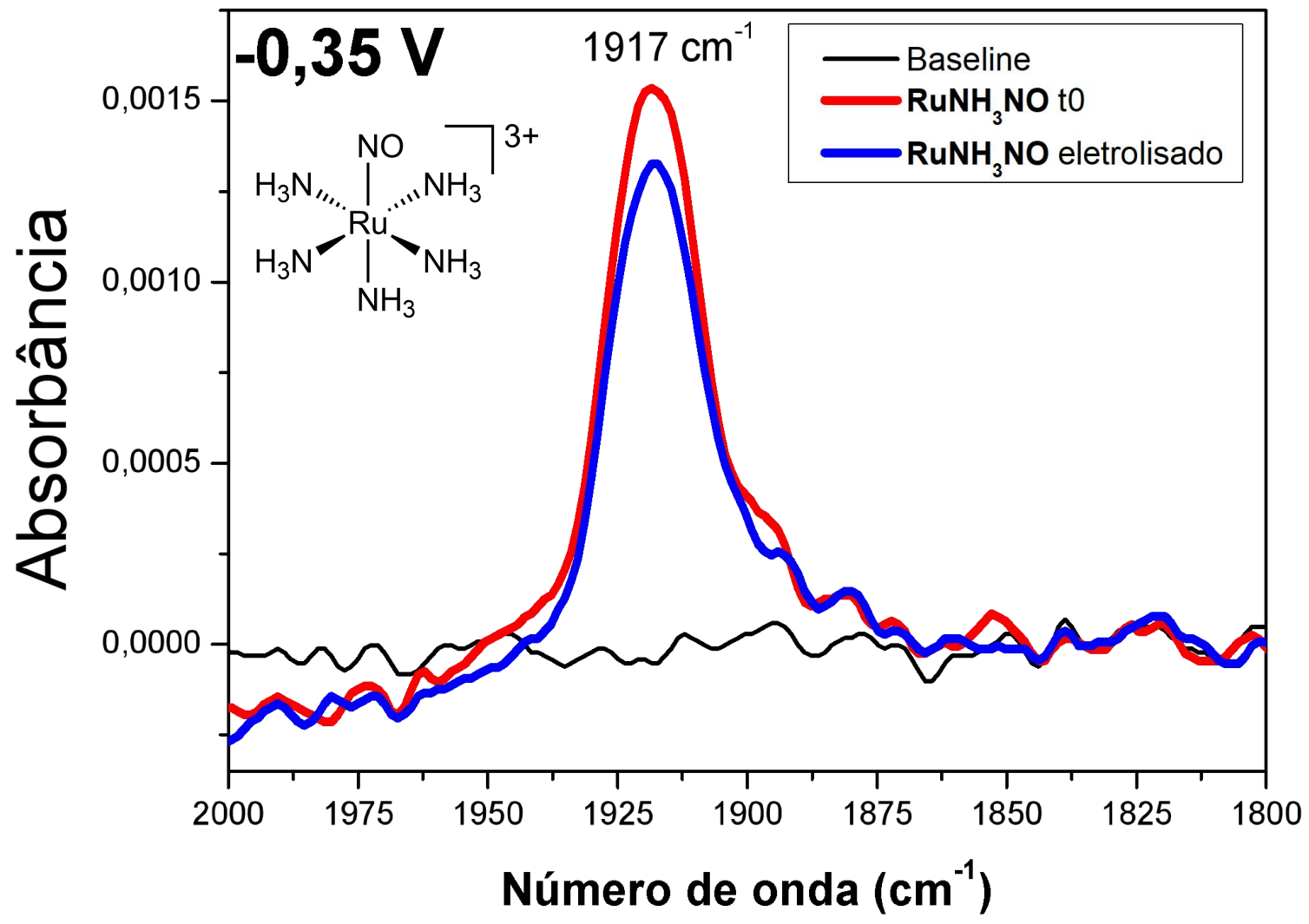

Na Figura 23 acima, é possível verificar o consumo da banda centrada em 1917 $\mathrm{cm}^{-1}$, referente ao estiramento de $\mathrm{NO}^{+}$trans a $\mathrm{NH}_{3}$ no complexo $\mathbf{R u N O}\left(\mathbf{N H}_{3}\right)$, sem formação de sinal na região de $1880 \mathrm{~cm}^{-1}$, esperado caso houvesse formação do complexo RuNO(OH). Como a amônia não realiza interação $\pi$ com orbitais $d_{\pi}$ do centro metálico, o diagrama de energia seria o seguinte: 
Figura 24. Diagrama de energia simplificado dos orbitais de fronteira do complexo RuNO(NH).

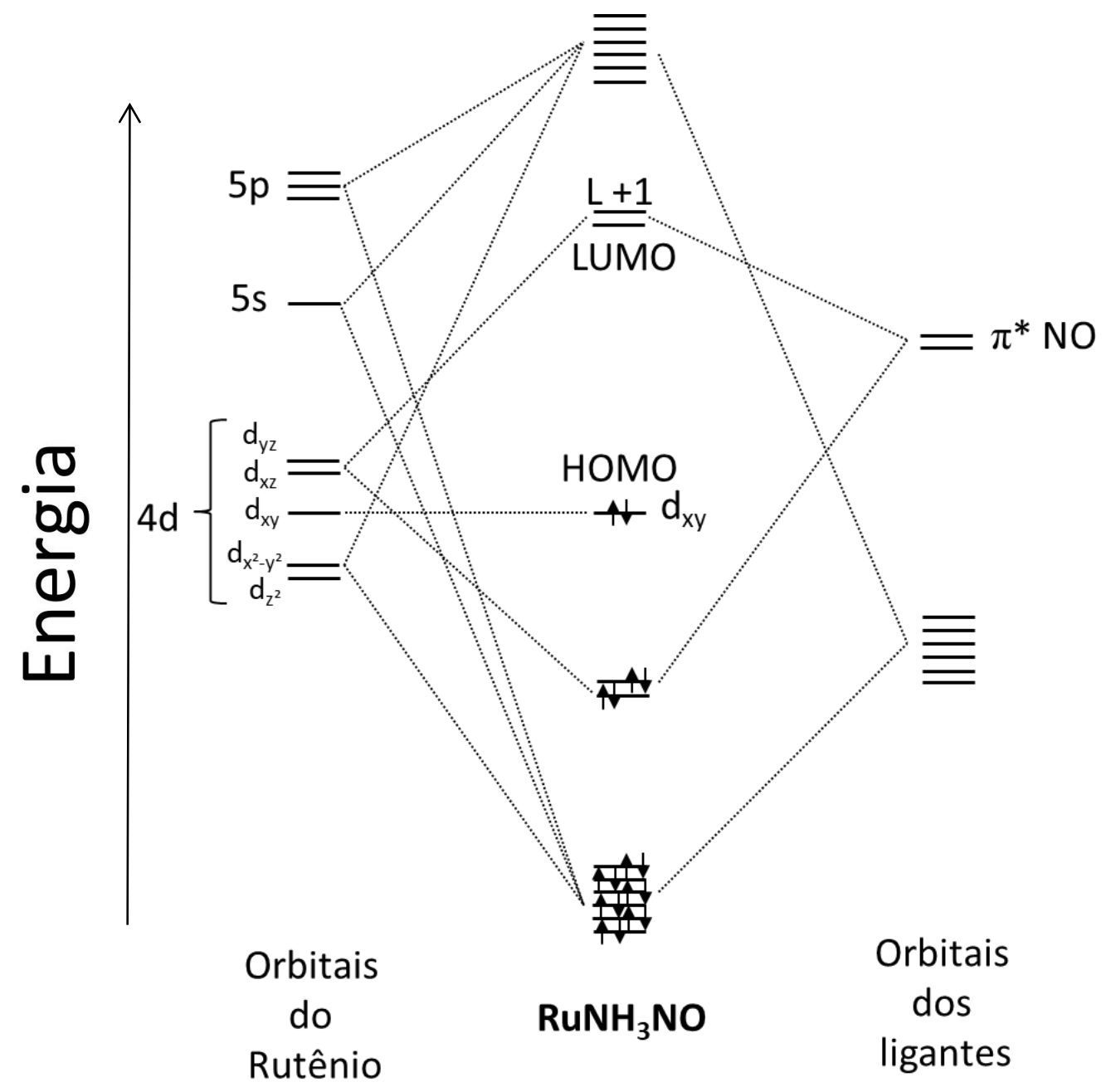

Fonte: Autoria própria.

E com isso, a redução por um elétron do $\mathbf{R u N O}\left(\mathbf{N H}_{3}\right)$ leva apenas a população de um orbital de característica antiligante da interação $d_{\pi}-\pi^{*} \mathrm{NO}$ entre os centros Ru-NO. (LUMO e L+1, segundo Figura 24). Isso, por sua vez leva a quebra da ligação Ru-NO, com a labilização de $\mathrm{NO}^{\bullet}$. Pelo fato do ligante $\mathrm{NH}_{3}$ no complexo $\mathbf{R u N O}\left(\mathbf{N H}_{3}\right)$ não interagir com o orbital $\mathrm{d}_{\mathrm{xy}}$ do $\mathrm{Ru}$, não se tem a formação do orbital que, quando populado, levaria a formação do complexo $\operatorname{RuNO}(\mathbf{O H})$ pela labilização de uma espécie de $\mathrm{NH}_{3}$. Com isso, não há a formação do complexo RuNO(OH) pelo processo de redução por um elétron do $\mathbf{R u N O}\left(\mathbf{N H}_{3}\right)$. 


\section{CONCLUSÕES}

Pela primeira vez é reportado a saída de um N-heterocíclico coordenado trans ao ligante $\mathrm{NO}^{+}$em tetraminas de rutênio(II), após redução por um elétron desse sistema em meio aquoso. É observado, por espectroeletroquímica de FTIR in situ, tanto a formação de NO livre quanto a formação do íon complexo trans-[Ru(NO) $\left.\left(\mathrm{NH}_{3}\right)_{4}(\mathrm{OH})\right]^{2+}$ que, por sua vez, sofre redução por 1-elétron $\left(-0,40 \mathrm{~V}\right.$ vs. $\left.\mathrm{Ag} / \mathrm{AgCl}_{\text {sat }}\right)$ resultando na liberação de $\mathrm{NO}$ e formação do aqua-complexo trans- $\left[\mathrm{Ru}\left(\mathrm{H}_{2} \mathrm{O}\right)_{2}\left(\mathrm{NH}_{3}\right)_{4}\right]^{2+}$ em meio aquoso com $\mathrm{pH}$ $=7,4$. A labilização do ligante N-heterocíclico pode ser atribuída à interação de seu orbital $\pi^{*}$ com o orbital $\mathrm{d}_{\mathrm{xy}}$ do centro metálico, uma vez que a para a redução por 1-

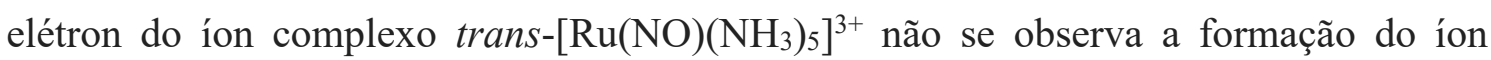
complexo trans- $\left[\mathrm{Ru}(\mathrm{NO})\left(\mathrm{NH}_{3}\right)_{4}(\mathrm{OH})\right]^{2+}$. A observação da labilização concorrente do ligante N-heterocíclico com a formação do íon complexo trans$\left[\mathrm{Ru}(\mathrm{NO})\left(\mathrm{NH}_{3}\right)_{4}(\mathrm{OH})\right]^{2+}$ em meio aquoso após redução por 1-elétron de complexos do tipo trans-[Ru(NO)(NH$\left.)_{4}(\mathrm{~L})\right]^{3+}(\mathrm{N}$-heterocíclicos) é de elevada relevância do ponto de vista biológico para a utilização destes compostos como agentes doadores de NO, uma vez que o ligante N-heterocíclico é labilizado após a redução como ânion radical o qual poderá apresentar relevante atividade em meio biológico. 


\section{Referências}

1 TOLEDO JUNIOR, J. C.; AUGUSTO, O. Connecting the chemical and biological properties of nitric oxide. Chemical Research Toxicology, Washington, v. 25, p. $975-$ 989, 2012.

2 FORD, P. C.; BOURASSA, J.; MIRANDA, K.; LEE, B.; LORKOVIC, I.; BOGGS, S.; KUDO, S.; LAVERMAN, L. Photochemistry of metal nitrosyl complexes. Delivery of nitric oxide to biological targets. Coordination Chemistry Reviews, Amsterdam, v. 171, p. 185-202, 1998.

3 IGNARRO, J. L. E. Nitric oxide, biology and pathobiology. San Diego: Academic Press, 2000. p. 1017.

4 FEELISCH, M.; STAMLER, J. S. Methods in nitric oxide research. New York: John Wiley \& Sons, 1996. p. 712.

5 ORENHA, R. P.; ROCHA, M. V. J.; POATER, J.; GALEMBECK, S. E.;

BICKELHAUPT, F.M. Nature of the Ru-NO coordination bond: Kohn-Sham molecular orbital and energy decomposition analysis. Chemistry Open, Weinheim , v. 6, p. 410416, 2017.

6 TORSONI, A. S.; BARROS, B. F.; TOLEDO JUNIOR, J. C.; HAUN, M.; KRIEGER, M. H.; TFOUNI, E.; FRANCO, D. W. Hypotensive properties and acute toxicity of trans-[Ru( $\left.\left.\mathrm{NH}_{3}\right)_{4} \mathrm{P}(\mathrm{OEt})_{3}(\mathrm{NO})\right]\left(\mathrm{PF}_{6}\right)_{3}$, a new nitric oxide donor. Nitric Oxide: Biology and Chemistry, Maryland Heights, v. 6, n. 3, p. 247-254, 2002.

7 METZKER, G.; STEFANELI, E. V.; PEREIRA, J. C. M.; LIMA, F. C. A.; SILVA, S. C.; FRANCO, D. W. Nitric oxide and nitroxyl formation in the reduction of transtetraamminenitrosyltriethylphosphiteruthenium(II) ion. Inorganica Chimica Acta, Amsterdam, v. 394, p. 765-769, 2013.

8 TOLEDO, J. C.; SILVA, H. A. S.; SCARPELLINI, M.; MORI, V.; CAMARGO, A. J.; BERTOTTI, M.; FRANCO, D. W. Ruthenium tetraammines as a model of nitric oxide donor compounds. European Journal of Inorganic Chemistry, Weinheim, n. 9, p. 1879-1885, 2004.

9 FREITAS, C. S.; ROVEDA JUNIOR, A. C.; TRUZZI, D. R.; GARCIA, A. C.; CUNHA, T. M.; CUNHA, F. Q.; FRANCO, D. W. Anti-inflammatory and antinociceptive activity of ruthenium complexes with isonicotinic and nicotinic acids (niacin) as ligands. Journal of Medicinal Chemistry, Washington, v. 58, n. 11, p. 4439-4448, 2015.

10 FENG, M.; ZHAO, J.; YU, P.; WANG, J. Linear and nonlinear infrared spectroscopies reveal detailed solute-solvent dynamic interactions of a nitrosyl ruthenium complex in solution. Journal of Physical Chemistry B, Washington, v. 122, n. 39, p. 9225-9235, 2018. 
11 WANNER, M.; SCHEIRING, T.; KAIM, W. EPR Characteristics of the $\left.[\mathrm{NC})_{5} \mathrm{M}(\mathrm{NO})\right]^{3-}$ Ions $(\mathrm{M}=\mathrm{Fe}, \mathrm{Ru}, \mathrm{Os})$. Experimental and DFT study estabilishing $\mathrm{NO}^{\bullet}$ as ligand. Inorganic Chemistry, Washington, v. 40, p. 5704-5707, 2001.

12 TOLEDO, J. C.; LIMA NETO, B. S.; FRANCO, D. W. Mutual effects in the chemical properties of the ruthenium metal center and ancillary ligands upon coordination. Coordination Chemistry Reviews, Amsterdam, v. 249, p. 419-431, 2005.

13 TFOUNI, E.; KRIEGER, M.; McGARVEY, B. R.; FRANCO, D. W. Structure, chemical and photochemical reactivity and biological activity of some ruthenium amine nitrosyl complexes. Coordination Chemistry Reviews, Amsterdam, v. 236, p. 57-69, 2003.

14 TFOUNI, E.; DORO, F. G.; FIGUEIREDO, L. E.; PEREIRA, J. C.; METZKER, G.; FRANCO, D. W. Tailoring NO donors metallopharmaceuticals: ruthenium nitrosyl ammines and aliphatic tetraazamacrocycles. Current Medicinal Chemistry, Sharjah, v. 17, p. 3643-3657, 2010.

15 TOLEDO JUNIOR, J. C.; LOPES, L. G. F.; ALVES, A. A.; SILVA, L. P.; FRANCO, D. W. Release of NO by a nitrosyl complex upon activation by the mitochondrial reducing power. Journal of Inorganic Biochemistry, Philadelphia, v. 89, p. 267-271, 2002.

16 BORGES, S. S. S.; DAVANZO, C. U.; CASTELLANO, E. E.; ZUKERMANSCHPECTOR, J.; SOLVA, S. C.; FRANCO, D. W. Ruthenium nitrosyl complexes with n-heterocyclic ligands. Inorganic Chemistry, Washington, v. 37, p. 2670-2677, 1998.

17 TFOUNI, E.; DORO, F. G.; GOMES, A. J.; SILVA, R. S.; METZKER, G.; BENINI, P. G. Z.; FRANCO, D. W. Immobilized rutheium complexes and aspects of their reactivity. Coordination Chemistry Reviews, Amsterdam, v. 254, p. 355-371, 2010.

18 AGUIAR, F. H.; ROVEDA JUNIOR. A. C.; PIVA, R. J.; ONODA, K. A.; MIYAKAWA, A. A.; KRIEGER, J. E.; FRANCO, D. W.; TADINI, C. C.

Compatibility of cassava starch films as nitric oxide carrier for potencial medical device. Journal of Applied Polymer Science, Hoboken, v. 132, n. 2, p. 1-10, 2015.

19 ORENHA, R. P.; GALEMBECK, S. E. Molecular Orbitals of NO, NO ${ }^{+}$, and NO-: A computational Quantum Chemistry Experiment. Journal of Chemical Education, Washington, v. 91, n. 7, p. 1064-1069, 2014.

20 COE, B. J.; GLENWRIGHT, S. J. Trans-effects in octahedral transition metal complexes. Coordination Chemistry Reviews, Amsterdam, v. 203, p. 5-80, 2000.

21 ROVEDA JUNIOR. A. C.; SANTOS, W. G.; SOUZA, M. L.; ADELSON, C. N.; GONÇALVES, F. S.; CASTELLANO, E. E.; GARINO, C.; FRANCO, D. W.; CARDOSO, D. R. Light-activated generation of nitric oxide (NO) and sulfite anion radicals $\left(\mathrm{SO}_{3}{ }^{\bullet-}\right)$ by a ruthenium(II) nitrosylsulphito complex. Dalton Transactions, Cambridge, v. 48, n. 29, p. 10812-10823, 2019. 
22 ISIED, S.; TAUBE, $\mathrm{H}$. Effects of $\mathrm{SO}_{2}, \mathrm{HSO}_{3}{ }^{-}$and $\mathrm{SO}_{3}{ }^{2-}$ as auxiliary ligands on reactivity of ammineruthenium(II)-ligans bonds. Inorganic Chemistry, Washington, v. 13, n. 7, p. 1545-1551, 1974.

23 SILVA, H. A. D.; MCGARVEY, B. R.; SANTOS, R. H. D.; BERTOTTI, M.; MORI, V.; FRANCO, D. W. Sulfate as a ligand in ruthenium(II) and (III) ammines. Canadian Journal of Chemistry-Revue Canadienne De Chimie, Ottawa, v. 79, n. 5, p. 679-687, 2001 .

24 GOMES, M. G.; DAVANZO, C. U.; SILVA, S. C.; LOPES, L. G. F.; SANTOS, P. S.; FRANCO, D. W. Cis- and trans-nitrosyltetraammineruthenium(II). Spectral and electrochemical properties and reactivity. Journal of the Chemical Society-Dalton Transactions, Cambridge, n. 4, p. 601-607, 1998.

25 BEZERRA, C. W. B.; SILVA, S. C.; GAMBARDELLA, M. T. P.; SANTOS, R. H. A.; PLICAS, L. M. A.; TFOUNI, E. FRANCO, D. W. Water $\pi$-Donation in transTetraammineruthenium(II): effect on coordinated-water properties induced by a trans NO ligand. Inorganic Chemistry, Washington, v. 38, p. 5660-5667, 1999.

26 KREZEL, A.; BAL, W. A formula for correlating $\mathrm{p} K_{a}$ values determined in $\mathrm{D}_{2} \mathrm{O}$ and $\mathrm{H}_{2} \mathrm{O}$. Journal of Inorganic Biochemistry, Philadelphia, v. 98, p. 161-166, 2004.

27 RICHTER-ADDO, G. B.; LEGZDINS, P. Metal nitrosyls. New York: Oxford University Press, 1992. 369 p.

28 IL'YIN, M. A.; EMEL'ANOV, V. A.; BELYAEV, A. V.; MAKHINYA, A. B.; TKACHEV, S. V.; ALFEROVA, N. I. New method for the synthesis of transhydroxotetraamminenitrosoruthenium(ii) dichloride and its caracterization. Russian Journal of Inorganic Chemistry, Moscow, v. 53, n. 7, p. 1070-1076, 2008.

29 HILL, A. D.; KATSOUKIS, G.; FREI, H. Photoinduced electron transfer from ZrOCo binuclear light absorber to pyridine elucidated by transient optical and infrared spectroscopy. Journal of Physical Chemistry C, Washington, v. 122, p. 20176-20185, 2018.

30 TALCOTT, C. L.; MYERS, R. J. Electron spin resonance spectra of the radical anions of pyridine and related nitrogen heterocyclics. Molecular Physics, Abingdon, v. 12 , n. 6 , p. 549-567, 1967.

31 TOMASIK, P.; RATAJEWICZ, Z. Pyridine-metal complexes. New York: John Wiley \& Sons, 1985. 2247 p. 
Anexo A. Espectroeletroquímica do RuNOpy em solução de tampão fosfato pH 7,4; 0,1 mol L ${ }^{-1} ; \mu=0,262 \mathrm{~mol} \mathrm{~L}^{-1} ; \mathrm{C}_{\mathrm{Ru}}=5 \times 10^{-3} \mathrm{~mol} \mathrm{~L}^{-1} ; \mathrm{T}=20 \pm 4{ }^{\circ} \mathrm{C}$. A variação no espectro foi acompanhada pelo tempo, com ciclos indicados nas figuras. Potencial exibido utiliza como referência eletrodo de $\mathrm{Ag} / \mathrm{AgCl} l_{\text {sat }}$
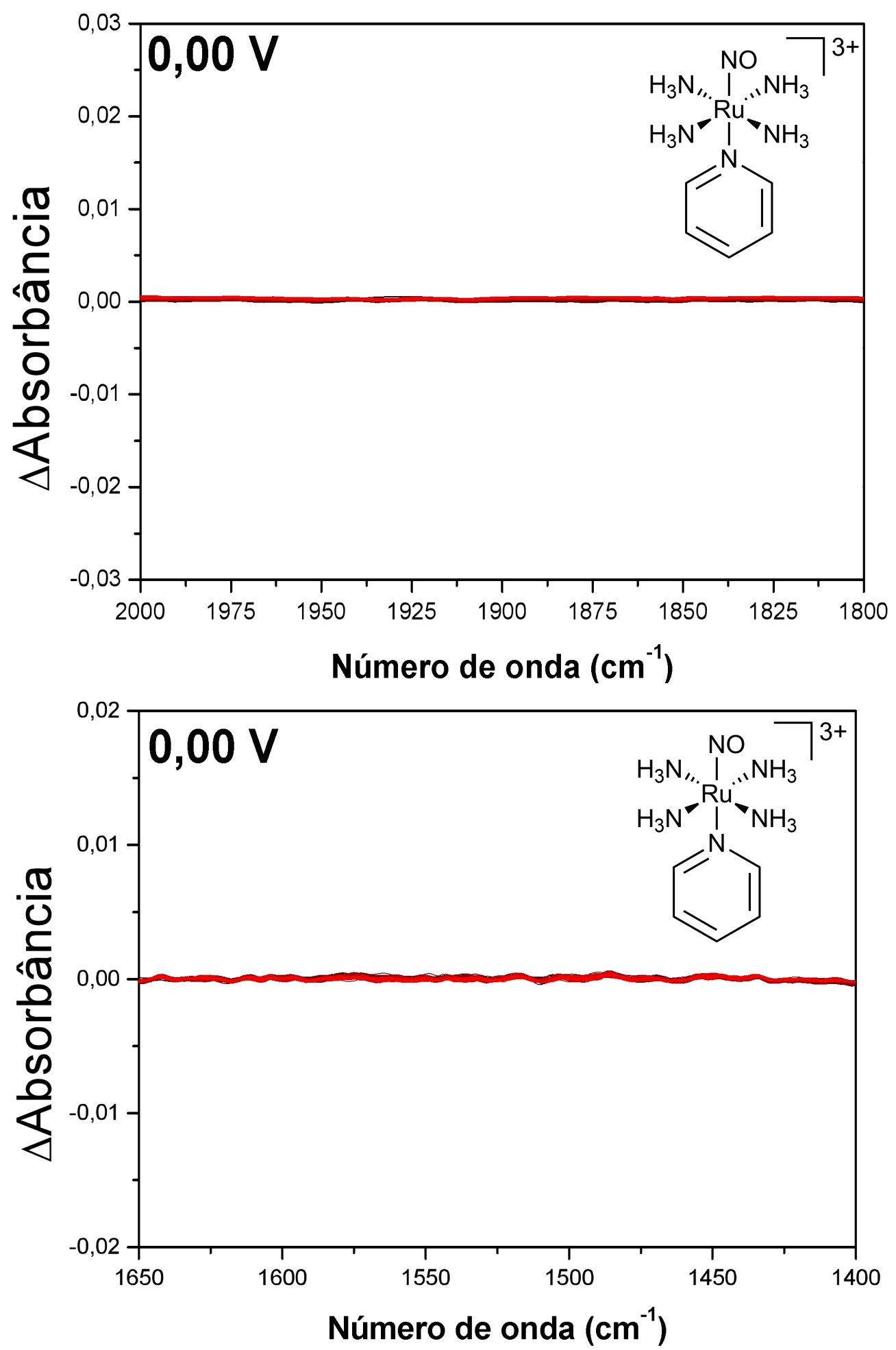

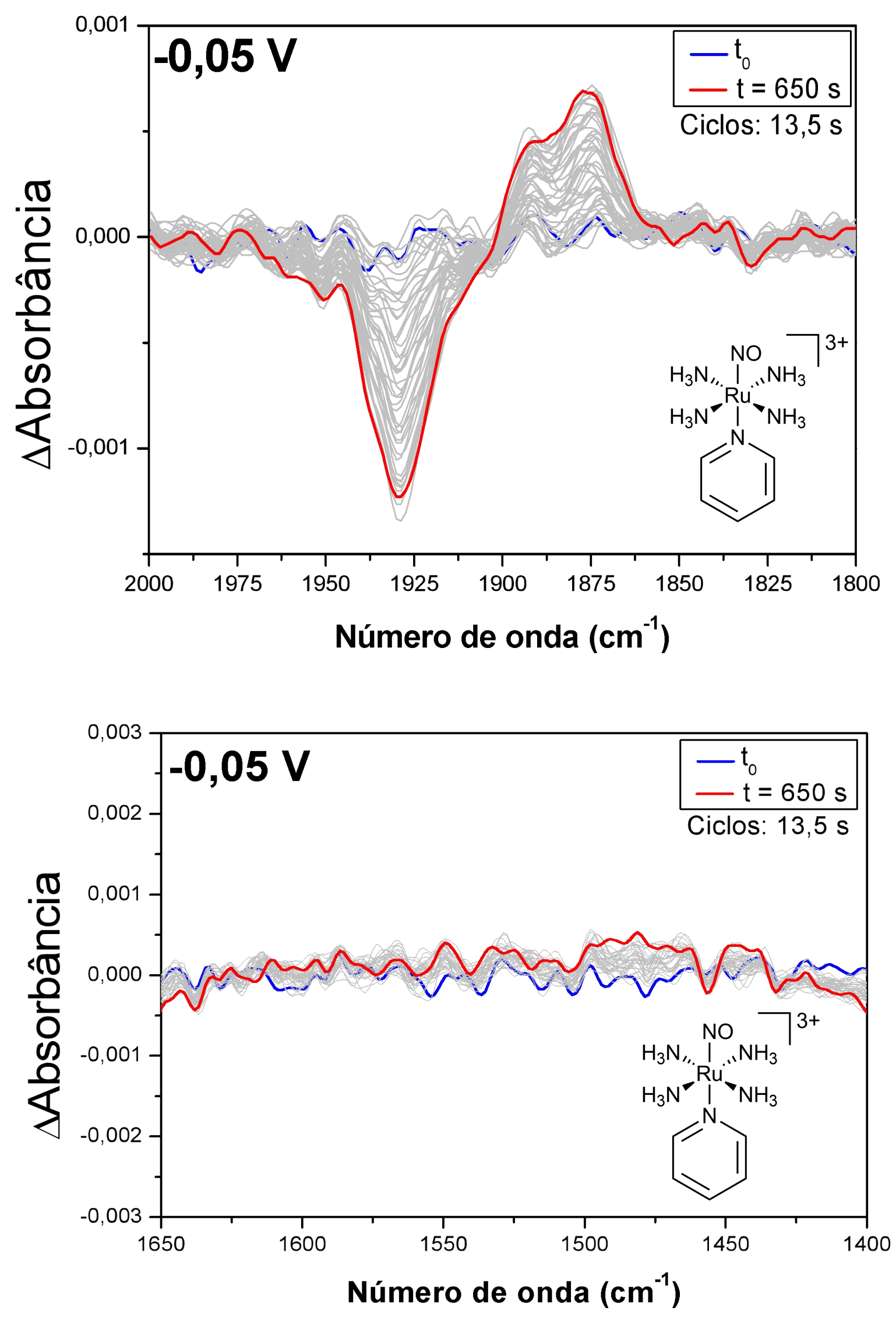

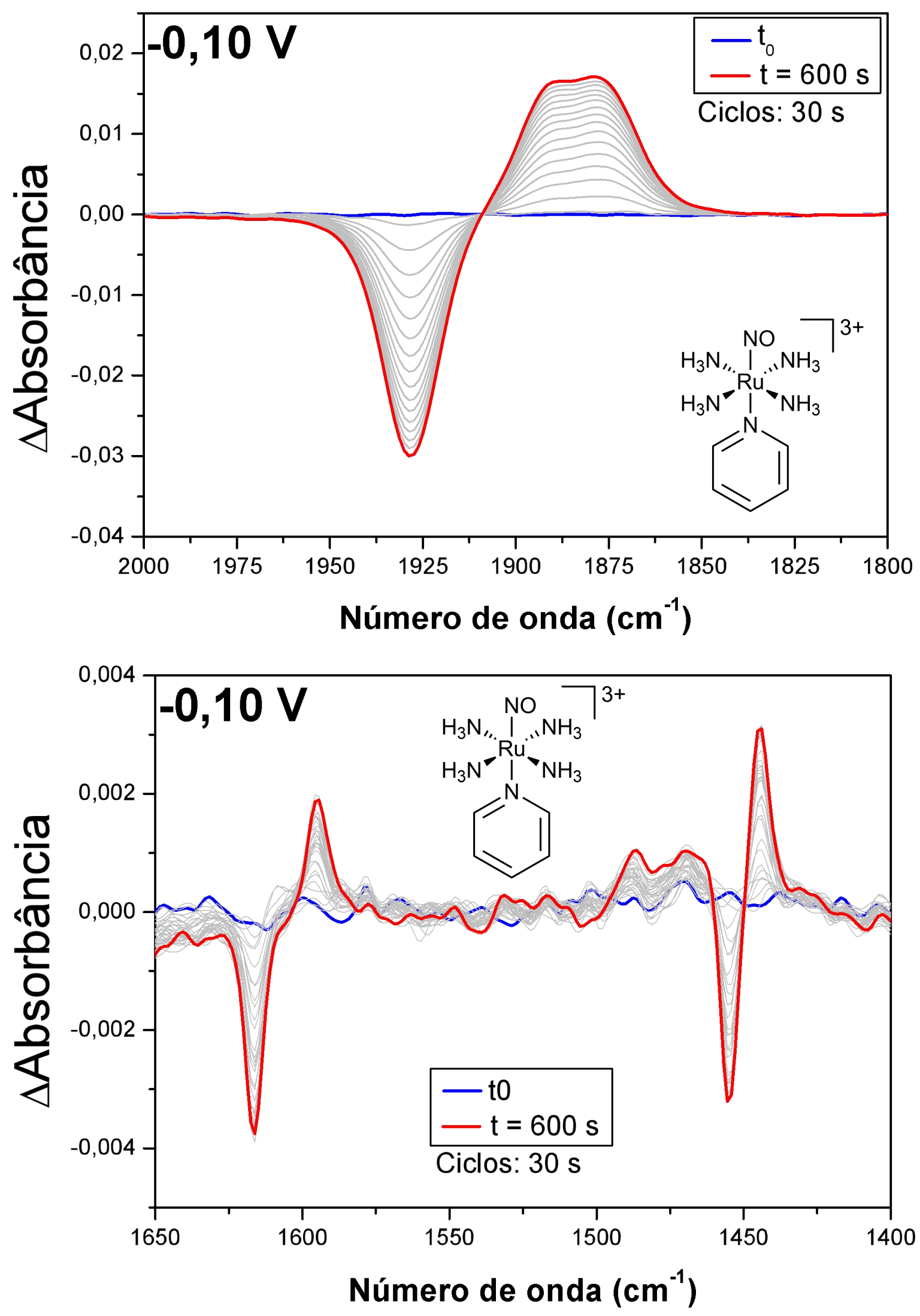

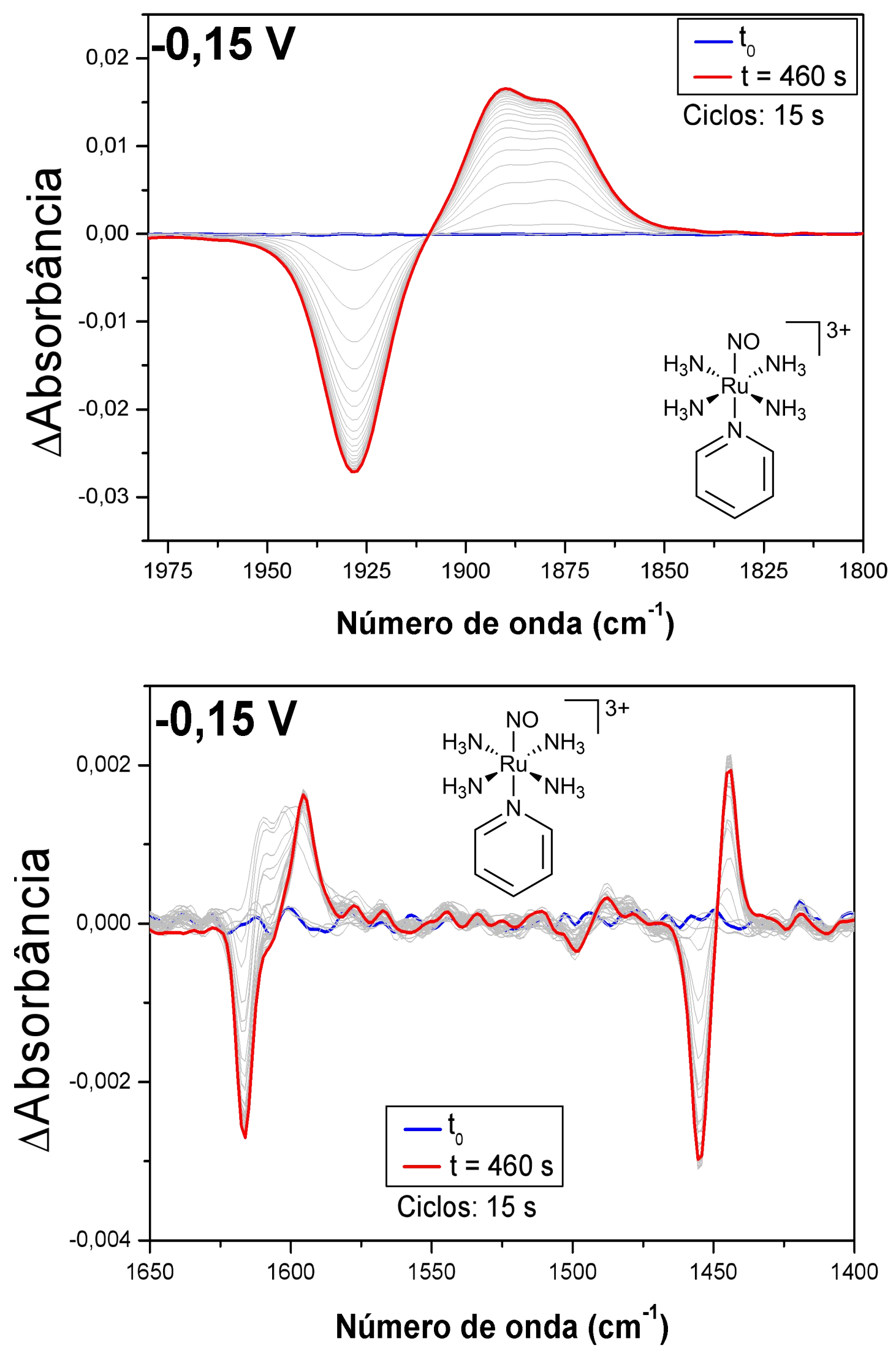

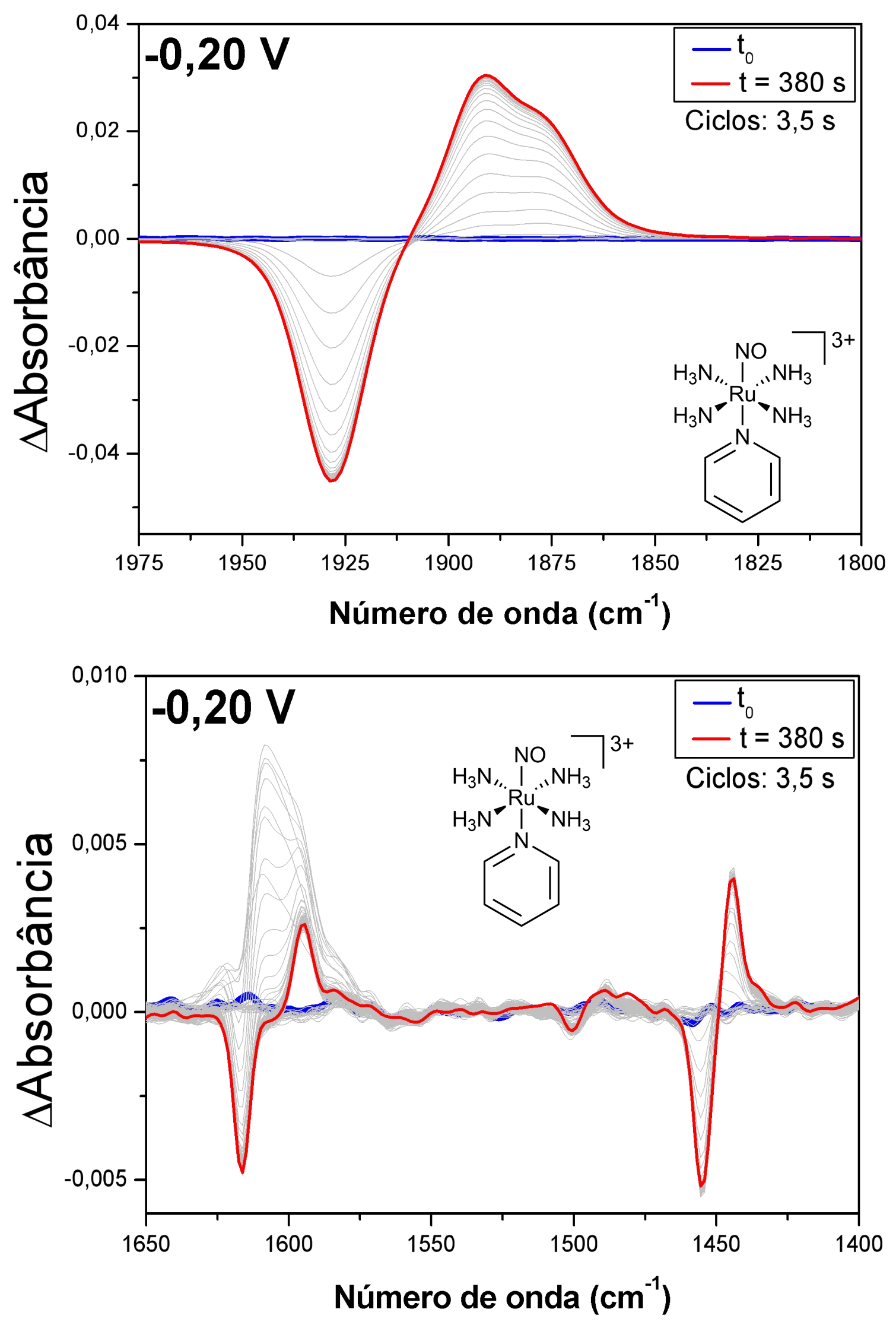

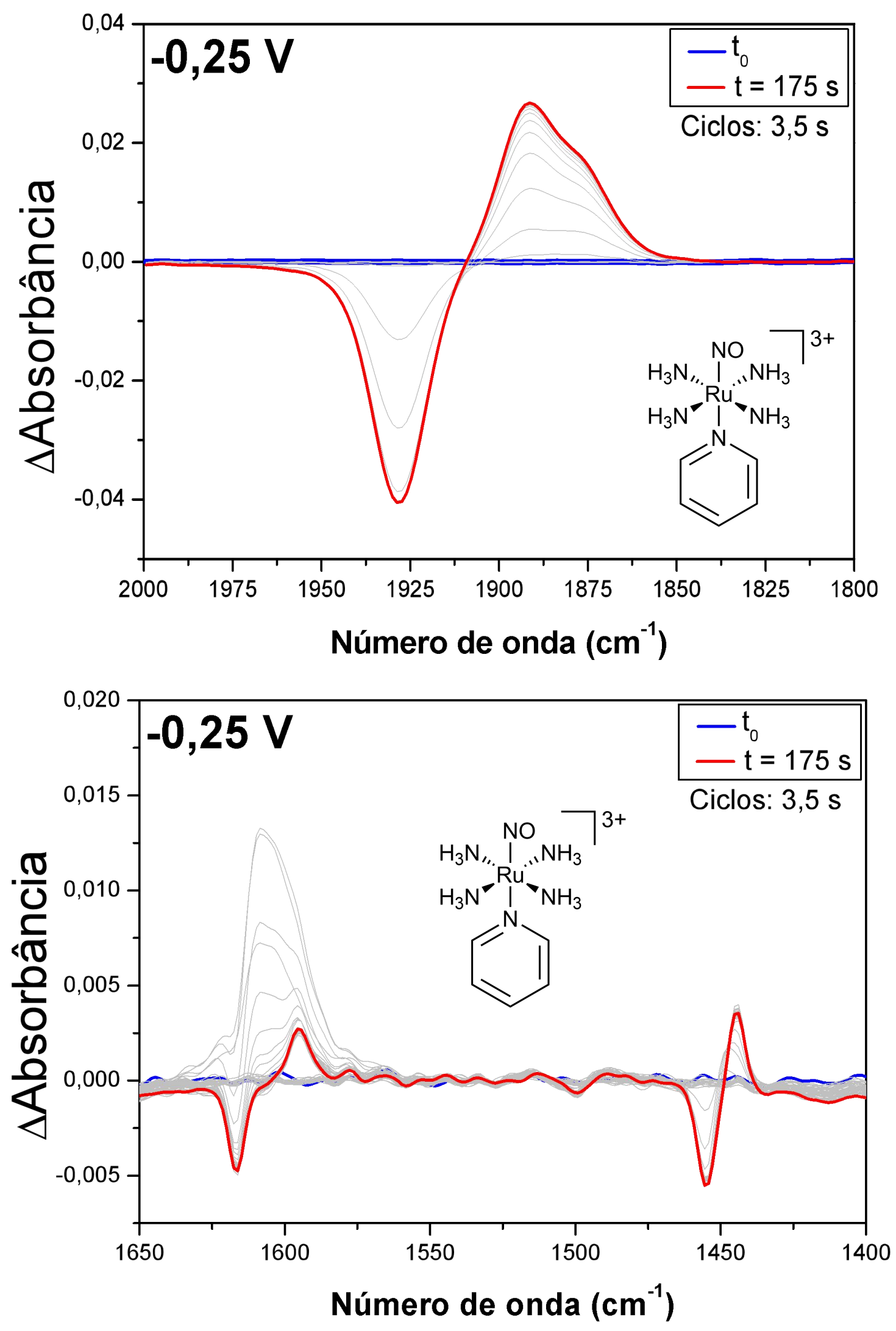

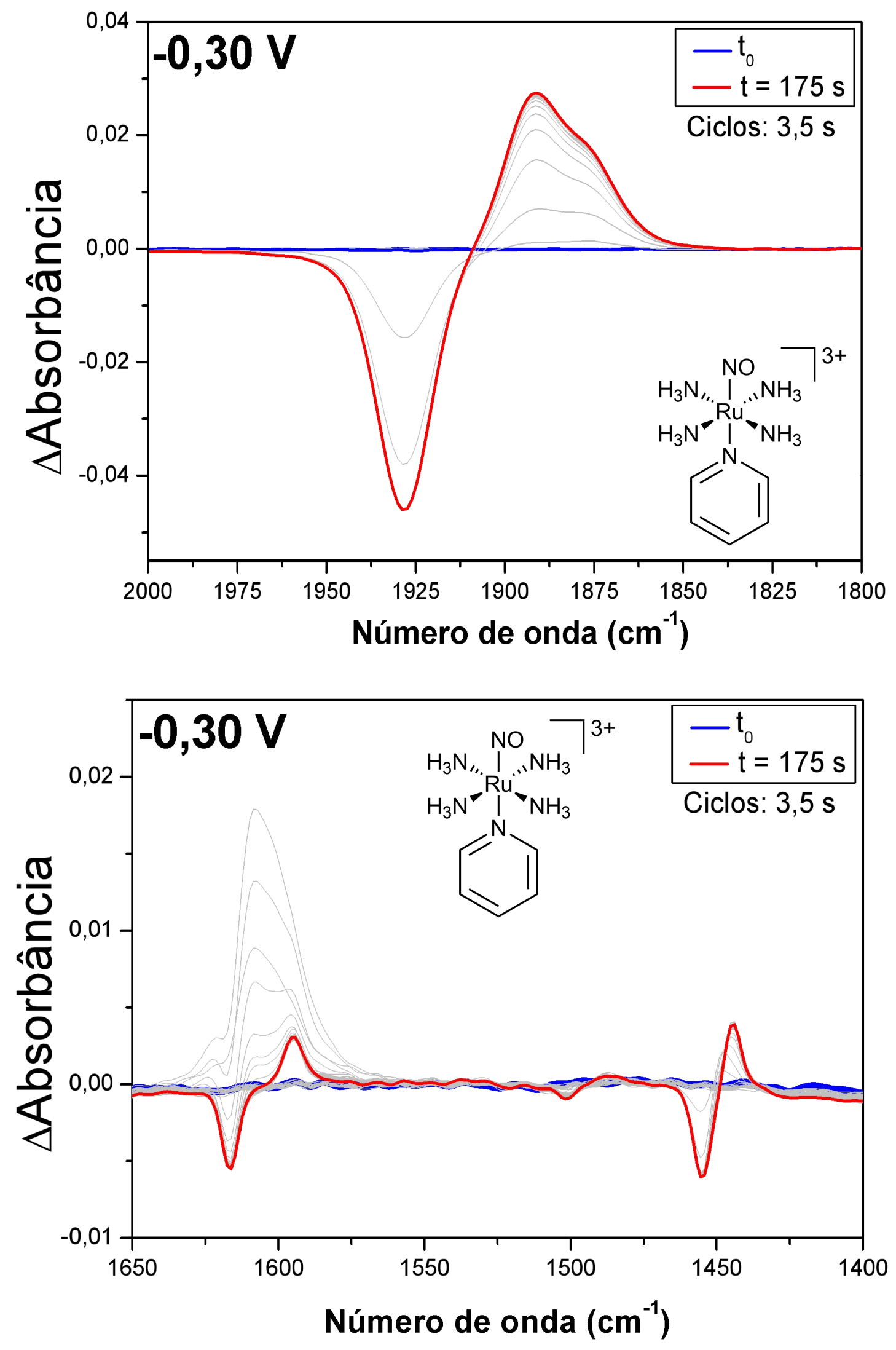

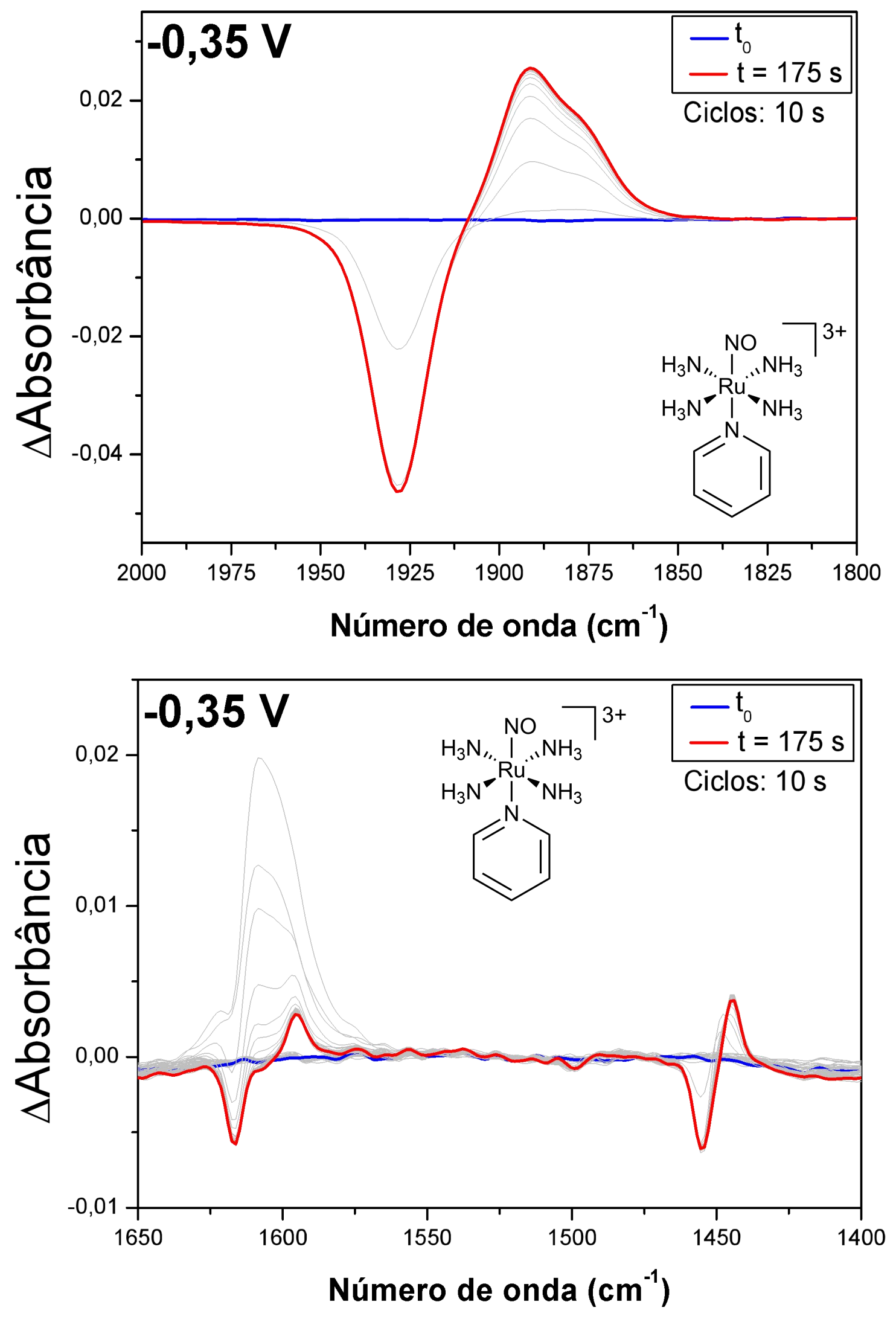

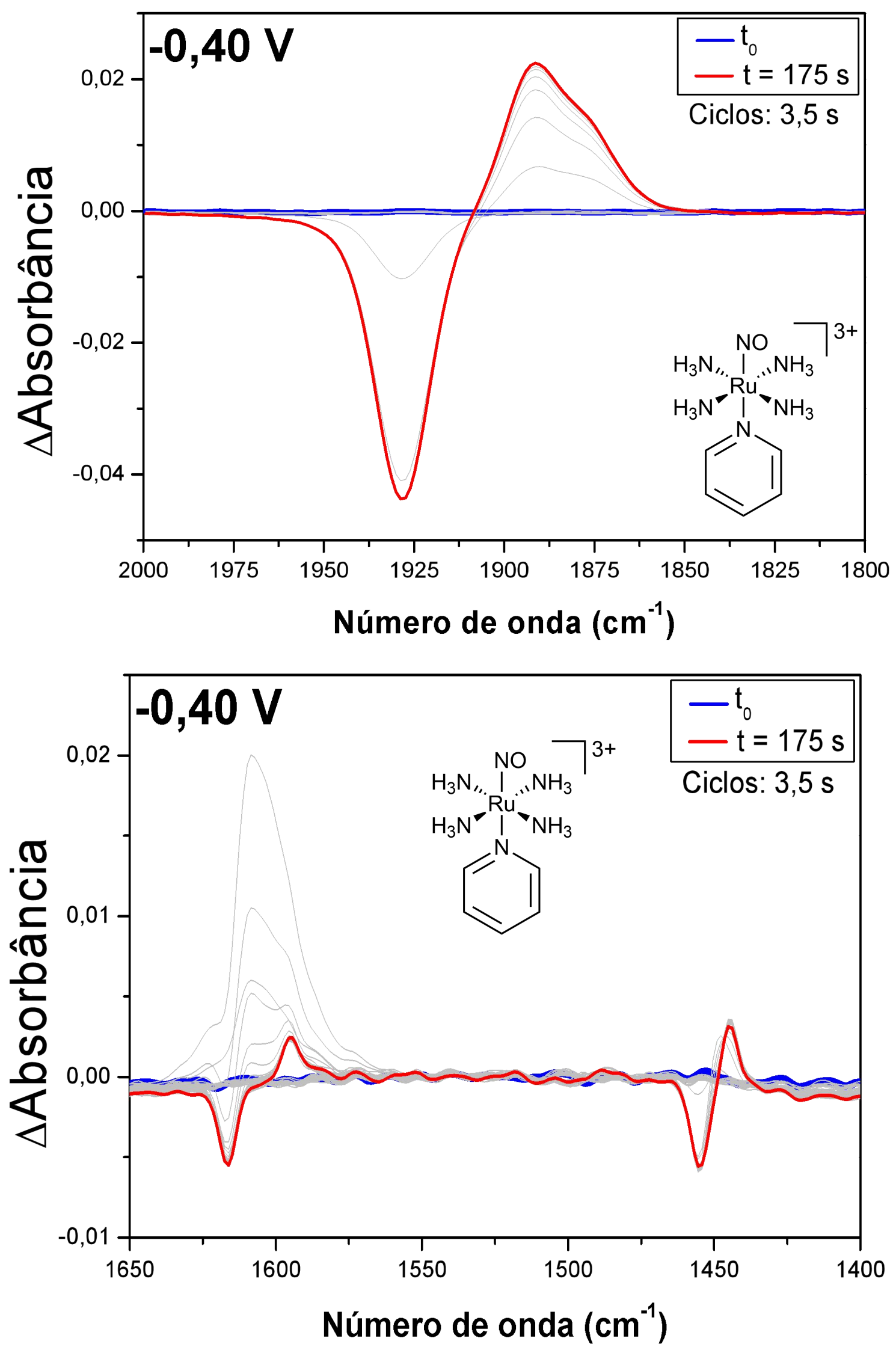

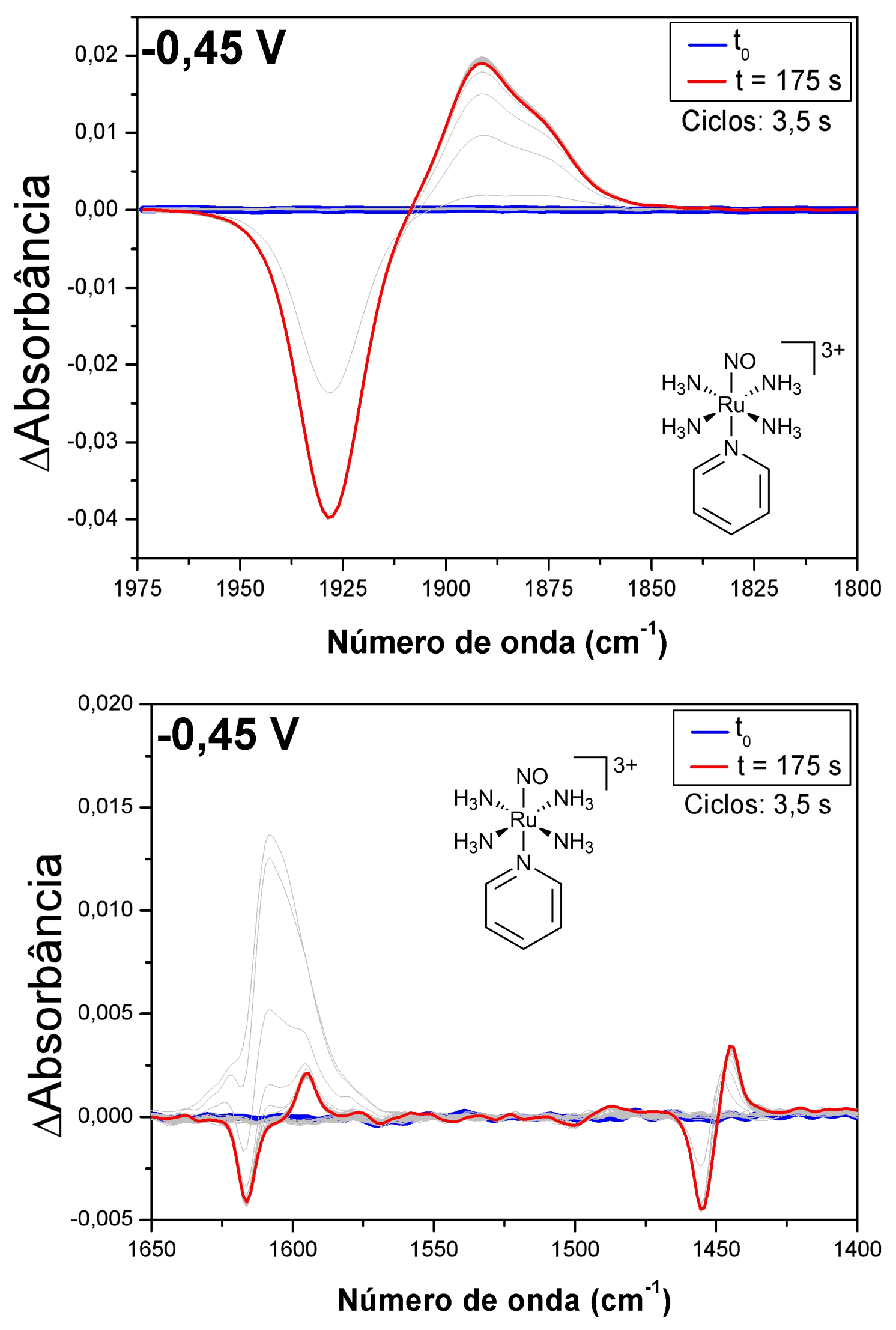

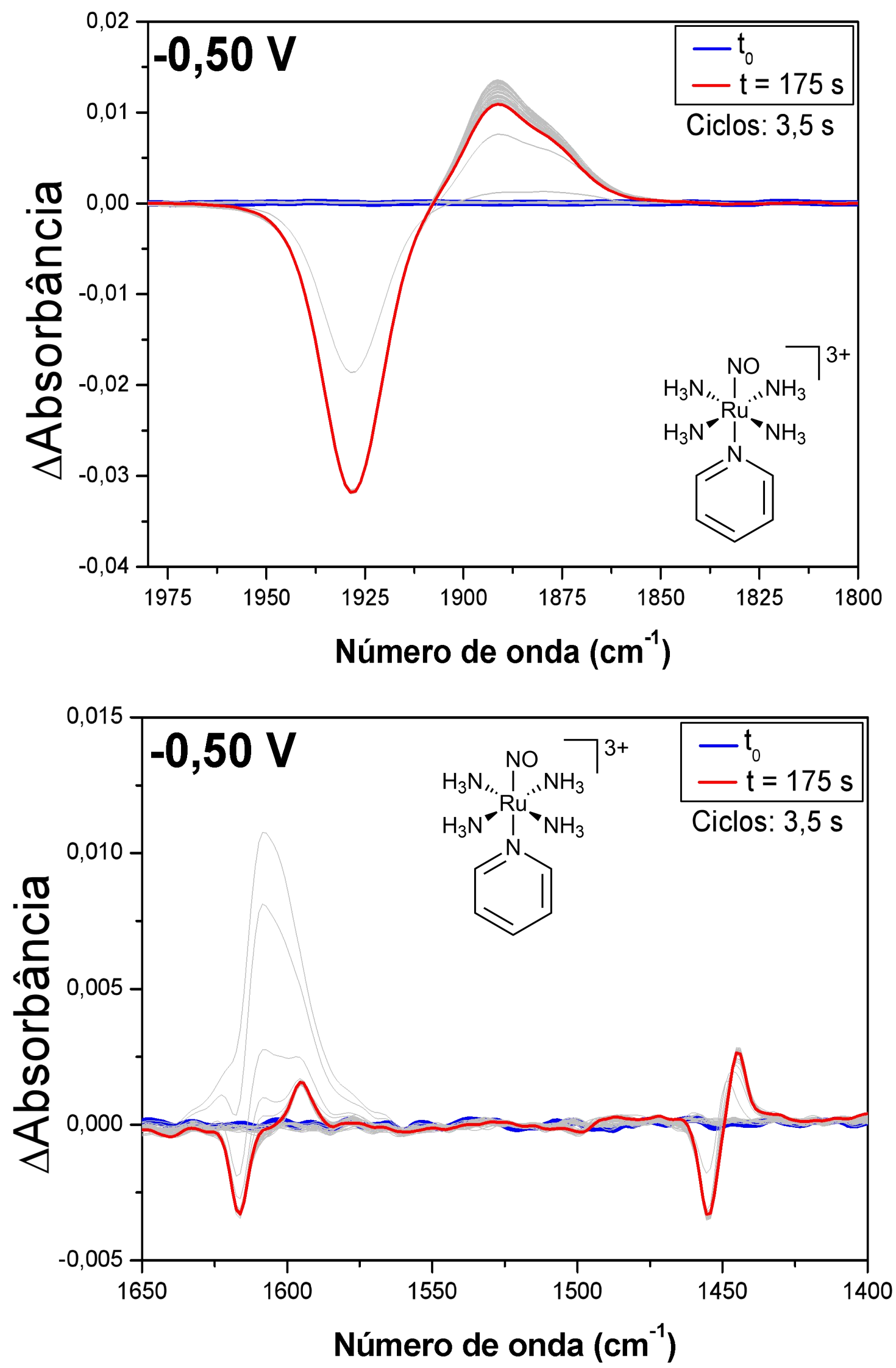
Anexo B. Espectroeletroquímica do $\mathbf{R u N O}(\mathbf{O H})$ em solução de tampão fosfato pH 7,4; 0,1 mol L ${ }^{-1} ; \mu=0,262 \mathrm{~mol} \mathrm{~L}^{-1} ; \mathrm{C}_{\mathrm{Ru}}=5 \times 10^{-3} \mathrm{~mol} \mathrm{~L}^{-1} ; \mathrm{T}=20 \pm 4{ }^{\circ} \mathrm{C}$. A variação no espectro foi acompanhada pelo tempo, com ciclos indicados nas figuras. Potencial exibido utiliza como referência eletrodo de $\mathrm{Ag} / \mathrm{AgCl} 1_{\text {sat. }}$.
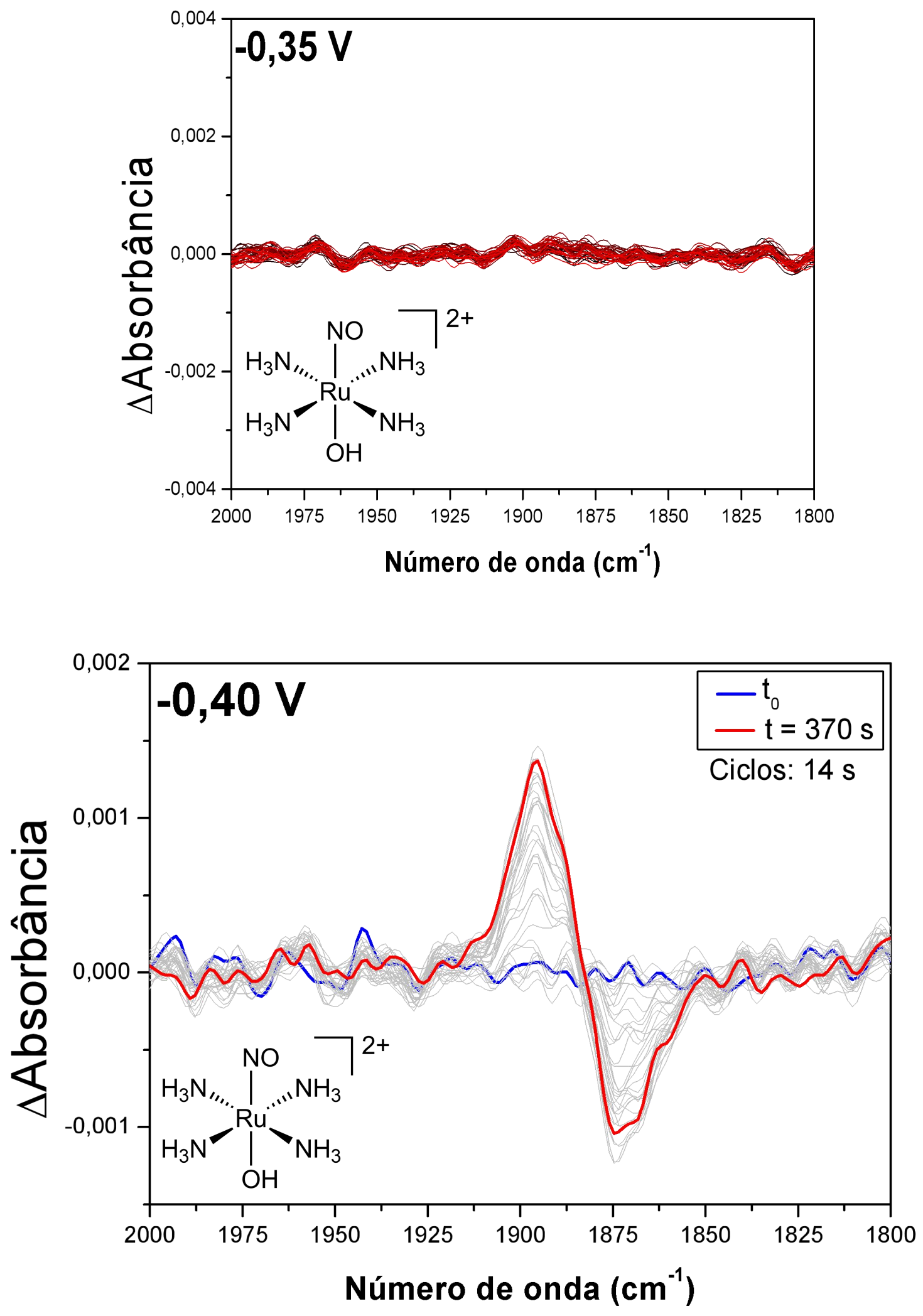

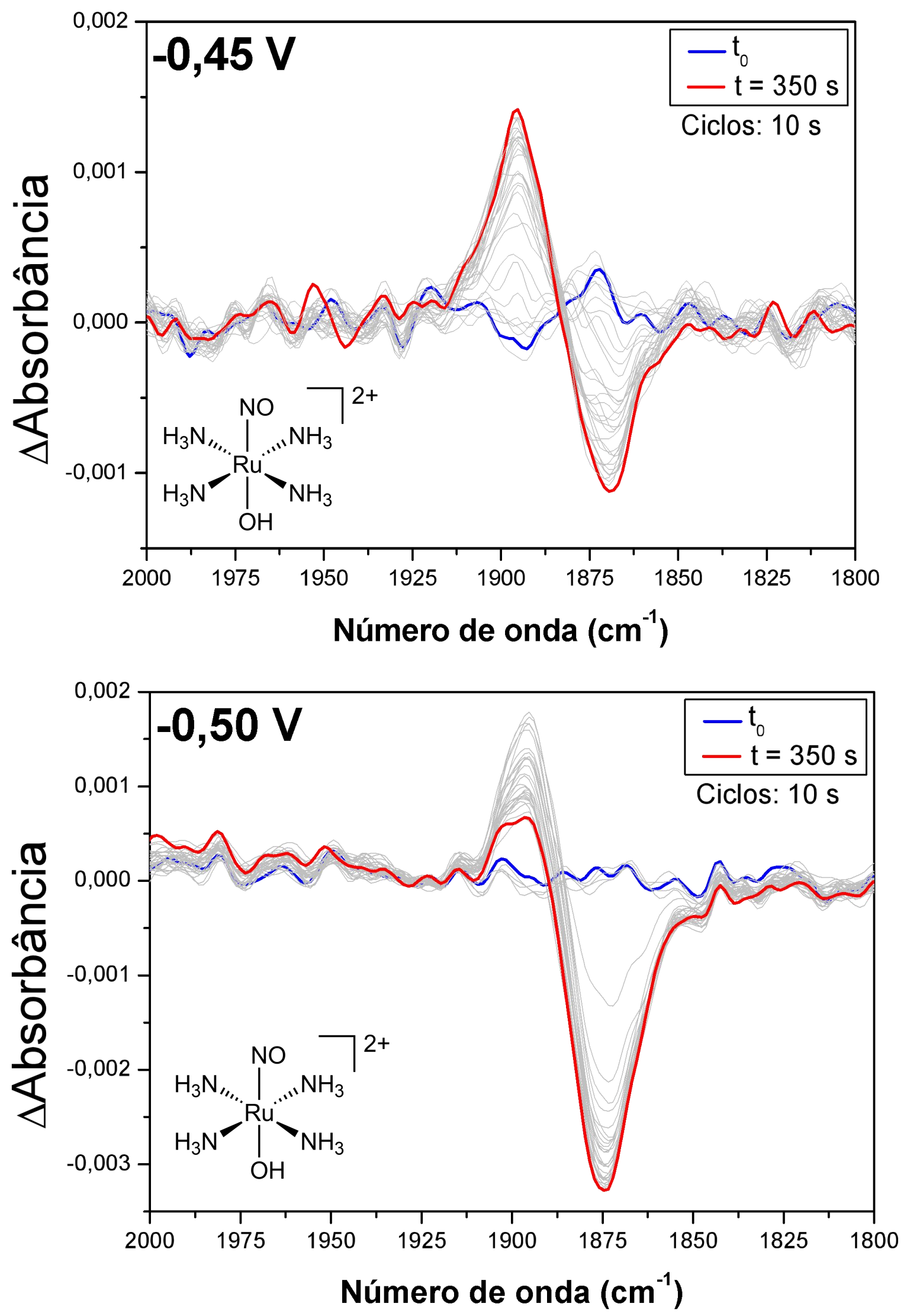
Anexo C. Espectroeletroquímica do $\mathbf{R u N O}\left(\mathbf{N H}_{3}\right)$ em solução de tampão fosfato $\mathrm{pH}$ 7,4; $0,1 \mathrm{~mol} \mathrm{~L}^{-1} ; \mu=0,262 \mathrm{~mol} \mathrm{~L}^{-1} ; \mathrm{C}_{\mathrm{Ru}}=5 \times 10^{-3} \mathrm{~mol} \mathrm{~L}^{-1} ; \mathrm{T}=20 \pm 4{ }^{\circ} \mathrm{C}$. A variação no espectro foi acompanhada pelo tempo, com ciclos indicados nas figuras. Potencial exibido utiliza como referência eletrodo de $\mathrm{Ag} / \mathrm{AgCl} 1_{\text {sat. }}$.
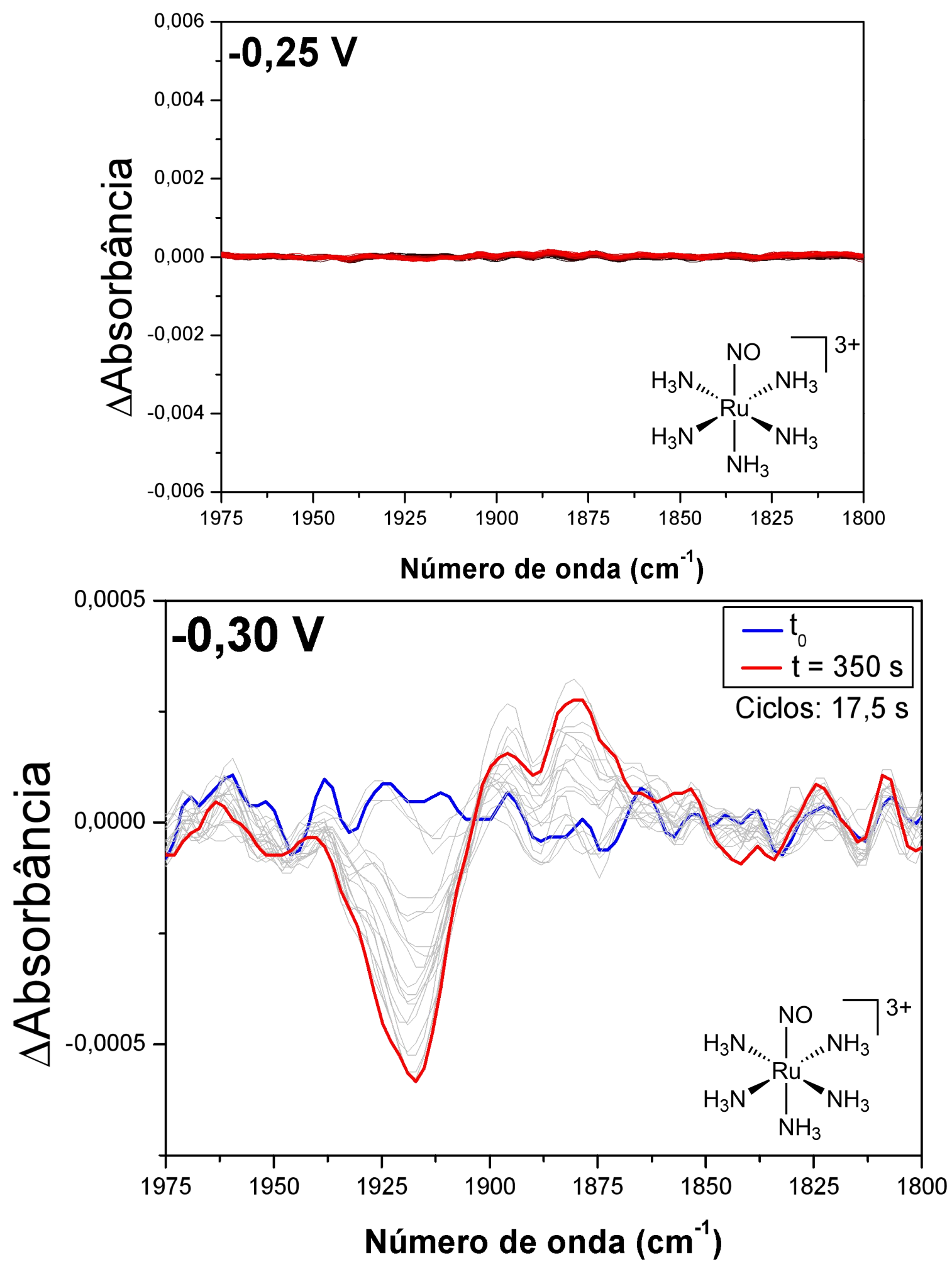

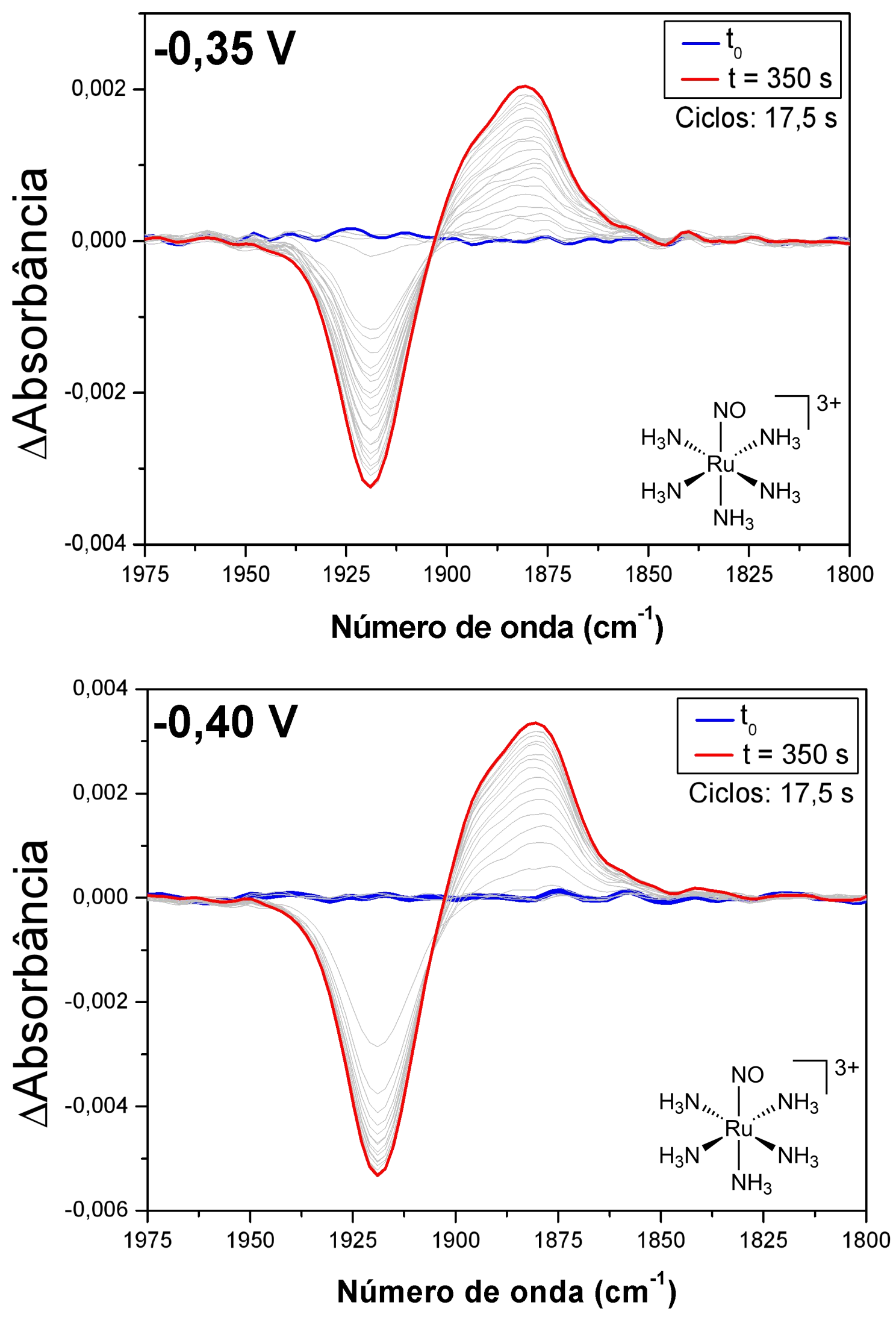

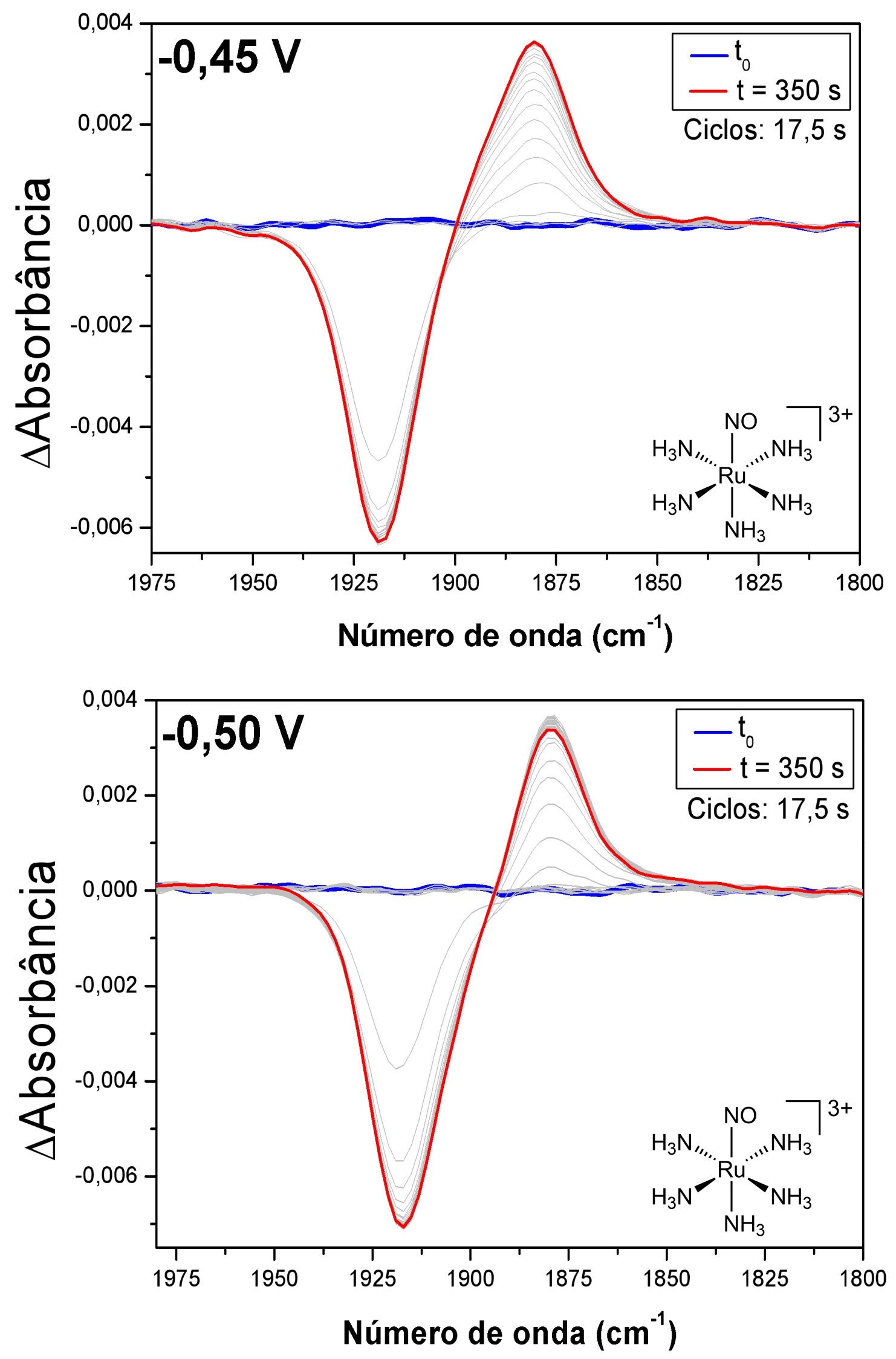
Anexo D. Caracterização dos nitrosilo complexos.

\section{D.1. Caracterização do complexo trans-[Ru(NO)( $\left.\left.\mathrm{NH}_{3}\right)_{4}(\mathrm{isn})\right]\left(\mathrm{BF}_{4}\right)_{3}$}

A seguir, são apresentados os espectros vibracional, eletrônico e de RMN e o voltamograma cíclico para o complexo trans- $\left[\mathrm{Ru}(\mathrm{NO})\left(\mathrm{NH}_{3}\right)_{4}(\mathrm{isn})\right]\left(\mathrm{BF}_{4}\right)_{3}$.

Figura D.1.1. Espectro vibracional do complexo trans- $\left[\mathrm{Ru}(\mathrm{NO})\left(\mathrm{NH}_{3}\right)_{4}(\mathrm{isn})\right]\left(\mathrm{BF}_{4}\right)_{3}$ em pastilha de $\mathrm{KBr}$

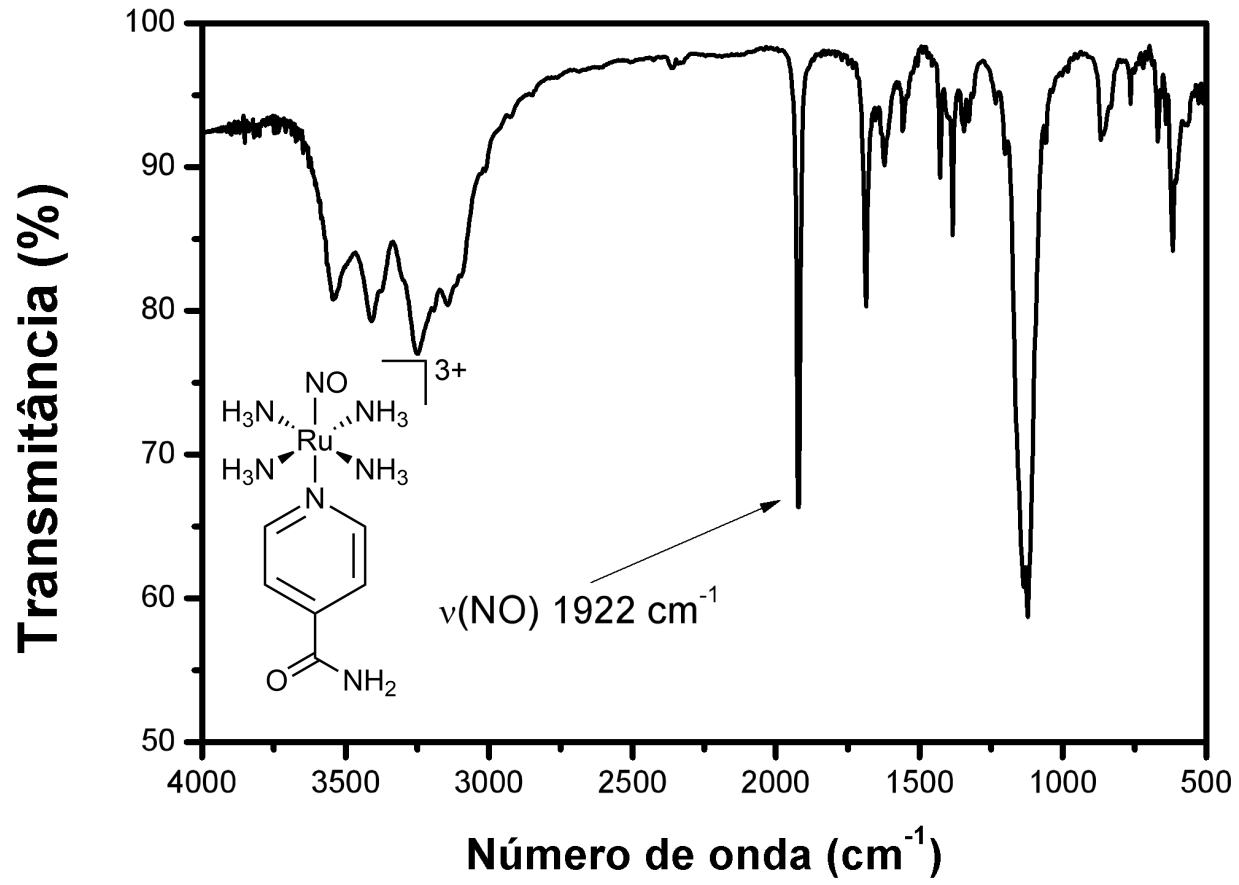

Figura D.1.2. Espectro eletrônico do complexo trans-[Ru(NO) $\left.\left(\mathrm{NH}_{3}\right)_{4}(\mathrm{isn})\right]\left(\mathrm{BF}_{4}\right)_{3}$ solubilizado em solução de tampão fosfato $\mathrm{pH} 7,4 ; 0,1 \mathrm{~mol} \mathrm{~L}^{-1} ; \mu=0,262 \mathrm{~mol} \mathrm{~L}^{-1} \cdot \mathrm{T}=25^{\circ} \mathrm{C}$.

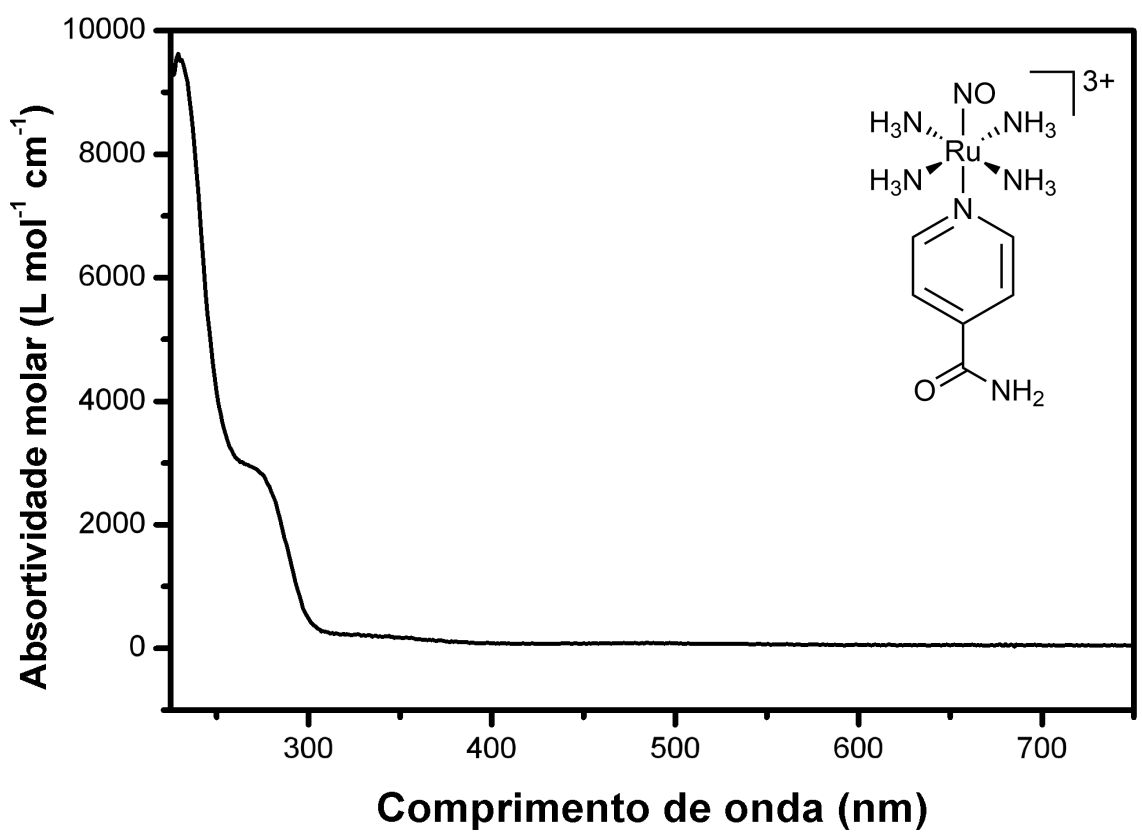




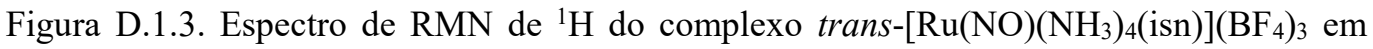
solução de $50 \%$ tampão fosfato $\mathrm{pH} 7,4$ e $50 \% \mathrm{D}_{2} \mathrm{O}$. Referência: TMSPd-4 $\delta=0,00 \mathrm{ppm}$.

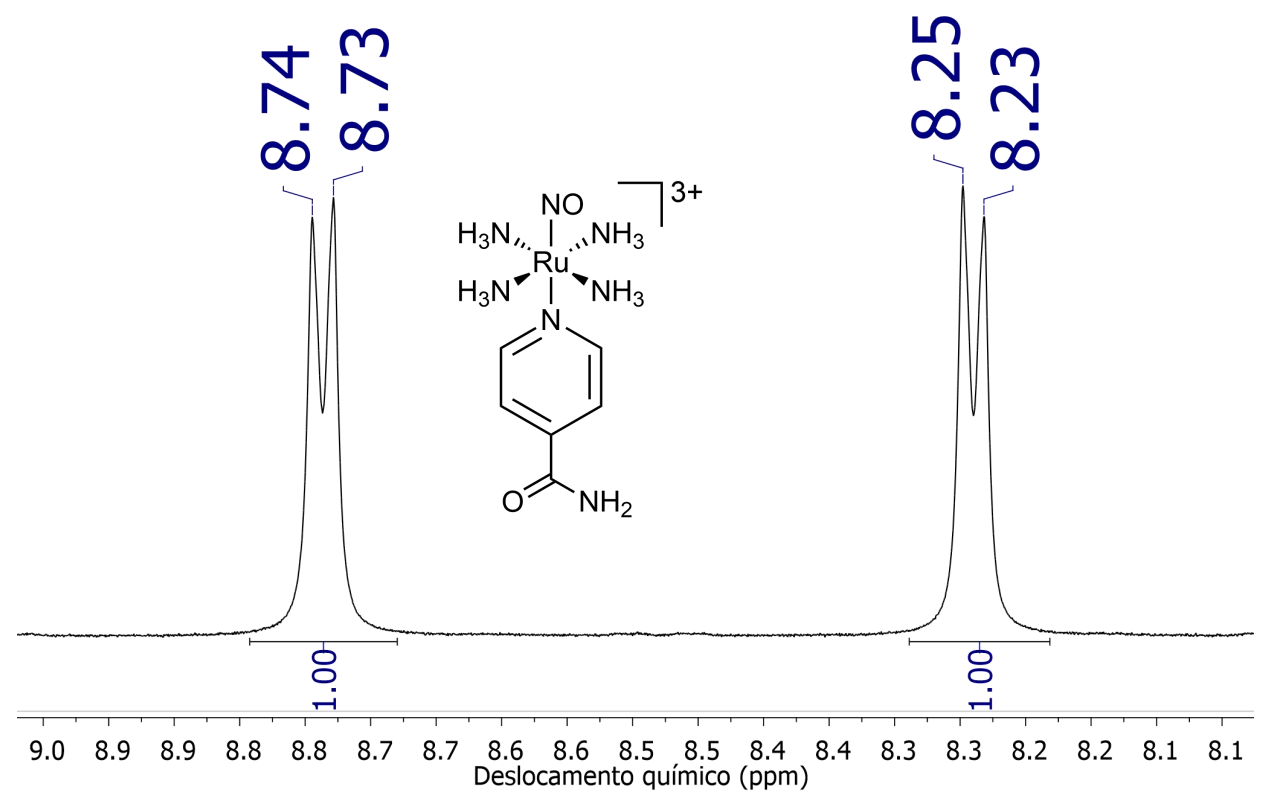

É possível observar, assim, que o estiramento de $v(\mathrm{NO})$ em $1922 \mathrm{~cm}^{-1}$ é condizente com a descrição do ligante $\mathrm{NO}^{+}$coordenado ao centro de $\mathrm{Ru}(\mathrm{II})$, esperado na região de $1930 \mathrm{~cm}^{-1}$, como reportado na literatura ${ }^{16}$. Além disso, por espectroscopia eletrônica, observa-se transições em 276 nm e 232 nm, referentes a transições eletrônica de transferência de carga do centro metálico para o ligante $\mathrm{NO}^{+}$. Por fim, $\mathrm{O}$ espectro de $\mathrm{RMN}$ de ${ }^{1} \mathrm{H}$ indica a coordenação do ligante isonicotinamida ao centro metálico pelo deslocamento dos sinais de isonicotinamida livre em 8,70 ppm e 7,78 $\mathrm{ppm}^{21}$ para região de menor blindagem, em 8,74 ppm e 8,25 ppm, indicando coordenação ao centro metálico de Ru(II).

A voltametria cíclica para o íon complexo trans- $\left[\mathrm{Ru}(\mathrm{NO})\left(\mathrm{NH}_{3}\right)_{4}(\mathrm{isn})\right]^{3+}$ em solução de tampão fosfato $\mathrm{pH}$ 7,4 é apresentada a seguir 
Figura D.1.4. Voltamogramas cíclicos para o íon complexo trans- $\left[\mathrm{Ru}(\mathrm{NO})\left(\mathrm{NH}_{3}\right)_{4}(\mathrm{isn})\right]^{3+} \mathrm{em}$ solução de tampão fosfato $\mathrm{pH} 7,4 ; 0,1 \mathrm{~mol} \mathrm{~L}^{-1} ; \mu=0,262 \mathrm{~mol} \mathrm{~L}^{-1} \cdot \mathrm{T}=25^{\circ} \mathrm{C} . \mathrm{v}=50 \mathrm{mV} / \mathrm{s} . \mathrm{C}_{\mathrm{Ru}}=$ $5 \times 10^{-3} \mathrm{~mol} \mathrm{~L}^{-1}$. Seta indica sentido de varredura.

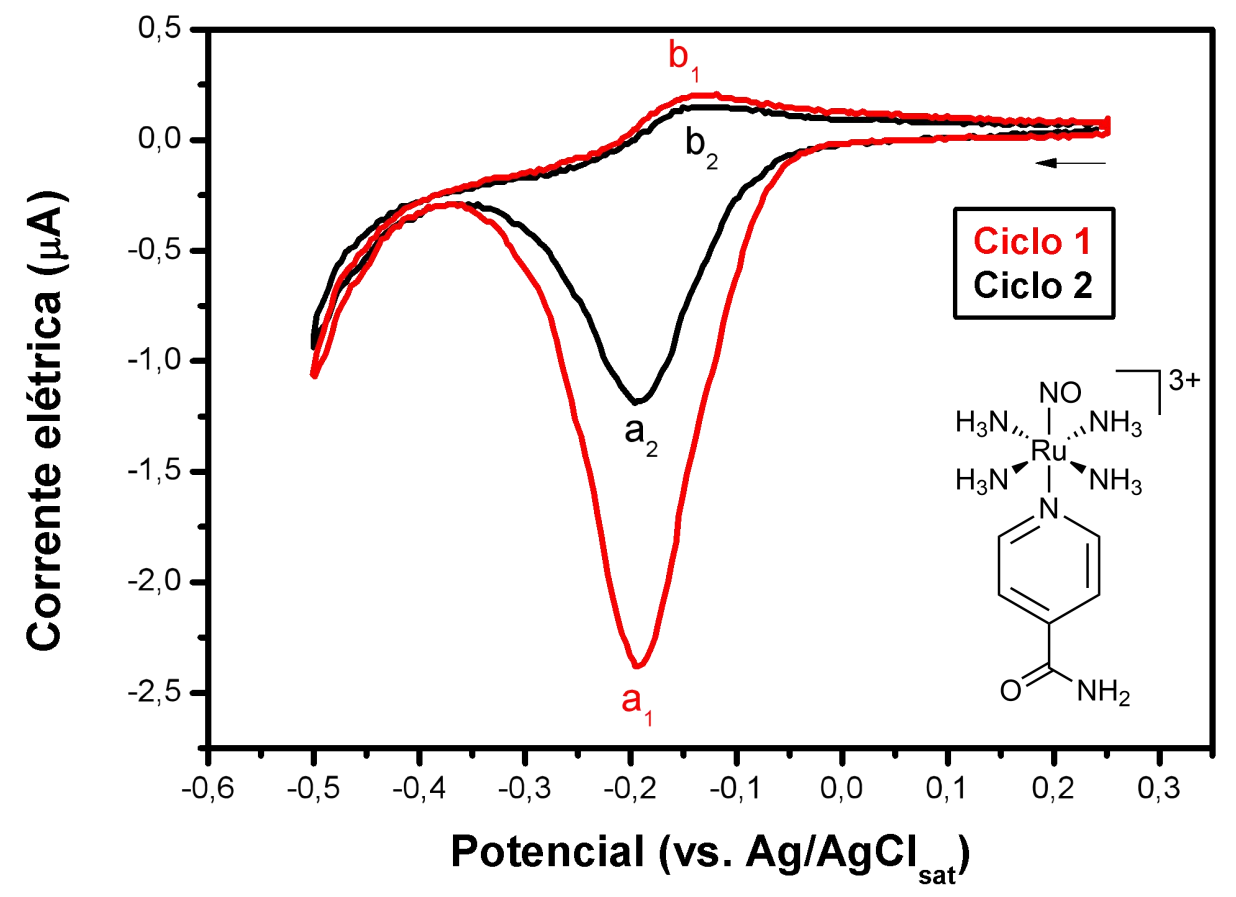

É reportado na literatura ${ }^{13}$ que a redução eletroquímica de nitrosilo complexos leva ao processo

$$
\begin{gathered}
\text { trans- }\left[\mathrm{Ru}(\mathrm{NO})\left(\mathrm{NH}_{3}\right)_{4}(\text { isn })\right]^{3+}+\mathrm{e}^{-} \rightarrow \text { trans }-\left[\mathrm{Ru}(\mathrm{NO})\left(\mathrm{NH}_{3}\right)_{4}(\text { isn })\right]^{2+} \text { (rápida) } \\
\text { trans- }\left[\mathrm{Ru}(\mathrm{NO})\left(\mathrm{NH}_{3}\right)_{4}(\text { isn })\right]^{2+}+\mathrm{H}_{2} \mathrm{O} \rightarrow \text { trans }-\left[\mathrm{Ru}\left(\mathrm{NH}_{3}\right)_{4}\left(\mathrm{H}_{2} \mathrm{O}\right)(\text { isn })\right]^{3+}+\mathrm{NO}^{\bullet} \text { (lenta) }
\end{gathered}
$$

Sendo que, com base no voltamograma apresentado acima, é possível observar o par redox $\mathrm{NO}^{+} / \mathrm{NO}^{\bullet}$ (representado por $\mathrm{a}_{1} / \mathrm{b}_{1}$ para o primeiro ciclo, e $\mathrm{a}_{2} / \mathrm{b}_{2}$ para o segundo ciclo). 


\section{D.2. Caracterização do complexo trans- $\left[\mathrm{Ru}(\mathrm{NO})\left(\mathrm{NH}_{3}\right)_{4}(\mathrm{py})\right]\left(\mathrm{PF}_{6}\right)_{3}$}

A seguir, são apresentados os espectros vibracional, eletrônico e de RMN e o voltamograma cíclico para o complexo trans-[Ru(NO) $\left(\mathrm{NH}_{3}\right)_{4}($ py) $]\left(\mathrm{PF}_{6}\right)_{3}$.

Figura D.2.1. Espectro vibracional do complexo trans $-\left[\mathrm{Ru}(\mathrm{NO})\left(\mathrm{NH}_{3}\right)_{4}(\mathrm{py})\right]\left(\mathrm{PF}_{6}\right)_{3}$ em pastilha de $\mathrm{KBr}$

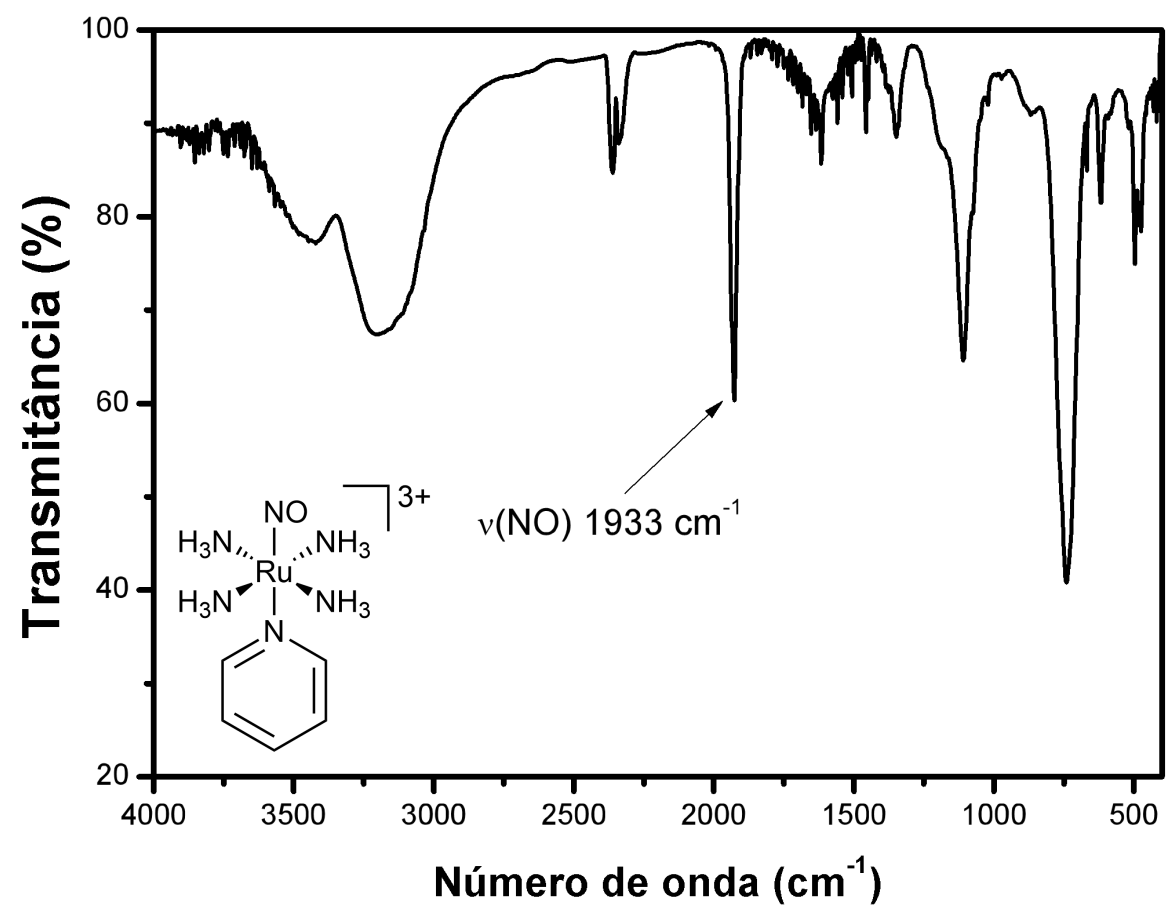

Figura D.2.2. Espectro eletrônico do complexo trans- $\left[\mathrm{Ru}(\mathrm{NO})\left(\mathrm{NH}_{3}\right)_{4}(\mathrm{py})\right]\left(\mathrm{PF}_{6}\right)_{3}$ solubilizado em solução de tampão fosfato $\mathrm{pH} 7,4 ; 0,1 \mathrm{~mol} \mathrm{~L}^{-1} ; \mu=0,262 \mathrm{~mol} \mathrm{~L}^{-1} \cdot \mathrm{T}=25^{\circ} \mathrm{C}$.

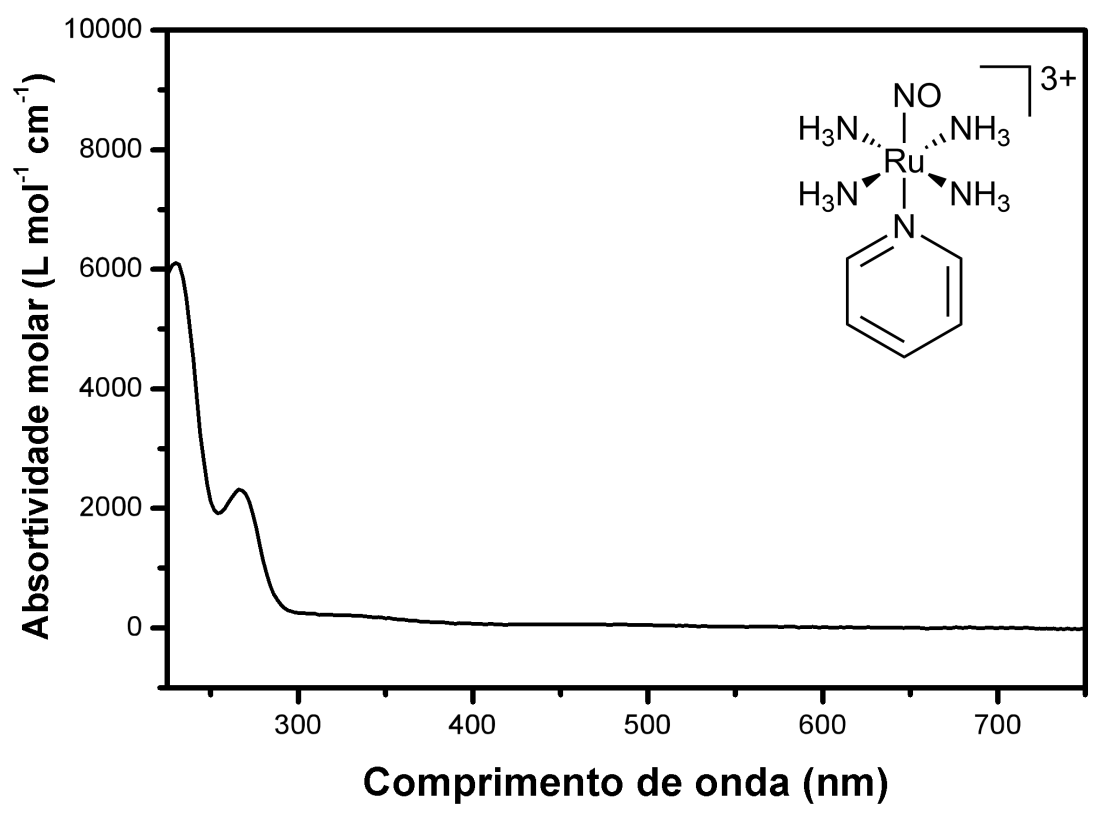


Figura D.2.3. Espectro de RMN de ${ }^{1} \mathrm{H}$ da piridina livre em solução de $50 \%$ tampão fosfato $\mathrm{pH} 7,4$ e $50 \% \mathrm{D}_{2} \mathrm{O}$. Referência: TMSPd-4 $\delta=0,00 \mathrm{ppm}$.

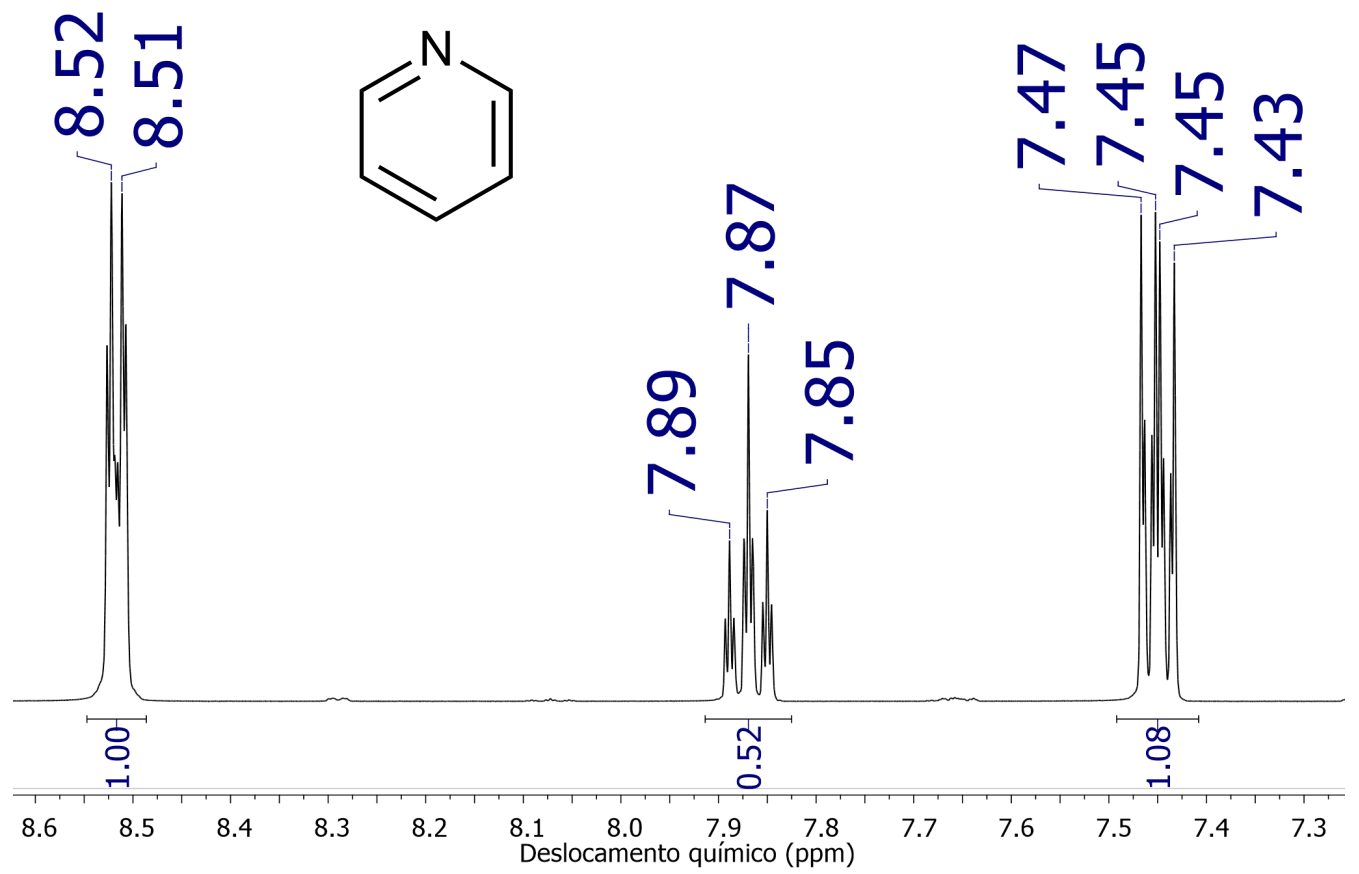

Figura D.2..4. Espectro de RMN de ${ }^{1} \mathrm{H}$ do complexo trans-[Ru(NO) $\left.\left(\mathrm{NH}_{3}\right)_{4}(\mathrm{py})\right]\left(\mathrm{PF}_{6}\right)_{3}$ em solução de $50 \%$ tampão fosfato $\mathrm{pH} 7,4$ e $50 \% \mathrm{D}_{2} \mathrm{O}$. Referência: TMSPd- $\delta=0,00 \mathrm{ppm}$.

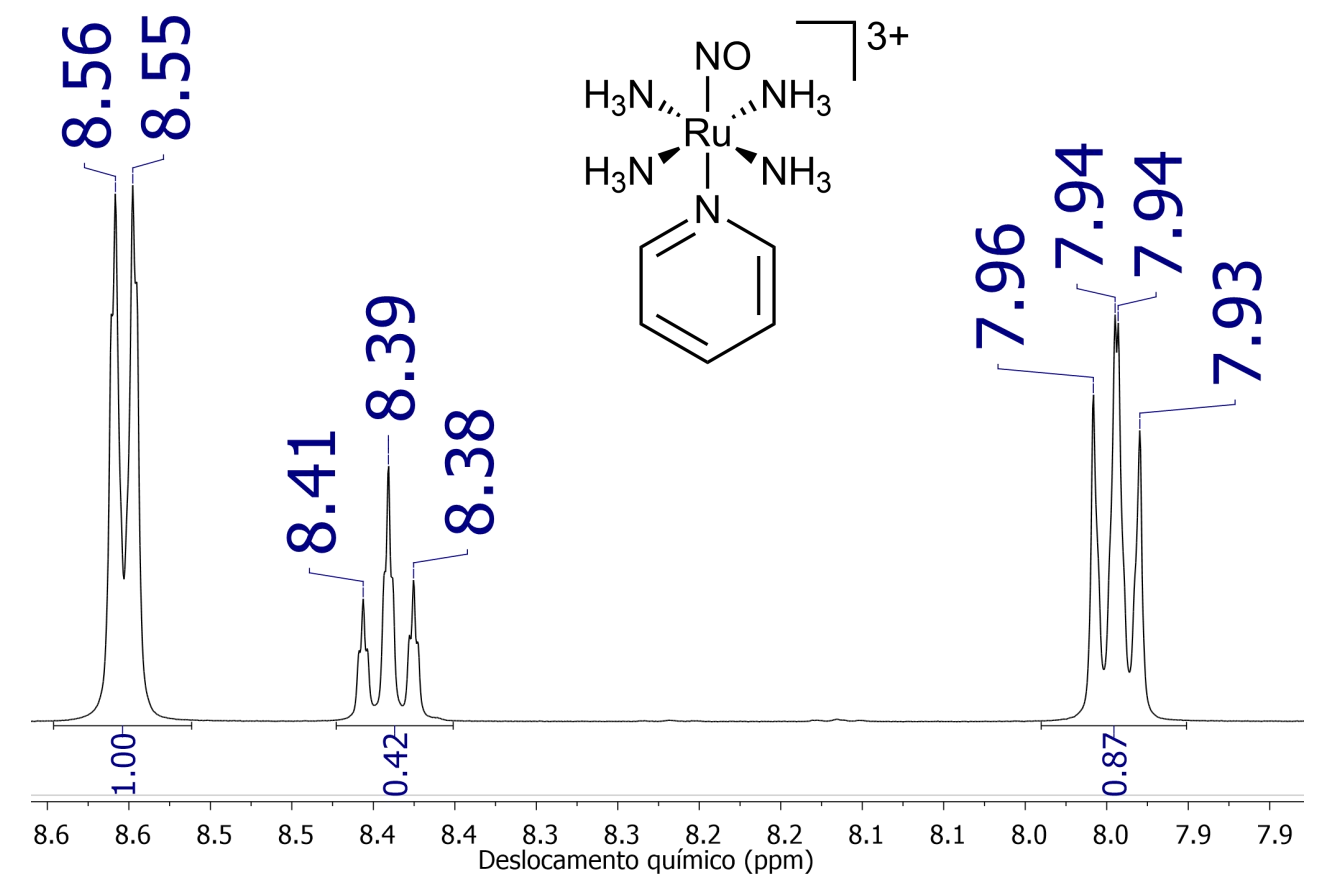


Com base nas figuras acima, o sinal do estiramento de NO em $1933 \mathrm{~cm}^{-1}$ condiz com o esperado para o ligante $\mathrm{NO}^{+}$trans posicionado a piridina, com ambos os ligantes coordenados ao centro de $\mathrm{Ru}(\mathrm{II})$. Por espectroscopia eletrônica, observa-se transições em 267 nm e $232 \mathrm{~nm}$, referentes a transições eletrônica de transferência de carga do centro metálico para o ligante $\mathrm{NO}^{+}$. O espectro de $\mathrm{RMN}$ de ${ }^{1} \mathrm{H}$ indica a coordenação do ligante piridina ao centro metálico pelo deslocamento dos sinais de piridina livre em 8,52 ppm, 7,89 ppm e 7,47 ppm para região de menor blindagem, em 8,56 ppm, 8,41 ppm e 7,96 ppm, indicando coordenação ao centro metálico de Ru(II).

Figura D.2.5. Voltamogramas cíclicos para o íon complexo trans-[Ru(NO)(NH$\left.)_{4}(\mathrm{py})\right]^{3+} \mathrm{em}$ solução de tampão fosfato $\mathrm{pH} 7,4 ; 0,1 \mathrm{~mol} \mathrm{~L}^{-1} ; \mu=0,262 \mathrm{~mol} \mathrm{~L}^{-1} . \mathrm{T}=25^{\circ} \mathrm{C} . \mathrm{v}=50 \mathrm{mV} / \mathrm{s}$. $\mathrm{C}_{\mathrm{Ru}}=$ $5 \times 10^{-3} \mathrm{~mol} \mathrm{~L}^{-1}$. Seta indica sentido de varredura.

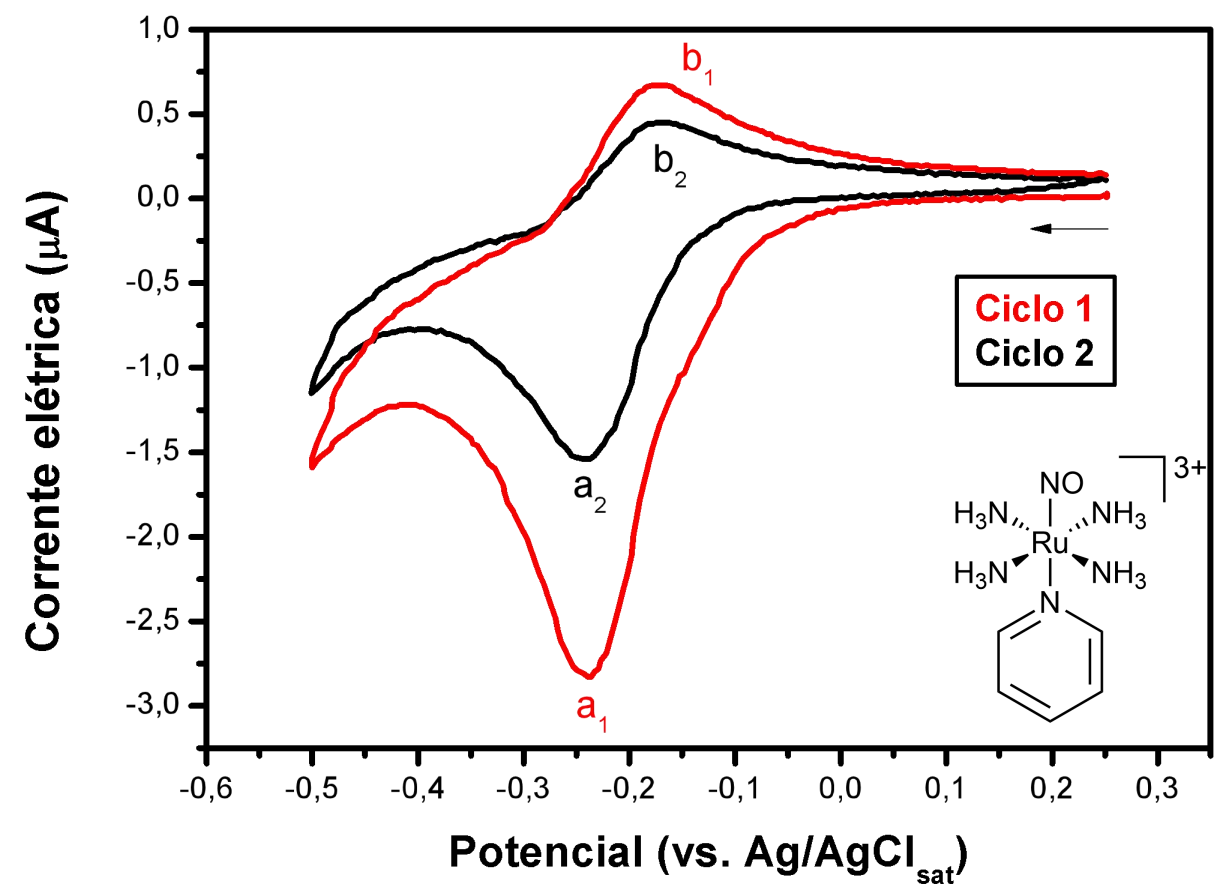

Como já foi discutido anteriormente, a redução eletroquímica de nitrosilo complexos leva ao processo

$$
\begin{gathered}
\operatorname{trans}-\left[\mathrm{Ru}(\mathrm{NO})\left(\mathrm{NH}_{3}\right)_{4}(\text { py })\right]^{3+}+\mathrm{e}^{-} \rightarrow \text { trans }-\left[\mathrm{Ru}(\mathrm{NO})\left(\mathrm{NH}_{3}\right)_{4}(\text { py) }]^{2+}\right. \text { (rápida) } \\
\text { trans }-\left[\mathrm{Ru}(\mathrm{NO})\left(\mathrm{NH}_{3}\right)_{4}(\text { py })\right]^{2+}+\mathrm{H}_{2} \mathrm{O} \rightarrow \text { trans }-\left[\mathrm{Ru}\left(\mathrm{NH}_{3}\right)_{4}\left(\mathrm{H}_{2} \mathrm{O}\right)(\text { py })\right]^{3+}+\mathrm{NO}^{\bullet} \text { (lenta) }
\end{gathered}
$$

Sendo que, com base no voltamograma apresentado acima, é possível observar o par redox $\mathrm{NO}^{+} / \mathrm{NO}^{\bullet}$ (representado por $\mathrm{a}_{1} / \mathrm{b}_{1}$ para o primeiro ciclo, e $\mathrm{a}_{2} / \mathrm{b}_{2}$ para o segundo ciclo). 


\section{D.3. Caracterização do complexo $\left[\mathrm{Ru}(\mathrm{NO})\left(\mathrm{NH}_{3}\right)_{5}\right] \mathrm{Cl}_{3}$}

A seguir, são apresentados os espectros vibracional, e o voltamograma cíclico para o complexo $\left[\mathrm{Ru}(\mathrm{NO})\left(\mathrm{NH}_{3}\right)_{5}\right](\mathrm{Cl})_{3}$.

Figura D.3.1. Espectro vibracional do complexo $\left[\mathrm{Ru}(\mathrm{NO})\left(\mathrm{NH}_{3}\right)_{5}\right] \mathrm{Cl}_{3}$ em solução de tampão fosfato, $\mathrm{pH} 7,4 ; 0,1 \mathrm{~mol} \mathrm{~L}^{-1} ; \mu=0,262 \mathrm{~mol} \mathrm{~L}^{-1}$. $\mathrm{C}_{\mathrm{Ru}}=5 \times 10^{-3} \mathrm{~mol} \mathrm{~L}^{-1}$.

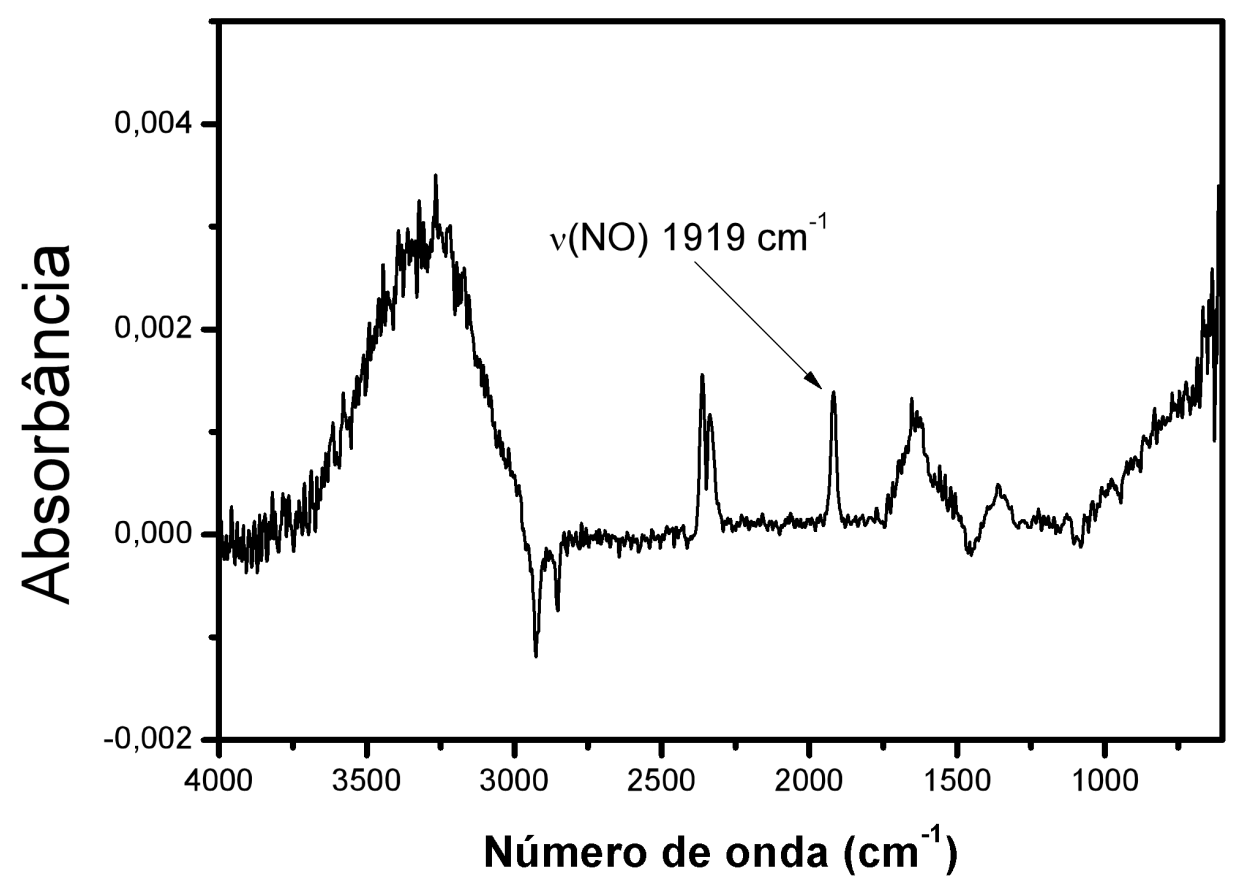


Figura D.3.2. Voltamogramas cíclicos para o íon complexo trans $-\left[\mathrm{Ru}(\mathrm{NO})\left(\mathrm{NH}_{3}\right)_{5}\right]^{3+}$ em solução de tampão fosfato $\mathrm{pH} 7,4 ; 0,1 \mathrm{~mol} \mathrm{~L}^{-1} ; \mu=0,262 \mathrm{~mol} \mathrm{~L}^{-1} \cdot \mathrm{T}=25^{\circ} \mathrm{C} . \mathrm{v}=50 \mathrm{mV} / \mathrm{s} . \mathrm{C}_{\mathrm{Ru}}=$ $5 \times 10^{-3} \mathrm{~mol} \mathrm{~L}^{-1}$. Seta indica sentido de varredura.

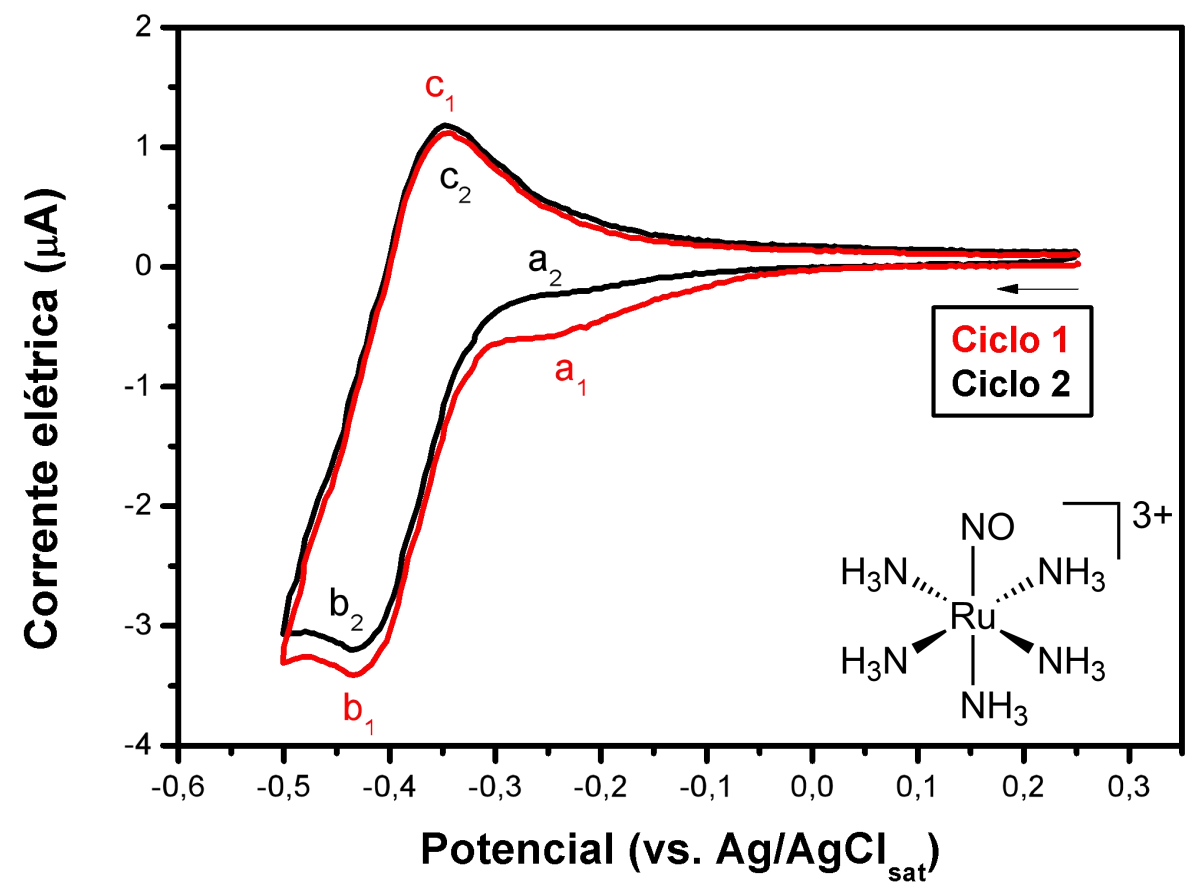

Semelhante ao que já foi apresentado aos nitrosilo complexos já estudados, o complexo $\left[\mathrm{Ru}(\mathrm{NO})\left(\mathrm{NH}_{3}\right)_{5}\right]^{3+}$, quando reduzido por um elétron, leva a labilização de óxido nítrico pelas reações abaixo

$$
\begin{gathered}
{\left[\mathrm{Ru}(\mathrm{NO})\left(\mathrm{NH}_{3}\right)_{5}\right]^{3+}+\mathrm{e}^{-} \rightarrow\left[\mathrm{Ru}(\mathrm{NO})\left(\mathrm{NH}_{3}\right)_{5}\right]^{2+} \text { (rápida) }} \\
{\left[\mathrm{Ru}(\mathrm{NO})\left(\mathrm{NH}_{3}\right)_{5}\right]^{2+}+\mathrm{H}_{2} \mathrm{O} \rightarrow\left[\mathrm{Ru}\left(\mathrm{NH}_{3}\right)_{5}\left(\mathrm{H}_{2} \mathrm{O}\right)\right]^{3+}+\mathrm{NO} \bullet \text { (lenta) }}
\end{gathered}
$$

No entanto, a reação de substituição de $\mathrm{NO}^{\bullet}$ por água é lenta o suficiente para que seja possível observar uma redução por um segundo elétron, sendo assim

$$
\left[\mathrm{Ru}(\mathrm{NO})\left(\mathrm{NH}_{3}\right)_{5}\right]^{2+}+\mathrm{e}^{-} \rightarrow\left[\mathrm{Ru}(\mathrm{NO})\left(\mathrm{NH}_{3}\right)_{5}\right]^{+}
$$

Sendo assim, é possível observar o processo $\mathrm{NO}^{+} / \mathrm{NO}^{\bullet}$ representado por $\mathrm{a}_{1}$ e $\mathrm{a}_{2}$ e também o par redox $\mathrm{NO}^{\bullet} / \mathrm{NO}^{-}$, representado por $b_{1} / c_{1}$ para o primeiro ciclo, e $b_{2} / c_{2}$ para o segundo ciclo. 
Anexo E. São apresentados dados com relação ao experimento de eletrólise exaustiva para o íon complexo trans- $\left[\mathrm{Ru}(\mathrm{NO})\left(\mathrm{NH}_{3}\right)_{4}(\mathrm{py})\right]^{3+}$ em solução de tampão fosfato $\mathrm{pH} 7,4$.

Figura E.1. Espectro de Ressonância Magnética Nuclear de solução preparada em $\mathrm{D}_{2} \mathrm{O}$. Tampão fosfato $\mathrm{pH} 7,4 ; 0,1 \mathrm{~mol} \mathrm{~L}^{-1} ; \mu=0,262 \mathrm{~mol} \mathrm{~L}^{-1}$ do íon complexo trans- $\left[\mathrm{Ru}(\mathrm{NO})\left(\mathrm{NH}_{3}\right)_{4}(\mathrm{py})\right]^{3+}$. $\mathrm{C}_{\mathrm{Ru}}=5 \times 10^{-3} \mathrm{~mol} \mathrm{~L}^{-1}$.

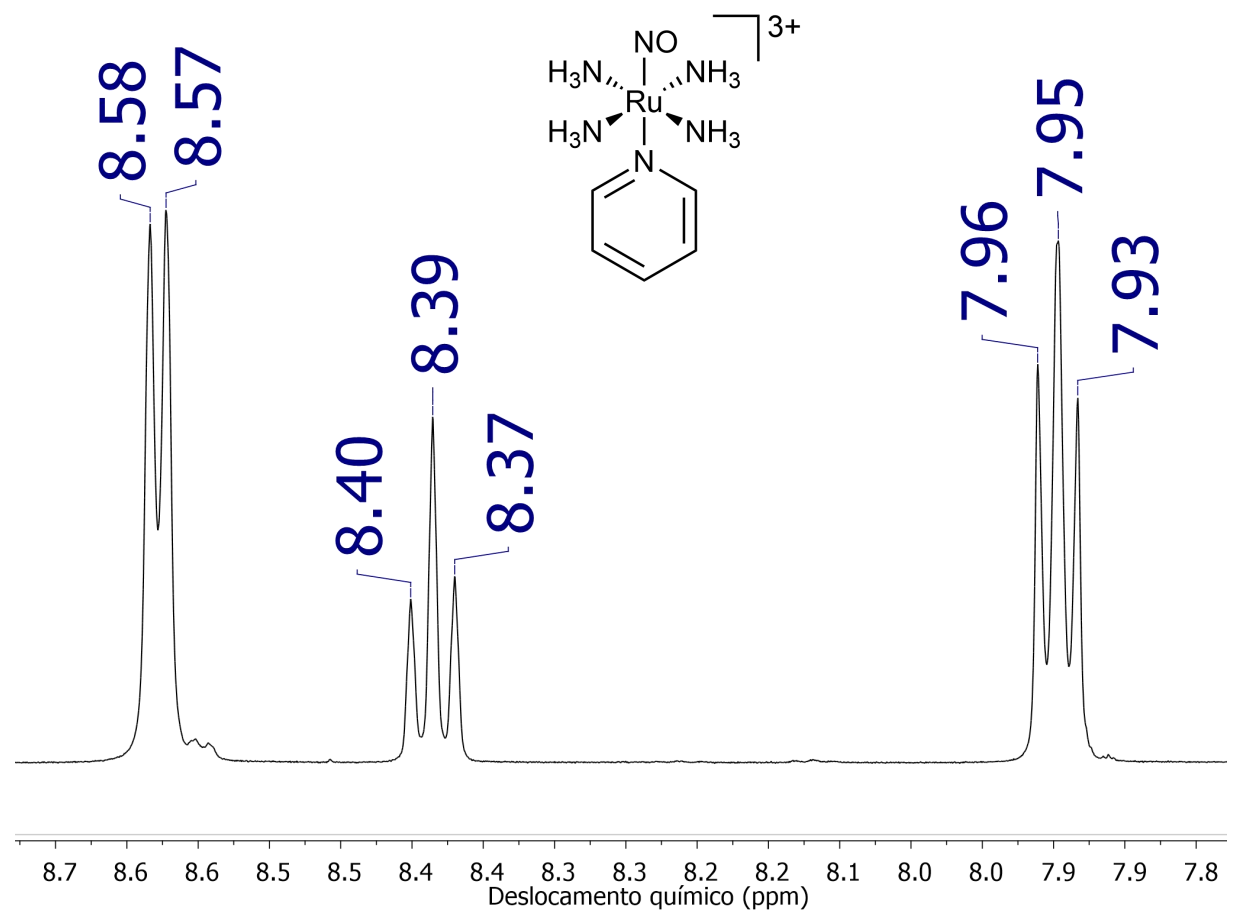

Figura E.2. Espectro de Ressonância Magnética Nuclear de solução preparada em $\mathrm{D}_{2} \mathrm{O}$. Tampão fosfato $\mathrm{pH} 7,4 ; 0,1 \mathrm{~mol} \mathrm{~L}^{-1} ; \mu=0,262 \mathrm{~mol} \mathrm{~L}^{-1}$ do íon complexo trans- $\left[\mathrm{Ru}(\mathrm{NO})\left(\mathrm{NH}_{3}\right)_{4}(\mathrm{py})\right]^{3+}$ após eletrólise exaustiva. Potencial aplicado: $-0,35 \mathrm{~V}$ vs. $\mathrm{Ag} / \mathrm{AgCl}_{\mathrm{sat}}$. $\mathrm{C}_{\mathrm{Ru}}=5 \times 10^{-3} \mathrm{~mol} \mathrm{~L}^{-1}$.

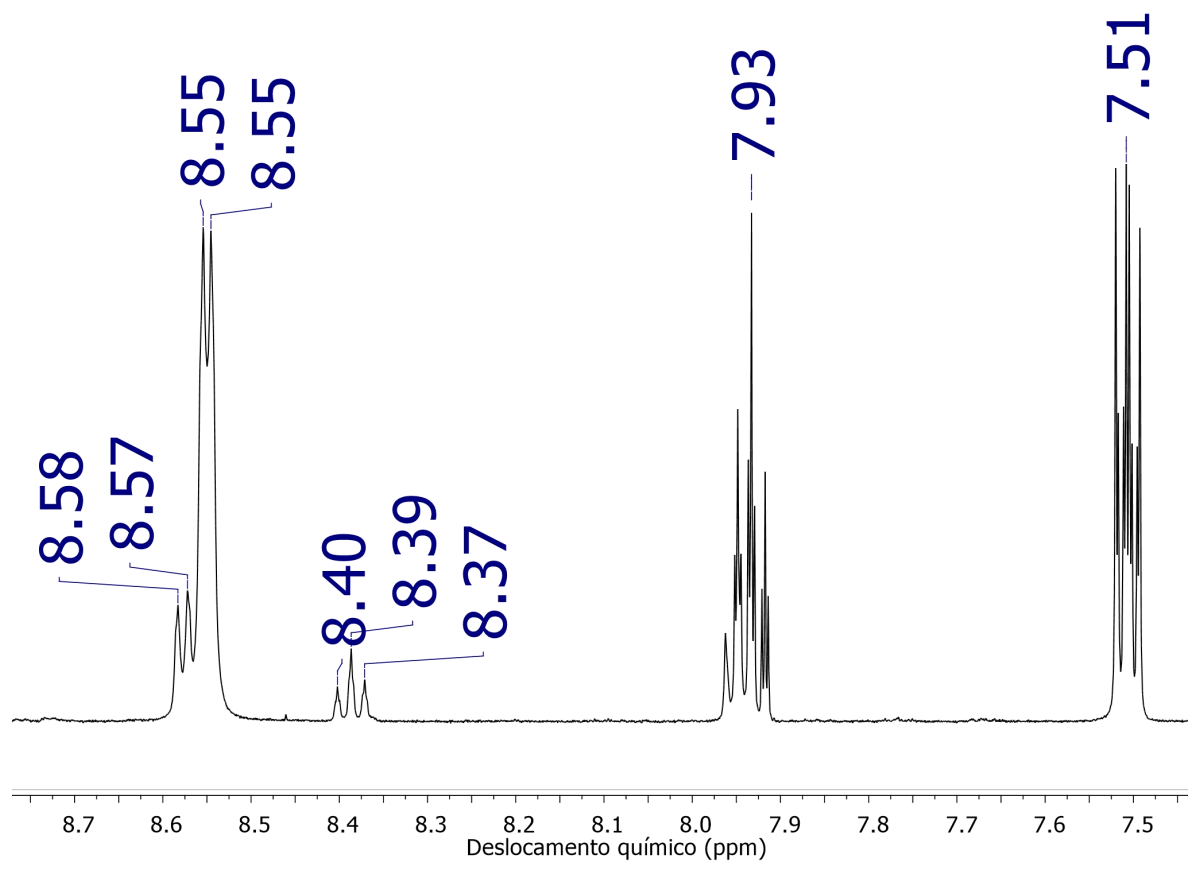


Figura E.3. Espectro de Ressonância Magnética Nuclear de solução preparada em $\mathrm{D}_{2} \mathrm{O}$. Tampão fosfato $\mathrm{pH} 7,4 ; 0,1 \mathrm{~mol} \mathrm{~L}^{-1} ; \mu=0,262 \mathrm{~mol} \mathrm{~L}^{-1}$ do íon complexo trans- $\left[\mathrm{Ru}(\mathrm{NO})\left(\mathrm{NH}_{3}\right)_{4}(\mathrm{py})\right]^{3+}$ após eletrólise exaustiva com respectiva adição de solução de piridina. $\mathrm{C}_{\mathrm{Ru}}=5 \times 10^{-3} \mathrm{~mol} \mathrm{~L}^{-1} \cdot \mathrm{C}_{\mathrm{py}}{ }^{\text {final }}=$ $2 \times 10^{-3} \mathrm{~mol} \mathrm{~L}^{-1}$.

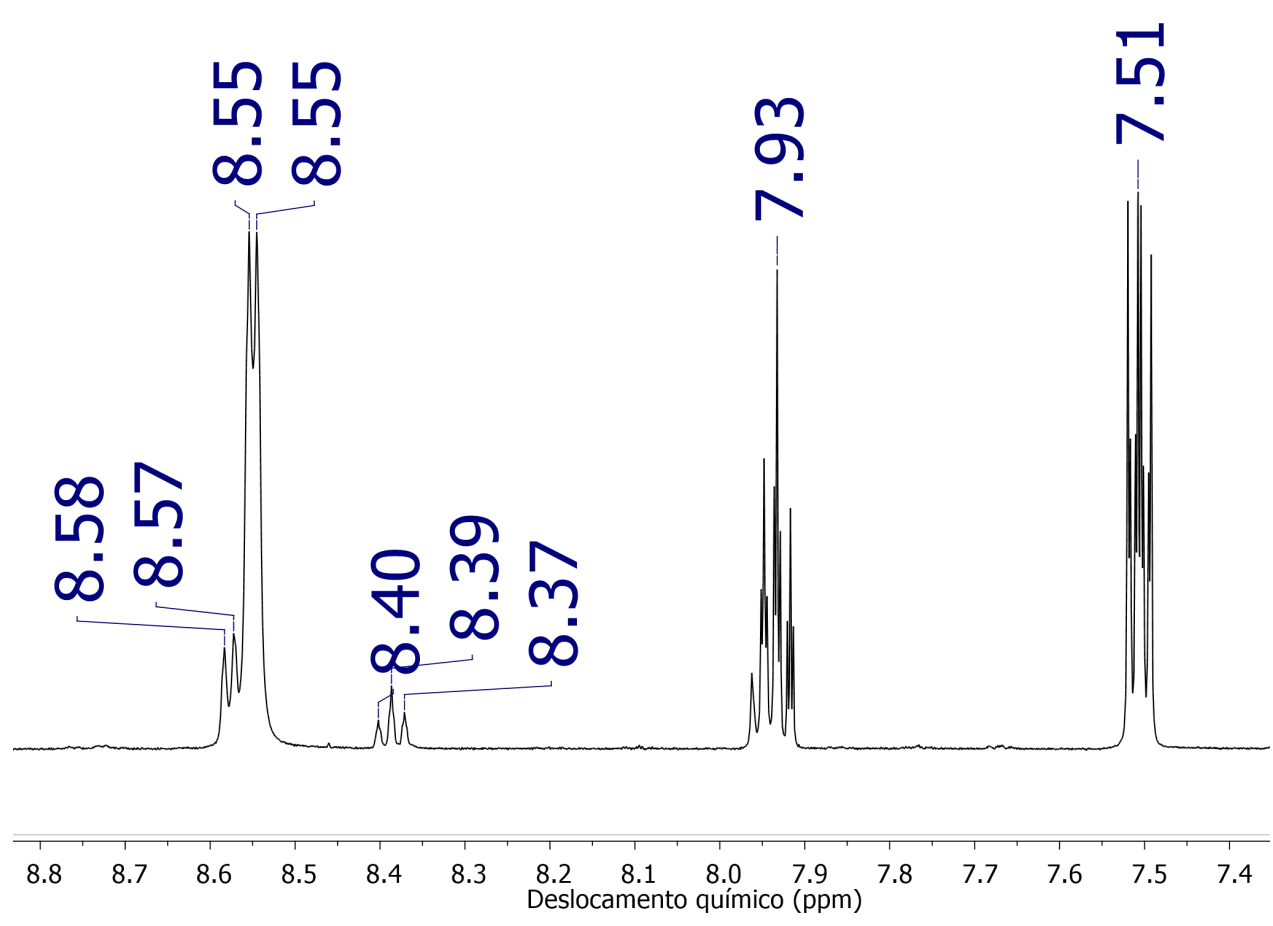

Com base no exposto nas figuras acima, é possível observar que pela aplicação de potencial $-0,35 \mathrm{~V}$ vs. $\mathrm{Ag} / \mathrm{AgCl}_{\text {sat }}$ há a labilização de piridina, pelo surgimento dos sinais em 8,55 ppm, 7,93 ppm e 7,51 ppm. E ainda, é verificada a atribuição dos sinais a piridina livre pela adição de solução de piridina, sem que haja a formação de novos sinais nessa região.

Sendo assim, a redução por um elétron do complexo trans$\left[\mathrm{Ru}(\mathrm{NO})\left(\mathrm{NH}_{3}\right)_{4}(\mathrm{py})\right]^{3+}$ deve levar a formação tanto de óxido nítrico livre, quanto a formação do hidróxido complexo pelas reações

$$
\begin{aligned}
& \text { trans- }\left[\mathrm{Ru}(\mathrm{NO})\left(\mathrm{NH}_{3}\right)_{4}(\text { py })\right]^{3+}+\mathrm{e}^{-}+\mathrm{H}_{2} \mathrm{O} \rightarrow \\
& \operatorname{trans}-\left[\mathrm{Ru}\left(\mathrm{NH}_{3}\right)_{4}\left(\mathrm{H}_{2} \mathrm{O}\right)(\mathrm{py})\right]^{2+}+\mathrm{NO}^{\bullet} \\
& \operatorname{trans}-\left[\mathrm{Ru}(\mathrm{NO})\left(\mathrm{NH}_{3}\right)_{4}(\text { py })\right]^{3+}+\mathrm{e}^{-}+\mathrm{H}_{2} \mathrm{O} \rightarrow
\end{aligned}
$$$$
\text { trans- }\left[\mathrm{Ru}(\mathrm{NO})\left(\mathrm{NH}_{3}\right)_{4}(\mathrm{OH})\right]^{2+}+\mathrm{py}^{\bullet-}+\mathrm{H}_{3} \mathrm{O}^{+}
$$ 